\title{
Effects of Pregnancy and Hormones on T Cell Immune Regulation in Multiple Sclerosis
}

\section{Sandra Hellberg}




\title{
Effects of Pregnancy and Hormones on T cell Immune Regulation in Multiple Sclerosis
}

\author{
Sandra Hellberg
}

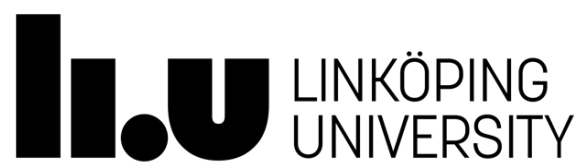

Clinical Immunology and Neurology

Department of Clinical and Experimental Medicine,

Faculty of Medicine and Health Sciences, Linköping University,

Linköping 2019 
Copyright (C Sandra Hellberg, 2019

Front cover "Hjärnan" by Nils Ibbe and illustrations by Sandra Hellberg

Published figures and papers have been reprinted with permission from the copyright holders:

Figure 12. Copyright 1998. Massachusetts Medical Society.

Paper I. Copyright 2016. Paper was published in Cell Reports. Reprinted with permission from Cell Press.

Paper III. Copyright 2019. Paper was published in the Journal of Allergy and Clinical Immunology. Reprinted with permission from Elsevier Inc.

Printed by LiU-tryck, Linköping, Sweden, 2019

ISBN: 978-91-7929-993-4

ISSN: 0345-0082

This work was supported by the Swedish Research Council, the County Council of Östergötland and Linköping University, Swedish foundation for strategic research (SSF), NEURO, the Medical Research Council of Southeast Sweden (FORSS), MS Forskningsfonden and ALF grants. 


\title{
Effects of Pregnancy and Hormones \\ on T Cell Immune Regulation in Multiple Sclerosis
}

\author{
Thesis for doctoral degree (Ph.D) \\ By
}

Sandra Hellberg

Principal supervisor:

Faculty opponent:

Professor Jan Ernerudh

Professor Manuel Friese

Linköping University

Department of Clinical and Experimental

Medicine

University Medical Center Hamburg-

Eppendorf

Institute of Neuroimmunology and

Multiple Sclerosis

Co-supervisors:

Professor Magnus Vrethem

Linköping University

Department of Clinical and Experimental

Medicine

Examination board:

Professor Charlotta Dabrosin

Linköping University

Department of Clinical and Experimental

Medicine

Professor Maria Jenmalm

Linköping University

Professor Charlotta Enerbäck

Department of Clinical and Experimental

Medicine

Linköping University

Department of Clinical and Experimental

Medicine

Professor Jan Brynhildsen

Linköping University

Professor Olov Ekwall

Department of Clinical and Experimental

Gothenburg University

Medicine

Department of Pediatrics

Institute of Clinical Sciences

Professor Tomas Olsson

Karolinska Institute

Department of Clinical Neuroscience

Neuroimmunology Unit 

A day without laughter is a day wasted

Charlie Chaplin 



\section{Abstract}

Multiple sclerosis (MS) is characterized by a dysregulated immune system leading to chronic inflammation in the central nervous system. Despite increasing number of treatments, many patients continue to deteriorate. A better understanding of the underlying disease mechanisms involved in driving disease is a pre-requisite for finding new biomarkers and new treatment targets. The improvement of MS during pregnancy, comparable to the beneficial effects of the most effective treatment, suggests that the transient and physiological immune tolerance established during pregnancy could serve as a model for successful immune regulation. Most likely the immune-endocrine alterations that take place during pregnancy to accommodate the presence of the semi-allogenic fetus contribute to the observed disease improvement.

The aim of this thesis was to characterize the dysregulated immune system in MS and define potential factors and mechanisms established during pregnancy that could be involved in the pregnancy-induced effects in MS, focusing on $\mathrm{CD}^{+} \mathrm{T}$ cells as one of the main drivers in immunity and in the MS pathogenesis. Using a network-based modular approach based on gene expression profiling, we could show that $\mathrm{CD} 4^{+} \mathrm{T}$ cells from patients with MS displayed an altered dynamic gene response to activation, in line with a dysregulated immune system in MS. The resulting gene module disclosed cell activation and chemotaxis as central components in the deviating response, results that form a basis for further studies on its modulation during pregnancy. Moreover, a combination of secreted proteins (OPN+CXCL1-3+CXCL10-CCL2), identified from the module, could be used to separate patients and controls, predict disease activity after 2 years and discriminate between high and low responders to treatment, highlighting their potential use as biomarkers for predicting disease activity and response to treatment.

The pregnancy hormone progesterone (P4), a potential factor involved in the pregnancy-induced amelioration of MS, was found to significantly dampen $\mathrm{CD} 4^{+} \mathrm{T}$ cell activation. Further detailed transcriptomic profiling revealed that P4 almost exclusively down-regulated immune-related pathways in activated T cells, several related to or downstream of T cell activation such as JAKSTAT signaling, T cell receptor signaling and cytokine-cytokine receptor interaction. In particular, P4 significantly affected genes of relevance to diseases known to be modulated during pregnancy, where genes associated to MS were most significantly affected, supporting a role for P4 in the pregnancy-induced immunomodulation. By using another approach, the role of thymus in T cell regulation during pregnancy was assessed. Two established measures of thymic output, CD31 
expression and TREC content, were used and showed that thymic output of T cells is maintained during human pregnancy, or even possibly increased in terms of regulatory $T$ cells.

This thesis further supports a pivotal role for $\mathrm{CD}^{+} \mathrm{T}$ cells and $\mathrm{T}$ cell activation in the MS pathogenesis and adds to the knowledge of how they could be involved in driving disease. We identified a novel strategy for capturing central aspects of the deviating response to T cell activation that could be translated into potentially clinically relevant biomarkers. Further, P4 is emerging as a promising candidate for the pregnancy-induced immunomodulation that could be of importance as a future treatment option. Lastly, maintained thymic output of T cells during human pregnancy challenges the rodent-based dogma of an inactive thymus during pregnancy. Thymic dysfunction has been reported not only in MS but also in rheumatoid arthritis, another inflammatory disease that improves during pregnancy, which highlights a potential role for thymus in immune regulation that could be involved in the pregnancy-induced amelioration. 


\section{Table of contents}

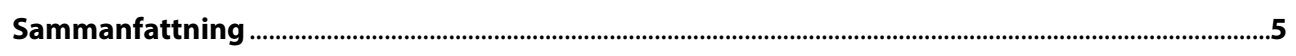

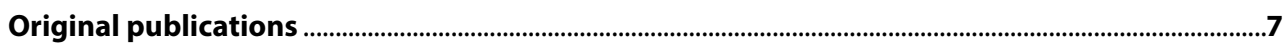

Supplemental relevant publications ....................................................................................................9

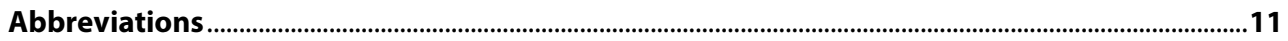

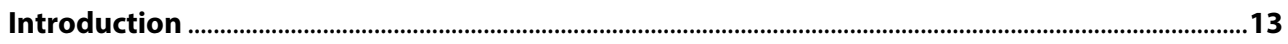

Pregnancy as a model of natural tolerance to understand immune regulation during chronic

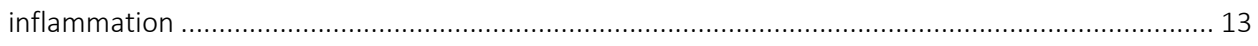

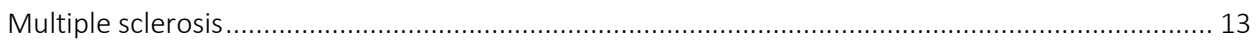

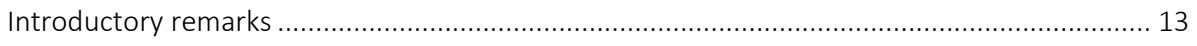

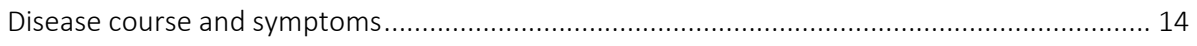

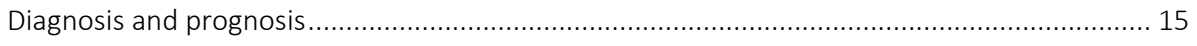

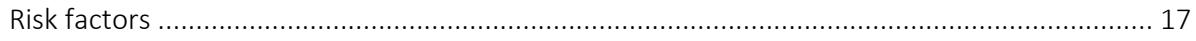

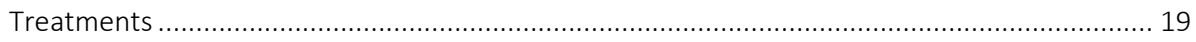

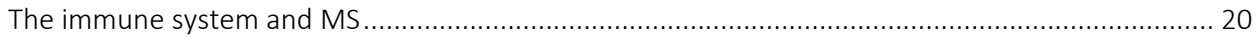

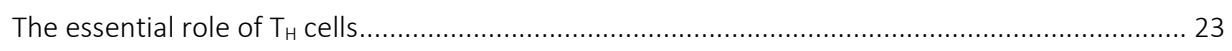

Activation of autoreactive $T_{H}$ cells sets the stage for inflammation ..................................... 23

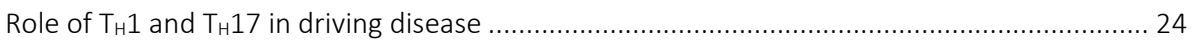

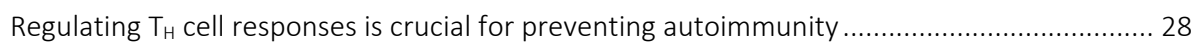

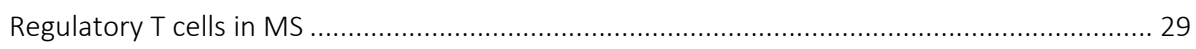

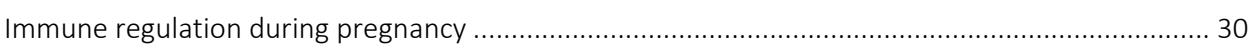

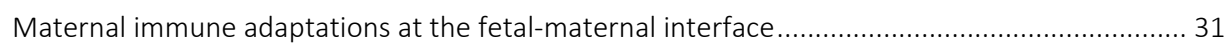

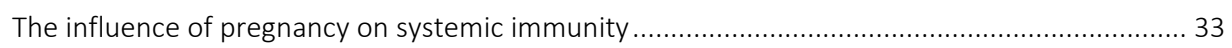

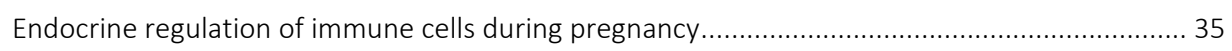

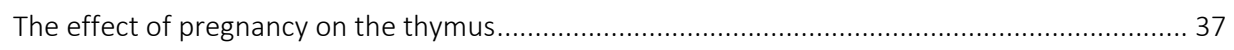

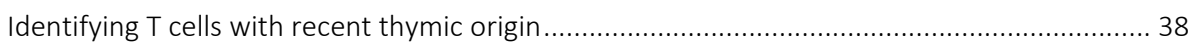

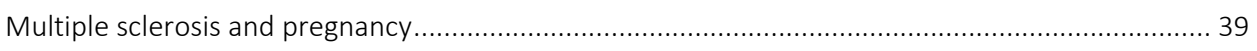

Why do patients with multiple sclerosis improve during pregnancy? ........................................ 41

Aims .....................................................................................................................................................

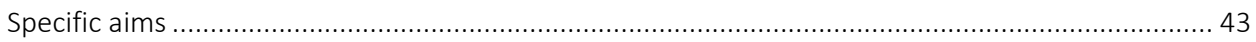

Study design and methodological considerations ..........................................................................45

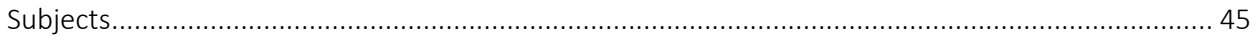




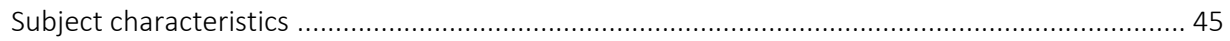

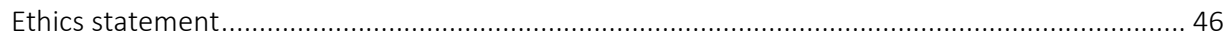

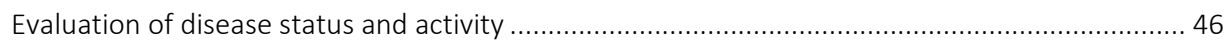

Expanded Disability Status Scale and Multiple Sclerosis Severity Score ..................................... 46

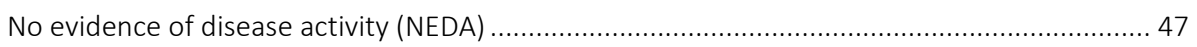

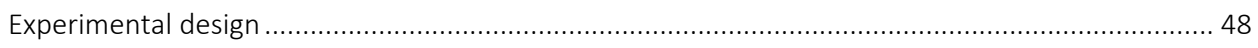

Peripheral blood as a tissue to study immunological mechanisms in MS................................... 48

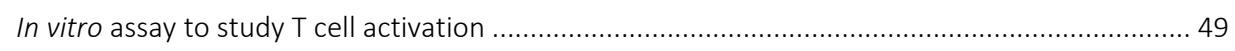

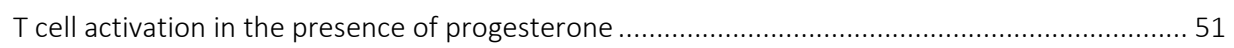

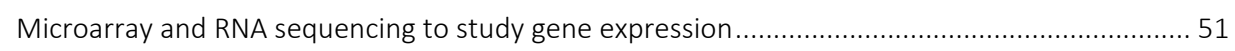

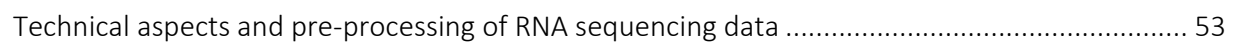

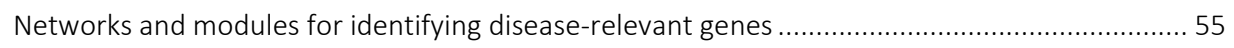

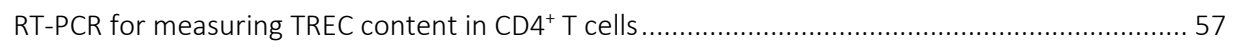

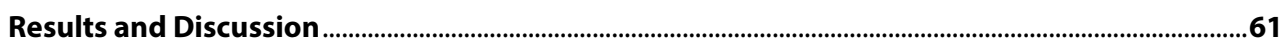

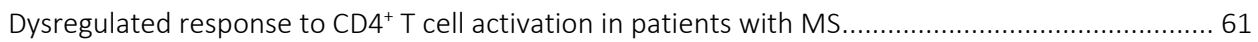

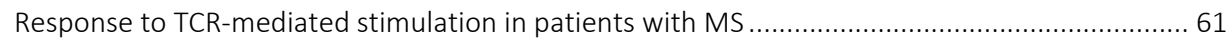

Differentially expressed genes in response to activation are enriched for MS-associated GWAS

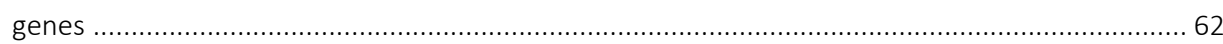

A network-based modular approach identifies cell activation and chemotaxis as central

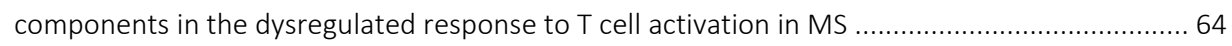

Module proteins discriminate between patients and controls with high accuracy........................ 65

Disease-associated proteins can be used as potential biomarkers for predicting disease activity

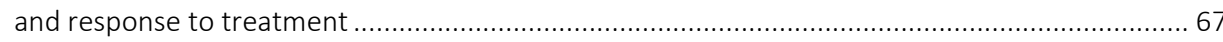

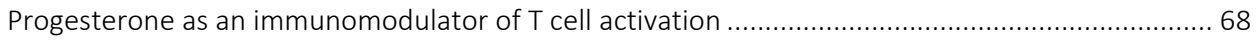

P4 dampens T cell activation and alters the transcriptomic profile in activated CD4 ${ }^{+} \mathrm{T}$ cells ........ 69

Immune-related pathways are significantly down-regulated by P4 ............................................. 69

Genes associated with immune-related diseases are most significantly affected by P4 ............... 72

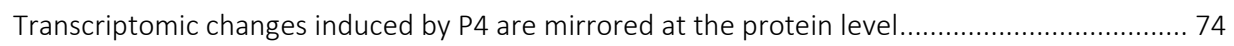

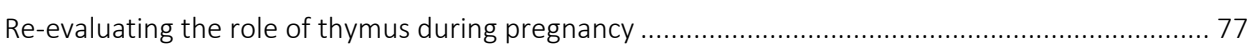

TREC levels are increased in naive $T_{\text {reg }}$ cells during $2^{\text {nd }}$ trimester pregnancy ................................. 77

Pregnancy does not alter the proportion or absolute numbers of CD $31^{+}$RTEs ............................. 78

Peripheral consumption of $T_{H}$ cells does not affect the distribution of cells with recent thymic

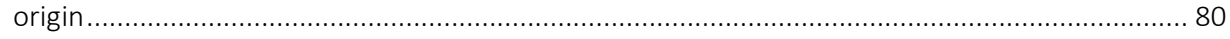

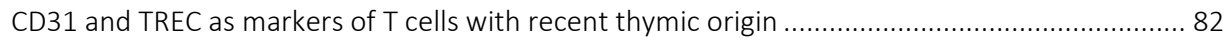

Summary and future perspectives .............................................................................................................8

Deciphering the dynamic responses to T cell activation holds promise for the future ...................... 86 
Progesterone as future treatment for multiple sclerosis?

Thymus-the forgotten organ revisited.

Concluding remarks

Acknowledgements.

References. 


\section{Sammanfattning}

Multipel skleros (MS) är en neurologisk sjukdom där kroppens egna immunförsvar angriper det centrala nervsystemet (hjärnan och ryggmärgen) och orsakar okontrollerad, kronisk inflammation som leder till symtom. Trots att nya bromsmediciner påtagligt förbättrat situationen så fortsätter ändå många patienter att försämras. För att kunna hitta nya behandlingsstrategier krävs ökad kunskap om de bakomliggande orsaker som driver sjukdomen. Vidare vore det önskvärt att kunna förutsäga prognos och effekt av olika läkemedel för att kunna skräddarsy behandling för den enskilda patienten. En outnyttjad källa till sådan kunskap är att studera MS under graviditet. Patienter med MS, liksom patienter med andra inflammatoriska sjukdomar, förbättras nämligen tillfälligt under graviditet, men med en övergående försämring efter förlossning. Graviditet utgör därför en perfekt modell för att både kunna studera faktorer som kan förklara hur sjukdomen kan förbättras men också för att hitta faktorer som kan leda till försämring. Förändringarna vid graviditet beror antagligen på de stora immunologiska och hormonella förändringar som sker för att mammans immunsystem ska kunna tolerera det till hälften främmande fostret (hälften av generna är från pappa).

Det övergripande syftet med avhandlingen var att studera det avvikande immunsvar som ses vid MS samt att identifiera faktorer som skulle kunna förklara varför patienter med MS förbättras under graviditet. Avhandlingen fokuserar på en viss typ av vita blodkroppar, så kallade Thjälpar $\left(T_{H}\right)$ celler, som har visat sig vara viktiga för uppkomst och progression av sjukdom. Särskilt viktigt verkar aktivering av dessa celler att vara då "felaktig" aktivering är en bidragande orsak till sjukdom. I första arbetet studerades i detalj på gennivå hur T cellerna svarar på aktivering hos patienter med MS. I andra och tredje arbetet undersöktes graviditetshormonet progesteron och tymus "brässen" som potentiellt viktiga faktorer i den omställning som sker under graviditet och som skulle kunna bidra till förbättringen av MS.

Genom att mäta uttrycket av tusentals gener samtidigt och med hjälp av systembiologiska metoder kunde vi i första arbetet visa att patienter med MS uppvisade ett avvikande immunsvar vid aktivering av $T_{H}$ celler. Vidare kunde detta avvikande svar detekteras på proteinnivå där förekomsten av osteopontin, CXCL1, CXCL10 och CCL2 tillsammans också kunde användas för att förutsäga sjukdomsaktivitet och svar på behandling. I andra arbetet kartlades effekten av progesteron på $T_{H}$ cellsaktivering på gennivå och vi fann att progesteron tydligt dämpade aktivering och immunsvaret. Vidare fann vi att progesteron särskilt påverkade gener som var kopplade till MS och andra inflammatoriska sjukdomar som påverkas under graviditet, vilket tyder 
på att progesteron skulle kunna vara en bidragande orsak till förbättringen av MS under graviditet då progesteronnivåerna är särskilt höga. I det tredje och sista arbetet undersöktes det "bortglömda" organet, tymus, och dess roll under graviditet. Tymus är särskilt centralt i immunförsvaret eftersom $T_{H}$ cellerna utbildas där för att skilja mellan kroppseget och kroppsfrämmande innan de släpps ut för att patrullera i blodet. Till skillnad från studier i möss som visat en minskad roll av tymus under graviditet så visade våra resultat att hos människa verkar tymus fortsatt spela roll med bibehållet utflöde av $T_{H}$ celler under graviditet.

Sammanfattningsvis stödjer våra resultat vikten av $T_{H}$ celler och $\mathrm{T}$ cellsaktivering vid MS och ger ökad kunskap om det avvikande immunsvar som bidrar till sjukdom. Vår metodik för att studera T cellsaktivering med hjälp av systembiologiska metoder kunde användas för att identifiera biomarkörer som är potentiellt användbara kliniskt, även om resultaten måste konfirmeras i nya studier. Progesteron framstår som en särskilt lovande kandidat för förbättringen av MS under graviditet eftersom immunsvar kopplade till MS var tydligt dämpande av progesteron och stödjer progesteron som ett framtida behandlingsalternativ. Vid MS har minskat utflöde av $T_{H}$ celler från tymus rapporterats och fynden av bibehållet utflöde av $T_{H}$ celler från tymus under graviditet stödjer en möjlig roll för tymus vid förbättringen av MS. 


\section{Original publications}

The thesis is based on the following papers, referred to in the text by their roman numerals.

I. Dynamic response genes in $\mathrm{CD}^{+} \mathrm{T}$ cells reveal a network of interactive proteins that classifies disease activity in multiple sclerosis

Sandra Hellberg*, Daniel Eklund*, Danuta R. Gawel, Mattias Köpsén, Huan Zhang, Colm E. Nestor, Ingrid Kockum, Tomas Olsson, Thomas Skogh, Alf Kastbom, Christopher Sjöwall, Magnus Vrethem, Irene Håkansson, Mikael Benson, Maria C. Jenmalm, Mika Gustafsson and Jan Ernerudh

Cell Reports, 2016, 16: 2929-2939

* Authors contributed equally

II. Progesterone specifically inhibits disease-associated immune-pathways at the global transcriptomic level during $T$ cell activation in vitro

Sandra Hellberg, Johanna Raffetseder, Rasmus Magnusson, Tejaswi V. Badam, Georgia Papapavlou, Olof Rundquist, Ingrid Kockum, Tomas Olsson, Maria C. Jenmalm, Jan Ernerudh and Mika Gustafsson

Manuscript

III. Maintained thymic output of conventional and regulatory T cells during human pregnancy

Sandra Hellberg, Ratnesh B. Mehta, Anna Forsberg, Göran Berg, Jan Brynhildsen, Ola

Winqvist, Maria C. Jenmalm and Jan Ernerudh

Journal of Allergy and Clinical Immunology, 2019, 143: 771-775 


\section{Supplemental relevant publications}

S1. A validated gene regulatory network and GWAS identifies early regulators of T cell-associated diseases

Mika Gustafsson, Danuta R. Gawel, Lars Alfredsson, Sergio Baranzini, Janne Björkander, Robert Blomgran, Sandra Hellberg, Daniel Eklund, Jan Ernerudh, Ingrid Kockum, Aelita Konstantinell, Riita Lahesmaa, Antonio Lentini, H. Robert I. Liljenström, Lina Mattson, Andreas Matussek, Johan Mellergård, Melissa Mendez, Tomas Olsson, Miguel A. Pujana, Omid Rasool, Jordi Serra-Musach, Margaretha Stenmarker, Subhash Tripathi, Miro Viitala, Hui Wang, Huan Zhang, Colm E. Nestor and Mikael Benson

Science Translational Medicine, 2015, 7: 313ra178

S2. On the prediction of protein abundance from RNA

Rasmus Magnusson, Olof Rundquist, Min Jung Kim, Sandra Hellberg, Chan Hyun Na, Mikael Benson, David Gomez-Cabrero, Ingrid Kockum, Jesper Tegnér, Fredrik Piehl, Maja Jagodic, Johan Mellergård, Claudio Altafini, Jan Ernerudh, Maria C. Jenmalm, Colm E. Nestor, Min-Sik Kim and Mika Gustafsson

BioRxiv, 2019, doi: https://doi.org/10.1101/599373

S3. Immunomodulating effects depend on prolactin levels in patients with hyperprolactinemia Lea Ewerman, Eva Landberg, Sandra Hellberg, Mina Hovland, Anna Sundin, Maria C Jenmalm, Bertil Ekman, Jan Ernerudh and Jeanette Wahlberg

Submitted

S4. Inflammation associated proteins as a prediction model in threatened preterm labor Maria Svenvik, Maria C. Jenmalm, Lars Brudin, Johanna Raffetseder, Sandra Hellberg, Daniel Axelsson, Gunnel Lindell, Marie Blomberg and Jan Ernerudh

Submitted 


\section{Abbreviations}

\begin{tabular}{|c|c|}
\hline APC & Antigen-presenting cell \\
\hline AUC & Area under the curve \\
\hline$b p$ & Base pairs \\
\hline $\mathrm{CIS}$ & Clinically isolated syndrome \\
\hline CNS & Central nervous system \\
\hline$C D$ & Crohn's disease \\
\hline CSF & Cerebrospinal fluid \\
\hline DC & Dendritic cell \\
\hline DEG & Differentially expressed gene \\
\hline DR & Dynamic response \\
\hline EAE & Experimental autoimmune encephalomyelitis \\
\hline EBV & Epstein-Barr virus \\
\hline EDA & Evidence of disease activity \\
\hline EDSS & Expanded disability status scale \\
\hline FACS & Fluorescence-activated cell sorting \\
\hline FDR & False discovery rate \\
\hline FS & Functional system \\
\hline GAPDH & Glyceraldehyde 3-phosphate dehydrogenase \\
\hline GM-CSF & Granulocyte-macrophage colony-stimulating factor \\
\hline GR & Glucocorticoid receptor \\
\hline GSE & Gene set enrichment \\
\hline GWAS & Genome-wide association study \\
\hline HLA & Human leukocyte antigen \\
\hline IFN & Interferon \\
\hline IL & Interleukin \\
\hline $\mathrm{MHC}$ & Major histocompatibility complex \\
\hline MN & Mature naive \\
\hline MRI & Magnetic resonance imaging \\
\hline
\end{tabular}




\begin{tabular}{|c|c|}
\hline MS & Multiple sclerosis \\
\hline MSSS & Multiple sclerosis severity score \\
\hline NEDA & No evidence of disease activity \\
\hline NFL & Neurofilament light chain \\
\hline NK & Natural killer \\
\hline OPN & Osteopontin \\
\hline OR & Odds ratio \\
\hline P4 & Progesterone \\
\hline PPI & Protein-Protein interaction \\
\hline PPMS & Primary progressive multiple sclerosis \\
\hline$P R$ & Progesterone receptor \\
\hline RA & Rheumatoid arthritis \\
\hline RNA-seq & RNA sequencing \\
\hline RRMS & Relapsing-remitting multiple sclerosis \\
\hline RTE & Recent thymic emigrant \\
\hline RT-PCR & Real time polymerase chain reaction \\
\hline sjTREC & Signal joint T cell receptor excision circle \\
\hline SLE & Systemic lupus erythematosus \\
\hline SNP & Single nucleotide polymorphism \\
\hline SPMS & Secondary progressive multiple sclerosis \\
\hline STAR & Spliced transcripts alignment to a reference \\
\hline STAT & Signaling transducer and activator of transcription \\
\hline$T_{\text {conv }}$ & Conventional T cell \\
\hline TCR & T cell receptor \\
\hline TGF & Transforming growth factor \\
\hline $\mathrm{T}_{\mathrm{H}}$ cell & $\mathrm{CD}^{+} \mathrm{T}$ helper cell \\
\hline TNF & Tumor necrosis factor \\
\hline TREC & T cell receptor excision circle \\
\hline $\mathrm{T}_{\text {reg }}$ & Regulatory T cell \\
\hline UC & Ulcerative colitis \\
\hline
\end{tabular}




\section{Introduction}

\section{Pregnancy as a model of natural tolerance to understand immune regulation during chronic inflammation}

Multiple sclerosis (MS) is a complex disease, most likely of autoimmune origin, with both inflammatory and neurodegenerative components targeting the central nervous system (CNS). Despite recent progress in the development of new treatments, many patients continue to deteriorate with increased disability and further disease progression. Interestingly, patients with MS improve during pregnancy, comparable to the effects observed with the most effective MS treatment available, but with a temporary worsening postpartum (Confavreux et al. 1998). Pregnancy, in contrast to MS, represents a temporary state of immunological tolerance induced to avoid rejection of the semi-allogenic fetus. The protective effects behind the amelioration of MS during pregnancy remain unknown but are most likely a consequence of this transient tolerance. Thus, pregnancy can be viewed as a natural model of immunological tolerance that can be used to study cellular and molecular mechanisms that could be of importance for the improvement and worsening of MS. In this thesis, I will discuss the inflammatory response and immunological mechanisms in MS in view of the tolerance mechanisms induced during pregnancy that could contribute to the clinical phenomenon observed in patients during pregnancy. The primary focus will be on immune-mediated mechanisms related to $C D 4^{+} T$ helper cells ( $T_{H}$ cells) as they constitute the switch between immunity and tolerance and are one of the main culprits in the MS pathogenesis.

\section{Multiple sclerosis}

\section{Introductory remarks}

MS is a chronic inflammatory and neurodegenerative disease, characterized by the presence of multifocal demyelinating lesions in the CNS causing a variety of neurological manifestations. The inflammatory response appears to be directed towards the myelin sheaths (the fat-rich insulator that surrounds the axons), resulting in demyelination, axonal damage and gliosis. The onset of symptoms is referred to as a relapse. Within a few weeks, the local inflammatory response subsides and remyelination ensues, resulting in partial or complete recovery of function (remission). However, over time as axonal damage accumulates, clinical improvement after each 
remission wanes, causing increased neurological disability and disease progression (Dendrou et al. 2015).

Globally, more than 2.3 million people are estimated to live with MS and it is the leading cause of non-traumatic disability in young adults (MSIF 2013). There is a trend towards increased prevalence and incidence of MS among the general population. The prevalence varies with sex and ethnicity and is highest in Northern Europe (188.9/100 000 in Sweden as compared to 33/100 000 globally) (Ahlgren et al. 2011, MSIF 2013). Women are affected 2-3 times more often the men (Alonso and Hernan 2008, Ahlgren et al. 2011, Boström et al. 2013, Kingwell et al. 2013). Most people are diagnosed between $20-40$ years of age, a time point in life decisive for career and family planning. Approximately 20 years after diagnosis, about $10 \%$ of patients require walking aid despite treatment (University of California San Francisco M. S. Epic Team et al. 2016). Hence, MS has a large socio-economic impact not only for the affected individuals and their families but also from a societal perspective. The estimated cost per patient (in Europe) for a mild-to-severe disease ranges from 22 800-57 $500 €$ per year (Kobelt et al. 2017) and the economic burden for disease management and treatment is constantly rising.

\section{Disease course and symptoms}

MS can broadly be divided into three different phases: (1) a preclinical phase where environmental, lifestyle, genetic and epigenetic factors trigger CNS inflammation and promote disease, (2) a relapsing-remitting, and (3) a progressive clinical phase (Baecher-Allan et al. 2018; Figure 1). Each subtype can also be classified as active or not active depending on relapse occurrence and lesion activity. The disease course in MS is very heterogeneous, but for about $85 \%$ of patients the disease starts in a relapsing-remitting manner (RRMS) with an initial episode of neurological dysfunction (termed clinically isolated syndrome (CIS)), followed by recurring bouts of clinical exacerbations between which there are periods of complete or partial remission. The relapses coincide with focal inflammatory demyelinating white matter lesions in the CNS that can be visualized by magnetic resonance imaging (MRI; Figure 2). Characteristic lesions are found in the periventricular and juxtacortical regions, in addition to the brainstem, spinal cord, optic nerve and cerebellum (Polman et al. 2011). Depending on the size and anatomical location of the lesions, MS can give rise to a wide variety of neurological symptoms including visual, motor, sensory or autonomic disturbances of the bowel and bladder. In addition, patients can also experience cognitive impairment, mood disorders, pain and fatigue (non-focal manifestations) 


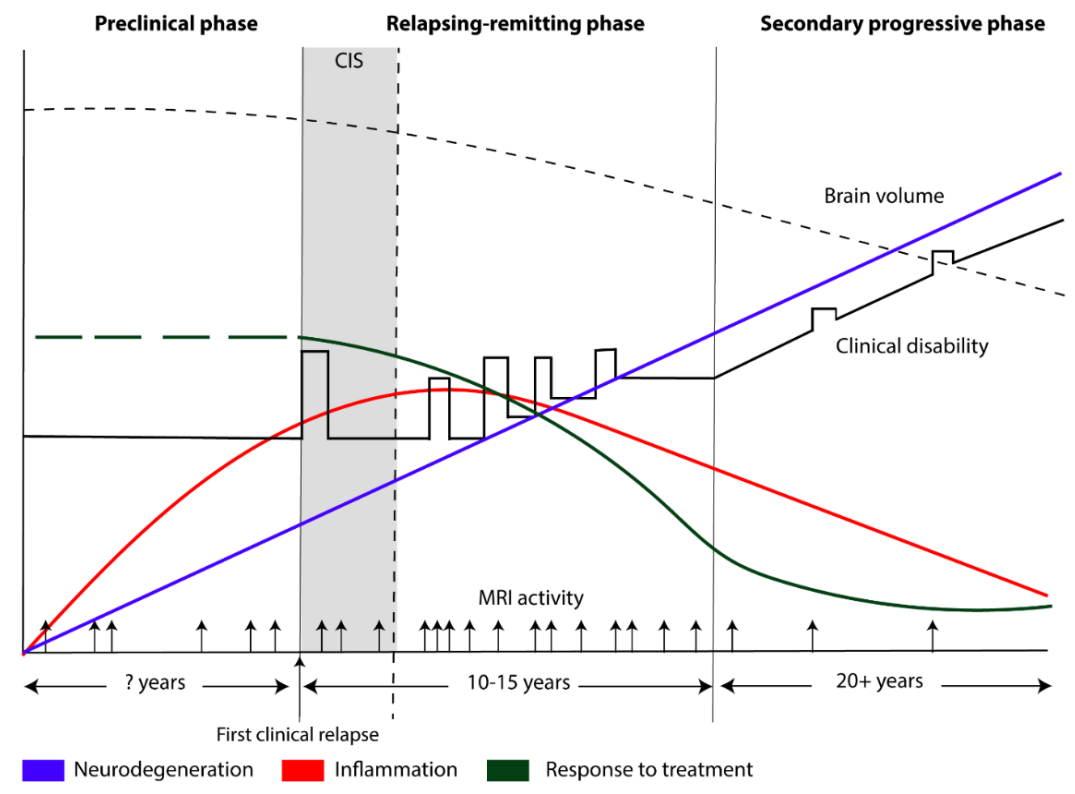

Figure 1. Disease course in MS.

that further contribute to functional impairment. Over time, as disability accumulates, the inflammatory lesions and periods of clinical relapses and remission become less pronounced and most patients eventually transition into a more progressive phase of the disease, secondary progressive MS (SPMS), characterized by increased axonal loss and brain atrophy (Figure 1 and 2). In SPMS, patients instead experience a steady increase in neurological disability, most commonly involving impaired ambulation, loss of bladder control and cognitive dysfunction. In contrast to RRMS and SPMS, about $10-15 \%$ of patients are diagnosed with primary progressive MS (PPMS) from onset, with progressive neurologic decline and absence of discernible relapses (Miller and Leary 2007).

\section{Diagnosis and prognosis}

There are no definite pathognomonic clinical features or diagnostic tests that can be used to diagnose MS with certainty. Instead, the diagnosis is based on a set of criteria that in the best way possible try to characterize the disease and differentiate MS from other diseases. The cornerstone for diagnosis rely on the demonstration of evidence of lesions in the CNS disseminated in space (involvement of multiple areas in the CNS) and in time (on more than one occasion) and for no better explanation of the presentation (Schumacher et al. 1965). The widely used McDonald 

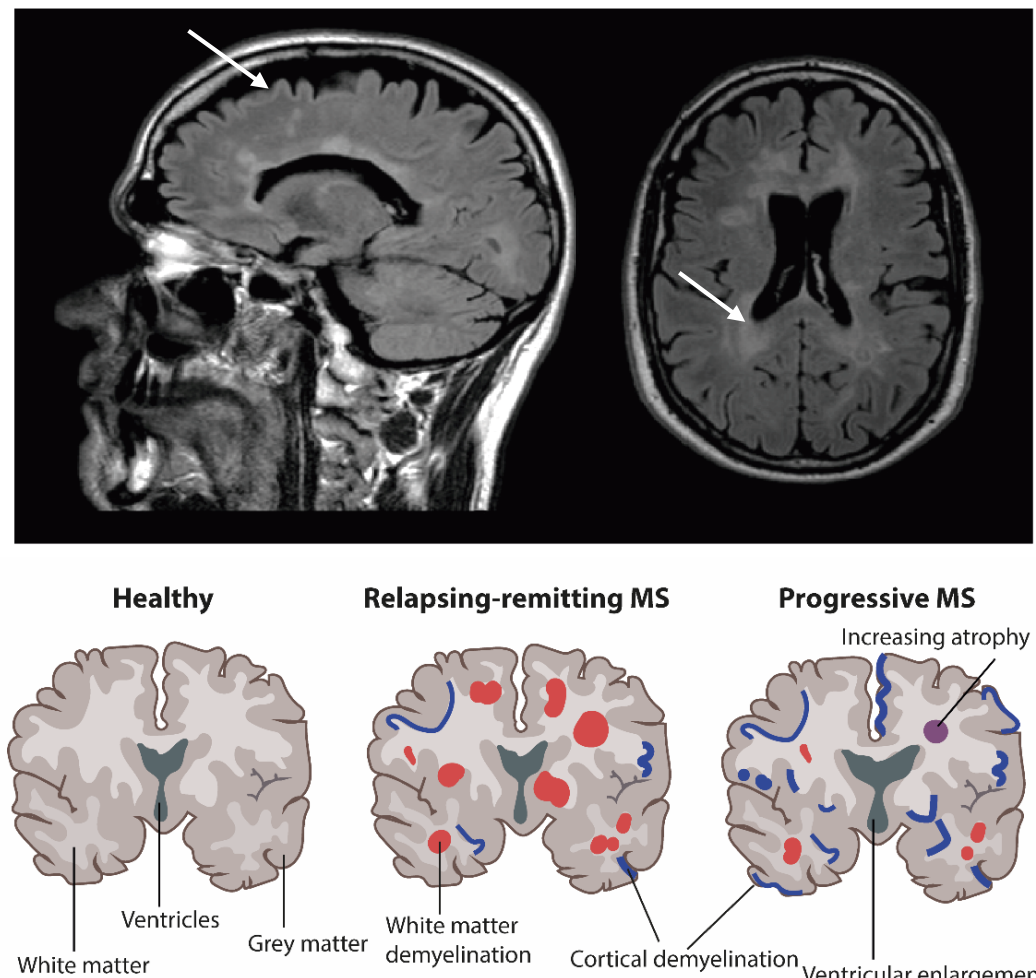

Progressive MS

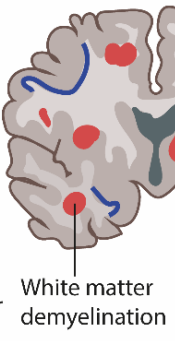

Increasing atrophy

Figure 2. Multiple sclerosis pathology. The upper panel shows a cerebral MRI with cortical atrophy and periventricular white matter lesions in MS (as indicated by the arrows in the left and right panel, respectively). The lower panel depicts schematic lesion distribution and progression in patients with relapsing-remitting and progressive MS compared to healthy individuals. Upper picture used with permission from Center for Medical Image Science and Visualization (CMIV).

Criteria for MS diagnosis relies on clinical evaluation together with paraclinical measurements; imaging (MRI) and laboratory findings (presence of oligoclonal bands in cerebrospinal fluid (CSF)) (McDonald et al. 2001, Polman et al. 2011, Thompson et al. 2018). One of the rationales of the criteria is to be able to diagnose MS as early as possible to initiate treatment early on in order to dampen disease activity and slow disease progression (Chalmer et al. 2018).

The severity of MS varies a lot, where some patients have a more benign disease course with few relapses and minimal disease accumulation, while some have a rapidly evolving and debilitating disease. Several prognostic factors have been suggested (Bergamaschi 2006; Figure 3). Age at disease onset is a strong prognostic factor in MS; the median time to reach Expanded Disability Status Scale (EDSS) score 6 was 26 years for patients who were diagnosed around 20-29 years of age compared to only 7 years for patients over 50 years of age at disease onset (Confavreux et al. 
2003). Clinical factors such as symptoms at disease onset, initial disease course and lesion location also hold prognostic value, where polysymptomatic disease onset with symptoms related to motor, cerebellar or sphincter function together with high infratentorial and spinal lesion load indicate poorer prognosis. Furthermore, soluble biomarkers such as chitinase 3-like proteins and neurofilament light chain (NFL) have also been shown to have predictive prognostic power (Hinsinger et al. 2015, Håkansson et al. 2017, Sellebjerg et al. 2018).

\section{Risk factors}

The exact cause of MS remains unknown but it is thought to arise in genetically susceptible individuals, where the microbiome together with environmental and lifestyle factors determine disease development (Olsson et al. 2017; Figure 3). Siblings of an individual with MS have an almost 17-fold higher risk of developing disease. Monozygotic twins have a higher concordance rate compared with dizygotic twins, which provides support for a significant yet complex genetic etiology in MS (O'Gorman et al. 2013). Genetic variations account for about $30 \%$ of the overall disease risk and the disease-associated single nucleotide polymorphisms (SNPs) are most often located in genes regulating innate or adaptive immunity (Sawcer et al. 2011). The human leukocyte antigen (HLA)-locus on chromosome 6 accounts for more than $20 \%$ of the susceptibility,

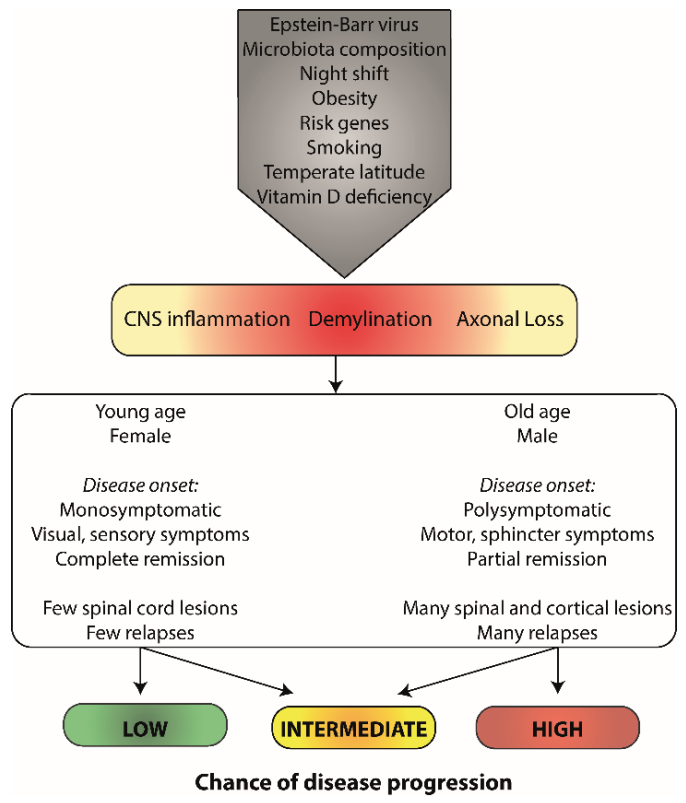

Figure 3. Risk factors, triggers and disease progression in MS. 
particularly HLA class I and II genes, whose functions are to present antigens to T cells, a crucial step in adaptive immunity. This region has been implicated in the development of hundreds of diseases, many immune-mediated, which suggests common predisposing immunological processes. In MS, carriers of the HLA-DRB1*15:01 allele have an increased risk of MS (odds ratio (OR) 3.9), whereas HLA-A*2 seems to confer protection (OR 0.6) (Moutsianas et al. 2015). Large genome-wide association studies (GWAS) have identified more than 200 genetic variants associated with MS, including several non-HLA-associated genes e.g. interleukin (IL)-2RA, IL7R, and STAT3, although each variant only modestly influences MS risk (Sawcer et al. 2011, Patsopoulos 2017). Furthermore, most likely different combinations of these variants contribute to disease susceptibility in different patients. The present view of the functional importance of the genetic variants in MS is that variations in the HLA genes are mainly involved in altering the T cell repertoire. Non-HLA variants are more involved in shaping the immune response towards antigens by influencing the threshold of immune cell activation and thereby altering the likelihood of a targeted CNS inflammatory response (Dendrou et al. 2015). However, even though there is a clear genetic component to MS, the importance of genetic predisposition for acquiring disease is less clear.

Regarding environmental factors, it has been shown that migrants moving from a low-risk to a high-risk country have a higher than expected MS prevalence and vice versa (Ahlgren et al. 2010, Ahlgren et al. 2012, Berg-Hansen and Celius 2015), which supports the importance of lifestyle and environmental factors in risk of developing MS. Indeed, several factors have been shown to increase the risk of MS (Waubant et al. 2019), in particular smoking and Epstein-Barr virus (EBV) infection (Hedström et al. 2013, Hedström et al. 2016, Tengvall et al. 2019; Figure 3). On the contrary, the use of oral tobacco, high coffee and alcohol consumption could reduce the risk. Several of these factors have been shown to interact with known HLA-risk genes (Olsson et al. 2017). For example, smokers that have certain HLA-risk alleles have a much higher risk for MS compared to non-smokers. This has been speculated to be related to immune-mediated mechanisms (Olsson et al. 2017). Smoking has been shown to induce an enzyme that can alter the peptides that are displayed to T cells (Makrygiannakis et al. 2008). This could increase the likelihood that the T cells recognizing these peptides have not undergone clonal deletion in the thymus and are thus more likely to become autoreactive.

More recently, the microbiome is receiving increasingly more attention as a potential source for influencing MS susceptibility (Probstel and Baranzini 2018). Our gut is inhabited by trillions of 
microbes that can modulate the immune system by regulating both innate and adaptive immune responses in order to maintain homeostasis (Belkaid and Hand 2014). It is therefore not surprising that several diseases, including MS, appear to be associated with dysbiosis (Abrahamsson et al. 2012, Jangi et al. 2016, Lynch and Pedersen 2016, Berer et al. 2017, Cekanaviciute et al. 2017). However, the functional importance of the microbiome in MS remains to be determined, as studies have not yet been able to show if the observed dysbiosis is the cause or merely a consequence of the disease.

\section{Treatments}

Today there are more than 10 disease-modifying treatments available for MS (seven approved for use in Sweden; www.lakemedelsverket.se; Figure 4) and more treatments are underway (clinicaltrials.gov). All of the available treatments affect the immune system and essentially all mainly target the inflammatory components of the disease, i.e. reducing relapse rate and contrast-enhancing lesions, which are most prominent during the relapsing stage of the disease (Comi et al. 2017). Traditionally, the treatments have been divided into first and second line drugs, although dividing into relapsing-remitting MS (first line) and relapsing-remitting with active disease (second line) is becoming more commonly used (Svenningsson 2016), because it might more accurately reflect the use and properties of the treatments. The injectable treatments (first line), including interferon beta and glatiramer acetate, reduce the annual relapse rate about one third (Ebers 1998, Mikol et al. 2008, O'Connor et al. 2009) and show a modest ability to reduce disease progression. The second line treatments have a higher efficacy (ranging from $45-70 \%$ reduction in relapse rate) and can also better affect disease progression. However, as many of these treatments induce sometimes quite severe immunosuppression, they are associated with more serious side effects compared to first line treatments (Comi et al. 2017). Therefore, deciding on which treatment any given patient should receive is a balance between effect and risk of treatment in relation to the disease activity. As disease activity during early disease has been shown to predict long-term disability, starting treatment as early as possible is important to delay disease progression and accumulation of disability (Kappos et al. 2009, Chalmer et al. 2018). Despite high efficacy, disease progression is not always stopped, even though different treatments are tested. This may require targeting more specifically the neurodegenerative component of the disease. Currently, there is only one treatment approved for progressive MS, the CD20+ B-cell depleting therapy ocrelizumab (Montalban et al. 2017), although long-term efficacy remains to be determined. 


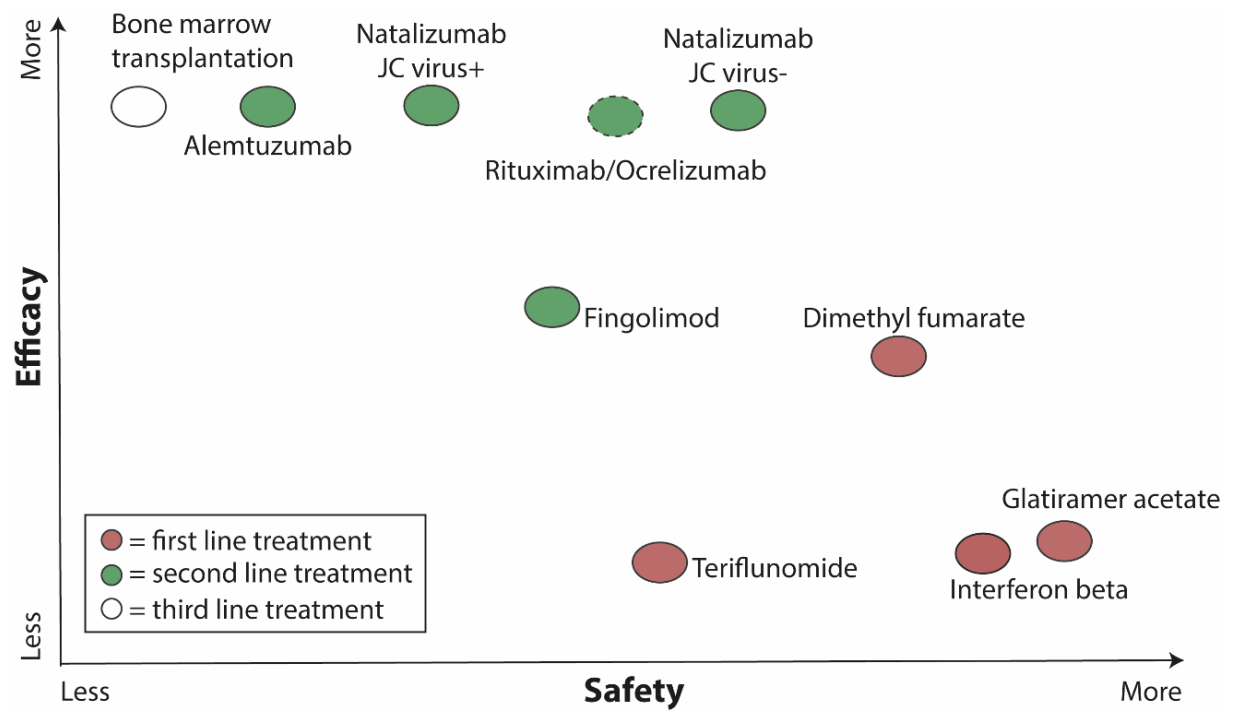

Figure 4. Treatments in MS. First line treatments have a lower efficacy but are not associated with as many severe side effects in contrast to second line treatments. The figure shows the relative efficacy (based on reduction in relapse rate, disease progression and MRI activity) in comparison to common side-effects and serious adverse effects. Rituximab is not formally approved as treatment in MS but is commonly used in Sweden as second line treatment. Figure adapted from Hauser et al. Ann Neurol, 2013.

Interestingly, rituximab, another $\mathrm{CD} 2 \mathrm{O}^{+} \mathrm{B}$-cell depleting treatment, has been used extensively offlabel as second line treatment in RRMS in Sweden and shown good efficacy (Hauser et al. 2008, Granqvist et al. 2018, Spelman et al. 2018), which suggests a prominent role for B cells in the disease pathogenesis.

\section{The immune system and MS}

Much of the knowledge regarding the MS pathogenesis comes from studies in animal models, in particular experimental autoimmune encephalomyelitis (EAE) in mice, which has provided us with valuable insights into disease-promoting mechanisms. The current view of the disease processes in MS involves the migration of peripherally activated lymphocytes across a leaky and damaged blood-brain barrier, causing multifocal inflammation that results in demyelination, axonal loss and gliosis. The pathogenesis is very complex where basically every type of immune cell, both innate and adaptive immune responses, are involved in orchestrating the inflammatory demyelinating damage (Dendrou et al. 2015; Figure 5). However, both genetic and pathological studies point toward a more prominent role for the adaptive immune system in driving the disease processes 
(Patsopoulos et al. 2011, Sawcer et al. 2011, Lucchinetti et al. 2000). The fact that the inflammatory responses are only directed towards the CNS strongly suggests that T and B cells are specifically recruited by antigens that are only expressed in the CNS. As such, MS is often depicted as an autoimmune disease, although it does not readily fulfill the classic definition of an autoimmune disease since "a precise autoantigen present in all patients with the disease" has not yet been identified (Rodriguez 2009). Myelin has for long been considered as the putative autoantigen in MS, as it is a demyelinating disease. Several lines of evidence support the relevance of myelin-reactive $\mathrm{CD}^{+} \mathrm{T}$ cells although direct evidence is still missing (Hohlfeld et al. 2016). Recently, other plausible autoantigens in MS have been suggested (Ayoglu et al. 2016, Planas et al. 2018), such as anoctamin 2, a $\mathrm{Ca}^{2+}$ activated chloride channel expressed in nerve cells (Ayoglu et al. 2016, Tengvall et al. 2019). Irrespective of target antigen, the presence of autoreactive lymphocytes, in combination with the strong major histocompatibility complex (MHC) association, implies that there is an autoimmune component to the disease.

It is debated whether the inflammatory responses in MS stems from mechanisms intrinsic or extrinsic to the CNS, i.e. that processes within the CNS, independently of inflammation, serve as the initial event causing release of CNS antigens to the periphery or that the inflammatory responses originates outside of the CNS, caused for example by molecular mimicry or bystander activation (Stys et al. 2012). However, there are several lines of evidence that unequivocally support MS as being a primarily immune-mediated disease that is triggered outside of the CNS; 1 ) the overrepresentation of immune-related genes associated with MS (Patsopoulos et al. 2011, Sawcer et al. 2011); 2) few genetic associations shared between MS and other neurodegenerative conditions (Dendrou et al. 2015); 3) the observation that EAE can be induced in the periphery using myelin-derived proteins; 4) blocking lymphocyte infiltration into the CNS is one of the most effective treatments available (Comi et al. 2017) and 5) alterations in peripheral immune cells have been associated with disease activity (Jones et al. 2017). Taken together, these findings highlight the importance of peripheral mechanisms for triggering inflammatory responses that drive disease. Regardless of cause, peripheral activation of autoreactive lymphocytes is a key event in the disease pathogenesis. Once activated, these cells gain the ability to invade the CNS where they are re-activated by resident microglia cells presenting self-antigens on MHC class II. 


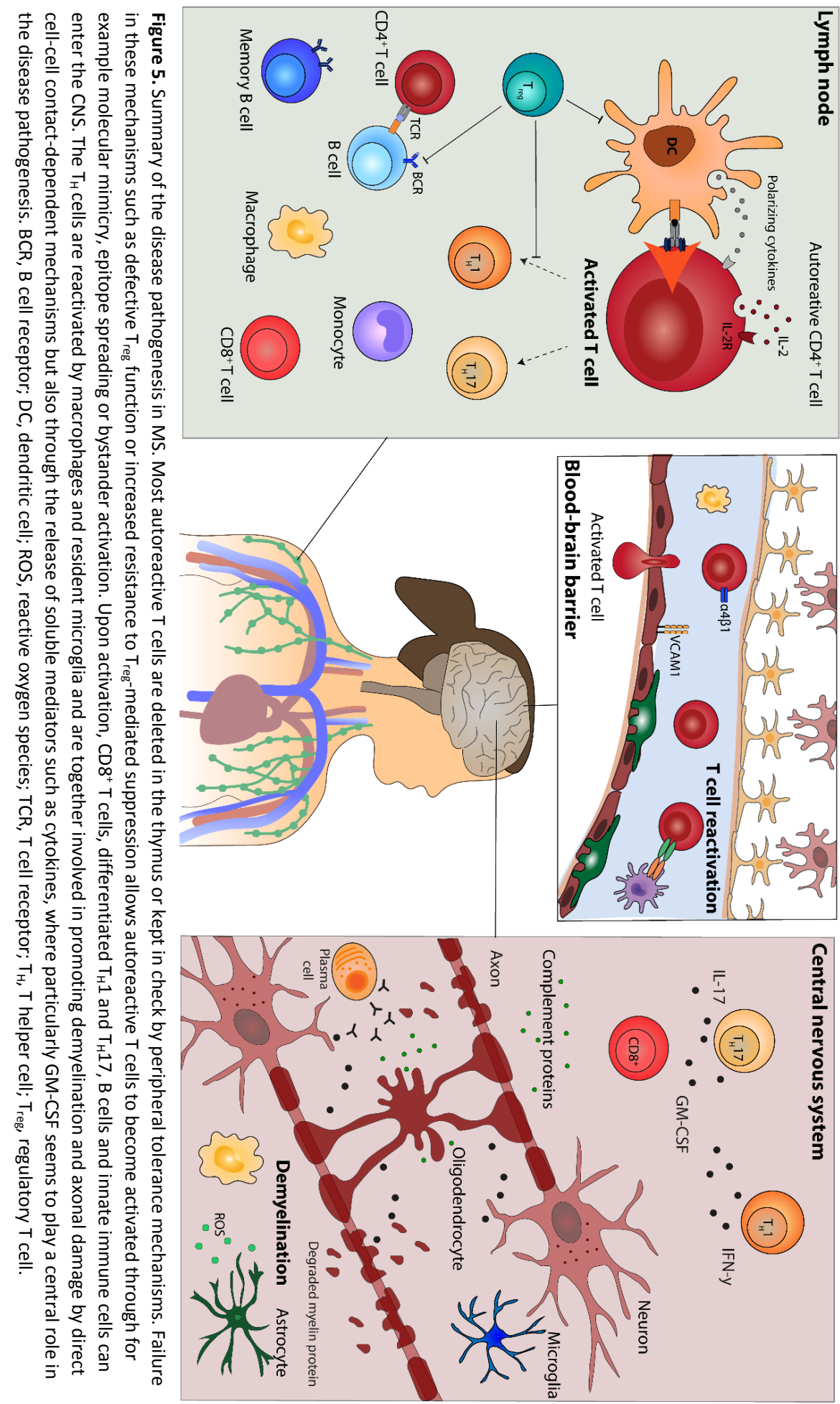


Subsequently, the activated $\mathrm{CD} 4^{+} \mathrm{T}$ cells together with microglia, macrophages, $\mathrm{CD} 8^{+} \mathrm{T}$ cells, $\mathrm{B}$ cells and plasma cells are involved in mediating tissue damage that causes the demyelination, which ultimately leads to disrupted nerve cell signaling and resulting clinical symptoms (Molyneux et al. 1998, Breij et al. 2008). Over time, as the disease progresses, the invasion of peripheral immune cells wanes and the inflammatory processes become confined and compartmentalized behind a closed blood-brain barrier (Michel et al. 2015), which is also evident by the lack of efficacy with current treatments for treating MS in the progressive phase. The failure of most immuno-modulatory treatments in the progressive phase also reflects a more complex disease pathogenesis and that different pathophysiological mechanisms probably exist during relapsing and progressive disease (Dutta and Trapp 2014).

\section{The essential role of $T_{H}$ cells}

The MS pathogenesis has for long been dominated by a $T_{H}$ cell centric view, much due to studies in the EAE model in mice (Fletcher et al. 2010). EAE is induced by triggering immune responses against CNS antigens and captures many central aspects of the MS pathogenesis. Immunization of mice with myelin peptides or proteins causes presentation of antigens by MHC class II and peripheral activation of myelin-specific $\mathrm{CD}^{+}{ }^{+} \mathrm{T}$ cells that enables them to migrate across the blood-brain barrier and cause inflammation and demyelination in the CNS. Disease can also, in some models, be induced by adoptive transfer of myelin-specific $\mathrm{CD} 4^{+} \mathrm{T}$ cells from a mouse with EAE to a healthy mouse, which further reinforces the view of MS as a T cell-mediated disease. Although we now know that this is a very simplified picture of the complex immunological processes that underlie disease initiation and propagation, there is an accumulating amount of evidence that supports a crucial role for $\mathrm{CD}^{+} \mathrm{T}$ cells in the disease pathogenesis such as the strong association with the $T_{H}$-specific antigen-presenting molecule HLA Class II (DRB1*15:01) and the over-representation of T cell-associated genes in large MS GWAS (Patsopoulos et al. 2011, Sawcer et al. 2011). Furthermore, many of the non-HLA MS risk genes are involved in processes that are crucial for the generation and function of the $T_{H}$ cells like $T_{H}$ cell-associated cytokines, chemokines and their receptors (e.g.CXCR5, IL-12A, IL-12B, IL-2RA, IL-7RA, IL-12RB1 and IRF8), costimulation (e.g. CD40, CD80, CD86, and CLECL1) and signal transduction (e.g. STAT3 and TYK2).

\section{Activation of autoreactive $T_{H}$ cells sets the stage for inflammation}

Activation of $T_{H}$ cells is a central process in the immune system and essential for shaping and directing the immune responses in the most efficient way to deal with potential threats (Abbas et 
al. 2017). The initial $T_{H}$ cell activation mainly occurs in secondary lymphoid organs although both the respiratory and gastrointestinal tracts have been implicated as sites for initial priming of encephalitogenic, autoreactive T cells in mice (Berer et al. 2011, Odoardi et al. 2012, Cekanaviciute et al. 2017). For a CD4 ${ }^{+} T$ cell to become activated it requires the presentation of antigens by antigen-presenting cells (APCS). Protein or peptide antigens captured by the APCs are processed and presented on MHC class II (Abbas et al. 2017). Dendritic cells (DCs) are the most prominent APCs during initial T cell activation, but macrophages and B cells can also present antigens to $\mathrm{TH}_{H}$ cells. Recognition of peptide-MHC II complexes by the T cell receptor (TCR) complex provides the initial signal for T cell activation (signal 1; Figure 6). The second signal required for proper T cell activation is provided through co-stimulation (signal 2), where engagement of CD28 on the T cell with B7-1/B7-2 (CD80/CD86) on the APCs is the best characterized co-stimulatory pathway involved in T cell activation. Signals 1 and 2 act in concert to drive the clonal expansion of the autoreactive T cells, whereas the qualitative function of the cells is shaped by signal 3, determined by the cytokines produced mainly by the APC. The importance of this process in driving disease is elegantly demonstrated by blockade of receptors and ligands involved, which ameliorates/prevents EAE (Grewal et al. 1996, Oliveira-dos-Santos et al. 1999, Perrin et al. 1999).

How the T cells specific towards CNS antigens become activated in the periphery still remains unclear, although mechanisms such as molecular mimicry, cross-reactivity, epitope spreading and bystander activation have been suggested (Riedhammer and Weissert 2015). A recent study suggests that immune reactivity toward an antigen associated with EBV, a common risk factor in MS, could speculatively contribute to disease through molecular mimicry with the proposed autoantigen anoctamin 2 (Tengvall et al. 2019). Nevertheless, peripheral activation of autoreactive $T_{H}$ cells sets the stage for the inflammatory response and changes in the proportion of activated $T_{H}$ cells have been associated with disease activity (Khoury et al. 2000, Jensen et al. 2004), which further highlights the importance of T cell activation in the disease pathogenesis.

\section{Role of $T_{H} 1$ and $T_{H} 17$ in driving disease}

Upon contact with antigen, $T_{H}$ cells become activated, differentiate and acquire various effector phenotypes. Many of the genes that have been implicated in the susceptibility of MS play a major role in the differentiation process of naive $T_{H}$ cells into the different $T_{H}$ subsets (Sawcer et al. 2011). $T_{H}$ cells can differentiate into three major established subsets depending on the surrounding cytokine environment: $T_{H} 1, T_{H} 2$ or $T_{H} 17$. Naive $T_{H}$ cells can also differentiate into 


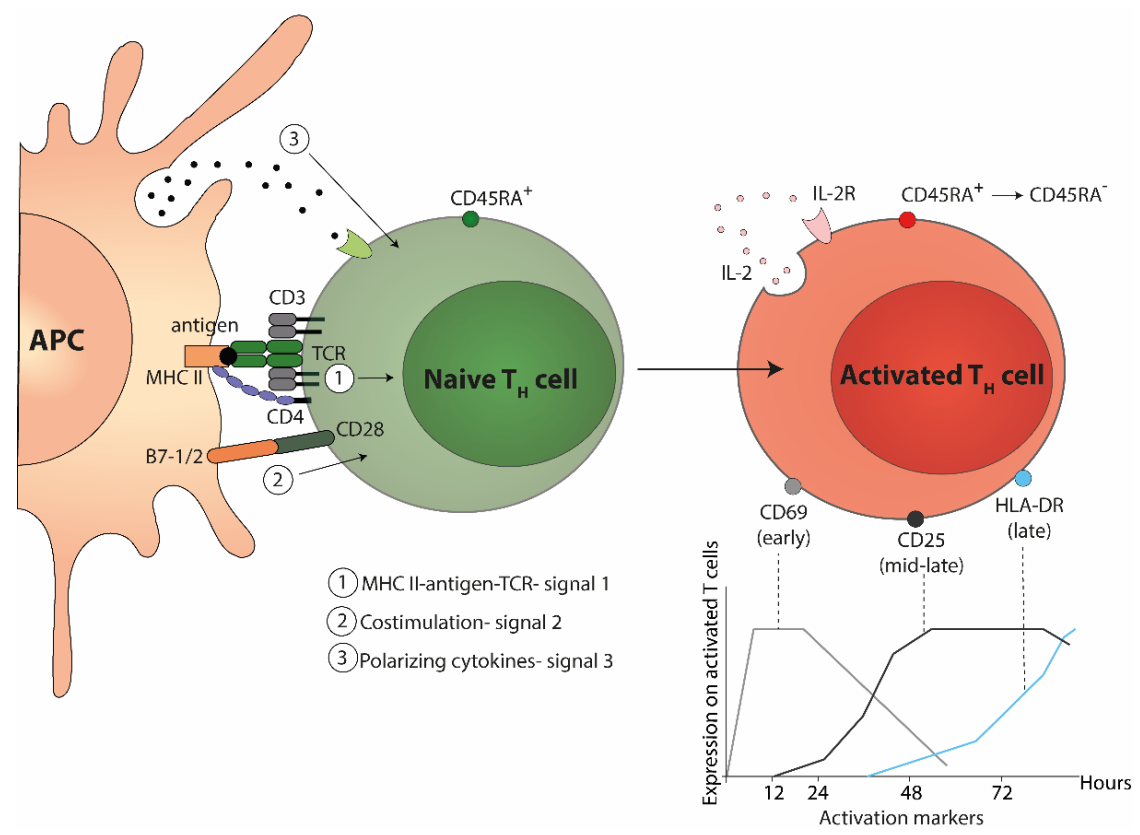

Figure 6. T cell activation. Once activated, the T cells start producing IL-2, which is required for continued proliferation and upregulation of different $\mathrm{T}$ cell surface activation markers that can be analyzed by flow cytometry as a measure of T cell activation. Expression of different activation markers reflect differences in the dynamics of the activation process, where some appear earlier and some later. APC, antigen-presenting cell; $\mathrm{MHC}$, major histocompatibility complex; TCR, T cell receptor; $\mathrm{T}_{\mathrm{H}}$, T helper cell.

regulatory $T\left(T_{\text {reg }}\right)$ cells, which play a central role in preserving immune tolerance and regulating the magnitude of the immune responses (described in detail in later sections). The distinction of different $T_{H}$ subpopulations is most often an oversimplification, and under many circumstances, $T_{H}$ cells can display characteristics of one or more of the different $T_{H}$ subsets (Annunziato and Romagnani 2009, Zhu 2018).

The different $T_{H}$ subsets have distinct effector functions for ensuring protective immunity. All $T_{H}$ subsets express lineage-specific master transcription factors that govern the most critical factors in the $T_{H}$ differentiation process (Zhu 2018). An overview of the different $T_{H}$ subsets and their phenotypic characteristics are shown in Figure 7. Briefly, $T_{H} 1$ cells are essential in the defense against intracellular pathogens but are also implicated in the development of certain autoimmune diseases. TH1 differentiation is induced by IL-12 and interferon (IFN)- - . Tbet is the master transcription factor for $\mathrm{T}_{\mathrm{H}} 1$ differentiation, promoting IFN- $\gamma$ production that activates macrophages, increasing their phagocytic activity that is necessary for destroying intracellular 


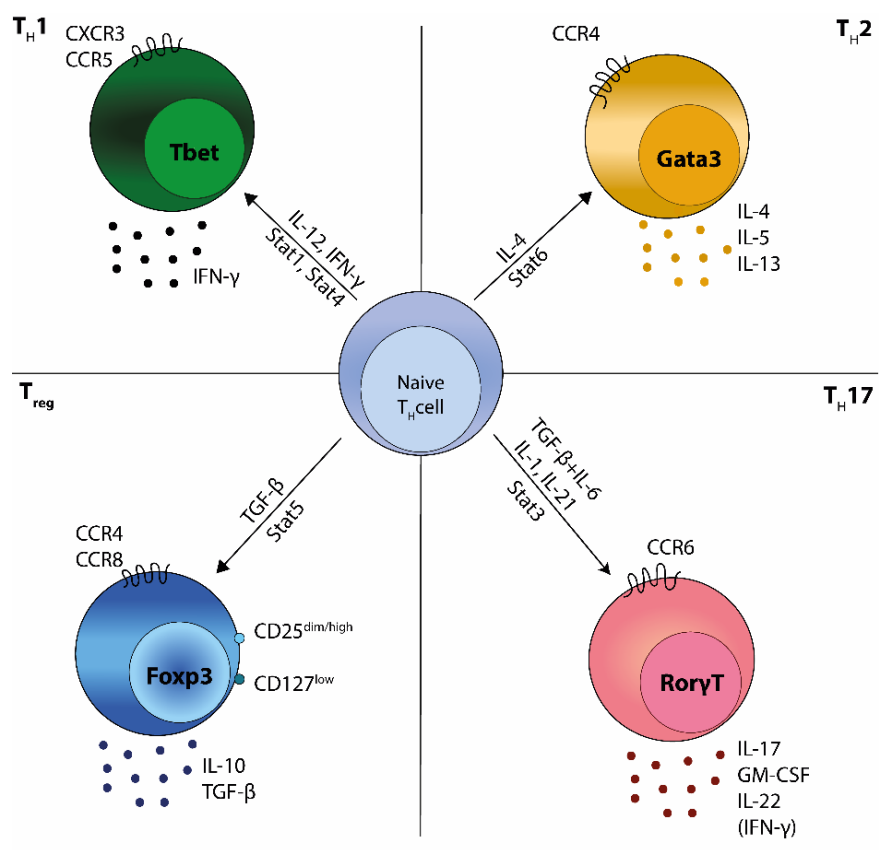

Figure 7. Schematic overview of the $T_{H}$ cell differentiation. Differentiation is induced in response to different cytokines in the surrounding environment, which activates the master transcription factors and the signaling transducer and activator of transcription (STAT) proteins that are required for $\mathrm{T}_{\mathrm{H}}$ cell fate determination and cytokine production. The different $T_{H}$ subsets secrete different characteristic cytokines and express different chemokine receptors that enables them to respond to different chemotactic signals produced at the site of inflammation.

pathogens. Furthermore, IFN- $\gamma$ also induces Tbet expression, which positively amplifies the $T_{H} 1$ responses (Zhu 2018). TH 2 cells on the other hand are crucial for mediating immune responses against extracellular parasites but have also been associated with allergic diseases (Nakayama et al. 2017). $T_{H} 2$ cells are induced in response to IL-4 and the master regulator of $T_{H} 2$ differentiation is Gata3, which induces production of IL-4, IL-5 and IL-13. These cytokines promote IgE antibody responses and recruitment of eosinophils that are required for the defense against certain extracellular parasites. The third subset of $T_{H}$ cells, $T_{H} 17$, are essential for the defense against extracellular bacteria and fungi and involved in different forms of autoimmunity such as psoriasis, MS and rheumatoid arthritis (RA) (Crome et al. 2010). RORYT is the master transcription factor of $\mathrm{T}_{\mathrm{H}} 17$ cells and enhances the expression of the signature cytokines IL-17A and IL-17F. The major function of IL-17 is recruitment and activation of neutrophils, which is required for clearance of extracellular bacteria and fungi. The different $T_{H}$ subsets home to the site of infections where they perform their effector functions, and their migration pattern depends upon the chemokines produced in the tissue and the distribution of chemokine receptors on the $T_{H}$ cells. $T_{H} 1$ cells 
express for example CXCR3 that binds CXCL9,10 and 11, induced in response to IFN- $\gamma$, and $T_{H} 2$ cells are mainly characterized by the expression of CCR4 that binds CCL17 and CCL22 (Sallusto et al. 1998). TH17 cells express CCR6, which responds to CCL20 expression (Singh et al. 2008). The different functional characteristics of the $T_{H}$ subsets allow the immune system to tailor the immune responses to combat any incoming threats in the best way possible.

Cytokines produced by different $T_{H}$ subsets are critical components in the inflammatory process and active players in disease development. Specifically, the $T_{H} 1$ and $T_{H} 17$ signature cytokines IFN- $\gamma$ and IL-17 are believed to be the pathogenic initiators in MS (Baecher-Allan et al. 2018).

Overexpression of both IFN- $y$ and IL-17 has been identified in MS brain lesions (Lock et al. 2002, Tzartos et al. 2008). Their importance in the MS pathogenesis is further supported by data from clinical trials where IFN- $\gamma$ treatment exacerbated disease (Panitch et al. 1987), and treatment with IL-17 antagonist could hold potential therapeutic promise, as it has been shown to reduce lesion formation (Havrdova et al. 2016). Furthermore, several of the MS susceptibility genes are related to $T_{H} 1$ and $T_{H} 17$ differentiation. For example, IL-12, a heterodimer between IL-12A and IL-12B, is essential for the development of IFN- $\gamma$-producing $T_{H} 1$ cells and IL-12B is also part of IL-23 that is necessary for $T_{H} 17$ development. However, the relative importance of $T_{H} 1$ versus $T_{H} 17$ in the MS pathogenesis remains unclear, and the importance of the different subsets could vary across individuals as well as from disease initiation to relapse and disease progression (Arellano et al. 2017, Frisullo et al. 2008). The importance of the different $T_{H}$ subsets is further complicated as for example $T_{H}$ cells expressing both IFN- $\gamma$ and IL-17 have been identified in patients with MS (Kebir et al. 2009) and CCR6 $6^{+}$myelin-reactive $C D 4^{+} T$ cells from patients express higher levels of IFN- $\gamma$, IL17 and granulocyte-macrophage colony-stimulating factor (GM-CSF) compared to healthy controls (Cao et al. 2015). GM-CSF has been identified as critical factor in the pathogenicity of $T_{H} 1$ and $T_{H} 17$ and GM-CSF deficient mice fail to induce neuroinflammation despite expression of both IL-17A and IFN- $\gamma$ (Codarri et al. 2011, El-Behi et al. 2011), indicating that GM-CSF is a pivotal factor in disease development. GM-CSF producing $T_{H}$ cells are significantly increased in MS compared to non-inflammatory neurological disorders and associated with disease severity (Hartmann et al. 2014). In a recent publication, using high-dimensional single cell mass cytometry, an MS-specific $T_{H}$ signature was identified, characterized by expression of GM-CSF, tumor necrosis factor (TNF),

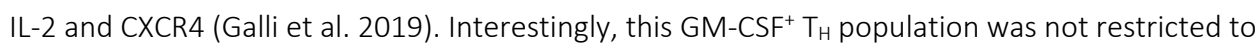
any particular $T_{H}$ subset, as both $T_{H} 1, T_{H} 2$ as well as $T_{H} 17$ cells all contributed, albeit to different extent, to the GM-CSF expression. Since this population did not belong to any of the classical $T_{H}$ 
subsets, $T_{H}$ cells may acquire properties that do not fall into the pre-defined categories of the different $T_{H}$ subsets during pathogenic conditions, further highlighting the complexity of the disease pathogenesis and importance of using more unbiased approaches to discover new disease mechanisms.

\section{Regulating $T_{H}$ cell responses is crucial for preventing autoimmunity}

$\mathrm{CD}^{+} \mathrm{T}$ cells are not only crucial for promoting immunity but also for ensuring immunological tolerance to avoid unwanted, potentially damaging immune responses. A breakdown of selftolerance is thought to be the first crucial step in the MS pathogenesis that enables the normal repertoire of circulating naive antigen-specific T cells to become activated (Goverman 2011). Tolerance can be ensured in the thymus during T cell development (central tolerance) and in peripheral tissue (peripheral tolerance). Failure in these crucial immune-regulatory check points could lead to loss of immunological tolerance and disease development.

The thymus constitutes the first avenue for controlling autoreactive $\mathrm{CD} 4^{+} \mathrm{T}$ cells, where thymocytes that display an unacceptable level of self-reactivity are deleted (Takahama 2006). Mice lacking the thymic transcription factor autoimmune regulator (AIRE), which controls the transcription of genes encoding for the tissue restricted antigens in the thymus (Anderson et al. 2002), are more susceptible to EAE than wild type mice (Aharoni et al. 2013), thus supporting the importance of thymus for maintaining tolerance. However, a link between loss of thymic tolerance and MS in humans remains to be determined. Even though there are numerous mechanisms operating to ensure that potentially self-reacting $C D 4^{+} T$ cells are eliminated already in the thymus, the presence of autoreactive cells in MS patients and in healthy controls clearly demonstrates that this process is not $100 \%$ efficient (Hellings et al. 2001, Saez-Torres et al. 2002).

There are numerous peripheral mechanisms at place for maintaining tolerance such as induction of anergy, clonal deletion and suppression by $T_{\text {reg }}$ cells (Abbas et al. 2017). Under normal circumstances co-stimulatory molecules, such as CD80/CD86, CD28 and CD40, are absent or very lowly expressed on APCs, while being induced by various stimuli in response to for example microbial products. When naive $T_{H}$ cells encounter antigens in the absence of co-stimulation it results in anergy and the $T_{H}$ cells are rendered unresponsive. This is most often the case under normal steady-state conditions, when APCs continuously present self-antigens to patrolling $T_{H}$ cells. Several studies point towards a significant role for co-stimulatory mechanisms in MS as myelin-reactive T cells from MS patients seem to be less dependent on co-stimulation compared 
to cells from healthy controls, potentially due to increased proportion of memory cells (LovettRacke et al. 1998, Scholz et al. 1998, Cao et al. 2015). Another important avenue for controlling immune responses and maintaining immune homeostasis is through co-inhibitory check-point molecules. These molecules are expressed on activated T cells and regulate $T$ cell responses by inhibiting T cell activation (Chen and Flies 2013). PD-1 has for example been shown to regulate disease severity in EAE and blockade of PD-1 results in an accelerated and more severe form of EAE (Salama et al. 2003). In humans, polymorphisms in the PD1 gene appear to be associated with disease progression (Kroner et al. 2005). Interestingly, low levels of the co-inhibitory molecules TIGIT and TIM-3 were suggested as unfavorable prognostic factors in MS (Lavon et al. 2019). Notably, attempts to restore peripheral tolerance in MS seem so far as a potentially promising treatment strategy (Lutterotti et al. 2013), where a recent phase $1 \mathrm{~b}$ trial using autologous DCs loaded with myelin proteins induced a tolerogenic immune response with increased frequency of $T_{\text {reg }}$ cells (Zubizarreta et al. 2019).

\section{Regulatory T cells in MS}

The presence of autoreactive T cells in healthy individuals underscores the importance of efficient control of immune responses. Treg cells play a major role as key regulators of immune homeostasis and self-tolerance. In a seminal paper by Sakaguchi et al., $T_{\text {reg }}$ cells were shown to be instrumental for preventing autoimmune disease (Sakaguchi et al. 1995). The importance of $T_{\text {reg }}$ cells became apparent in patients with mutations in the Foxp3 gene, the lineage-defining transcription factor of $T_{\text {reg }}$ cells, who developed a severe and fatal systemic autoimmune disorder called polyendrocrinopathy, enteropathy, X-linked syndrome (Bennett et al. 2001).

There are two main types of $\mathrm{T}_{\text {reg }}$ cells: (1) thymic (also called natural) $\mathrm{T}_{\text {regs }}$ that develop in the thymus and believed to be important for suppressing autoreactive T cells and (2) induced (or peripheral) $T_{\text {regs }}$ that are generated in the periphery from naive $C D 4^{+} T$ cells to limit potentially damaging immune reactions (Workman et al. 2009, Bluestone and Abbas 2003). Treg cells were originally defined, in mice, by $C D 4^{+} C D 25^{+}$(Sakaguchi et al. 1995) and were later shown to be regulated by Foxp3 (Fontenot et al. 2003). The majority of $T_{\text {reg }}$ cells express the transcription factor Foxp3 and its expression correlates with their suppressive capacity (Miyara et al. 2009; Figure 7). There are no single markers that can accurately identify $T_{\text {reg }}$ cells as both CD25 and Foxp3 are transiently upregulated in activated non-suppressive $T_{H}$ cells (Wang et al. 2007, Kmieciak et al. 2009). Indeed, Foxp $3^{+} \mathrm{CD}^{+} \mathrm{T}$ cells can be divided into resting/naive 
CD45RA $^{+}$Foxp3 $^{\text {lo }}\left(\right.$ CD25 $\left.^{++}\right)$and activated/memory CD45RA-Foxp3 ${ }^{\text {hi }}\left(C D 25^{+++}\right) T_{\text {reg }}$ cells, which differ slightly in their suppressive capacity and a population of non-Treg cells, defined by CD45-Foxp3 ${ }^{\text {lo }}$ $\left(C D 25^{++}\right)$, with no suppressive abilities (Miyara et al. 2009). In addition, CD127 (the IL-7 receptor $\alpha$-chain) has been shown to inversely correlate with Foxp3 expression and suppressive capacity and thus, $T_{\text {regs }}$ can additionally be defined as $C D 127^{\text {lo }}$ (Liu et al. 2006). Furthermore, $T_{\text {reg }}$ cells also express several functional markers such as the co-inhibitory receptor CTLA-4 (Miyara et al. 2009) and CD39, an endonuclease that mediates immunosuppression by degrading ATP (Borsellino et al. 2007), although the expression of these markers is not exclusive to $T_{\text {reg }}$ cells.

$T_{\text {reg }}$ cells employ an arsenal of regulatory mechanisms for mediating their suppressive effects where some depend on cell-cell contact such as CTLA-4, while other work through soluble mediators such as secretion of immune regulatory cytokines like IL-10 and transforming growth factor (TGF)- $\beta$ (Workman et al. 2009). Treg cells from MS patients have been shown to have a reduced suppressive capacity as compared to Treg cells from healthy controls (Viglietta et al. 2004, Haas et al. 2005, Venken et al. 2008, Baecher-Allan et al. 2011). However, the definition of $\mathrm{CD} 4^{+} \mathrm{CD} 25^{+}$alone could lead to inclusion of non-suppressive activated $T_{H}$ cells, which could account for some of the results. Most studies have not found any differences in the proportion of circulating $T_{\text {reg }}$ cells (Viglietta et al. 2004, Haas et al. 2005), which suggests a more qualitative abnormality in the $T_{\text {reg }}$ cells rather than quantitative. The observed $T_{\text {reg }}$ dysfunction appears to not only result from a functional defect within the $T_{\text {reg }}$ compartment itself (Viglietta et al. 2004), as patient-derived $T_{H}$ cells have been shown to be more resistant to $T_{\text {reg-mediated suppression }}$ (Bhela et al. 2015), implying a more heterogenous cause of the observed $T_{\text {reg }}$ dysfunction in MS. Interestingly, reduced output of $\mathrm{T}_{\text {regs }}$ from the thymus has been observed in patients with MS (Haas et al. 2007, Venken et al. 2008, Haas et al. 2011) and thus, thymic dysfunction resulting in disturbed peripheral $\mathrm{T}_{\text {reg }}$ homeostasis has been suggested as a possible explanation for the observed $T_{\text {reg }}$ defects (Venken et al. 2010).

\section{Immune regulation during pregnancy}

During pregnancy the intimate association between mother and the developing embryo creates a potential problem since the maternal immune system needs to tolerate the presence of paternal alloantigens (non-self) in order to allow the two genetically distinct individuals to co-exist for the duration of pregnancy. It was previously postulated that a successful pregnancy was dependent upon immunological inertness of the maternal immune system (Medawar 1953). However, the 
presence of anti-placental and anti-paternal antibodies in sera from pregnant women demonstrates that the semi-allogenic fetus is indeed recognized by the maternal immune system (Power et al. 1983, Innes et al. 1990, Billington 1992). Furthermore, the maternal immune system does not only recognize the fetus but also responds to it in a way that can determine the success or failure of pregnancy (Raghupathy 1997, Bates et al. 2002). Many analogies have been made between organ transplantation and pregnancy, two conditions whose success depend upon the immunological response to a semi-allogenic presence. However, whereas the success of a transplantation requires sustained immunosuppression, applying the same approach in pregnancy can be detrimental and lead to pregnancy loss (Mor et al. 2017). Instead, a successful pregnancy requires a robust and dynamic response by the maternal immune system in order to establish an environment that reduces the likelihood of immune rejection of the fetus. Immune modulation and establishment of tolerance are essential to allow for embryo implantation and continued growth of the developing fetus. By the end of pregnancy, immune tolerance is broken, which initiates inflammation and parturition, further emphasizing the immune system's role in regulating normal pregnancy. At the same time, a successful pregnancy also depends upon the ability of the maternal immune system to respond and protect both mother and fetus against environmental insults if necessary. Thus, pregnancy is a unique immunological condition, balancing the need for immunological tolerance whilst maintaining effective immunity (Mor and Cardenas 2010).

\section{Maternal immune adaptations at the fetal-maternal interface}

The immunological changes that take place during pregnancy are most pronounced at the fetalmaternal interface, where the close proximity between maternal and fetal-derived cells in conjunction with the invasive nature of the trophoblasts require tight and precise regulation in order to avoid triggering unwanted maternal immune responses (Figure 8). The focus of the thesis is related to the changes induced during pregnancy at the systemic level and hence, the local immunological adaptations at the fetal-maternal interface will only be described briefly. During early pregnancy, there is an influx of leukocytes to the maternal endometrium (decidua), consisting of both innate and adaptive immune cells. The decidua eventually becomes populated by a unique composition of immune cells that have specialized functions in order to meet the particular requirements during pregnancy (Svensson-Arvelund et al. 2014). The majority of early human decidual leukocytes are innate immune cells, where specialized uterine decidual natural killer (NK) cells ( $70 \%$ of all decidual leukocytes) and macrophages ( $20 \%)$ make up the larger 

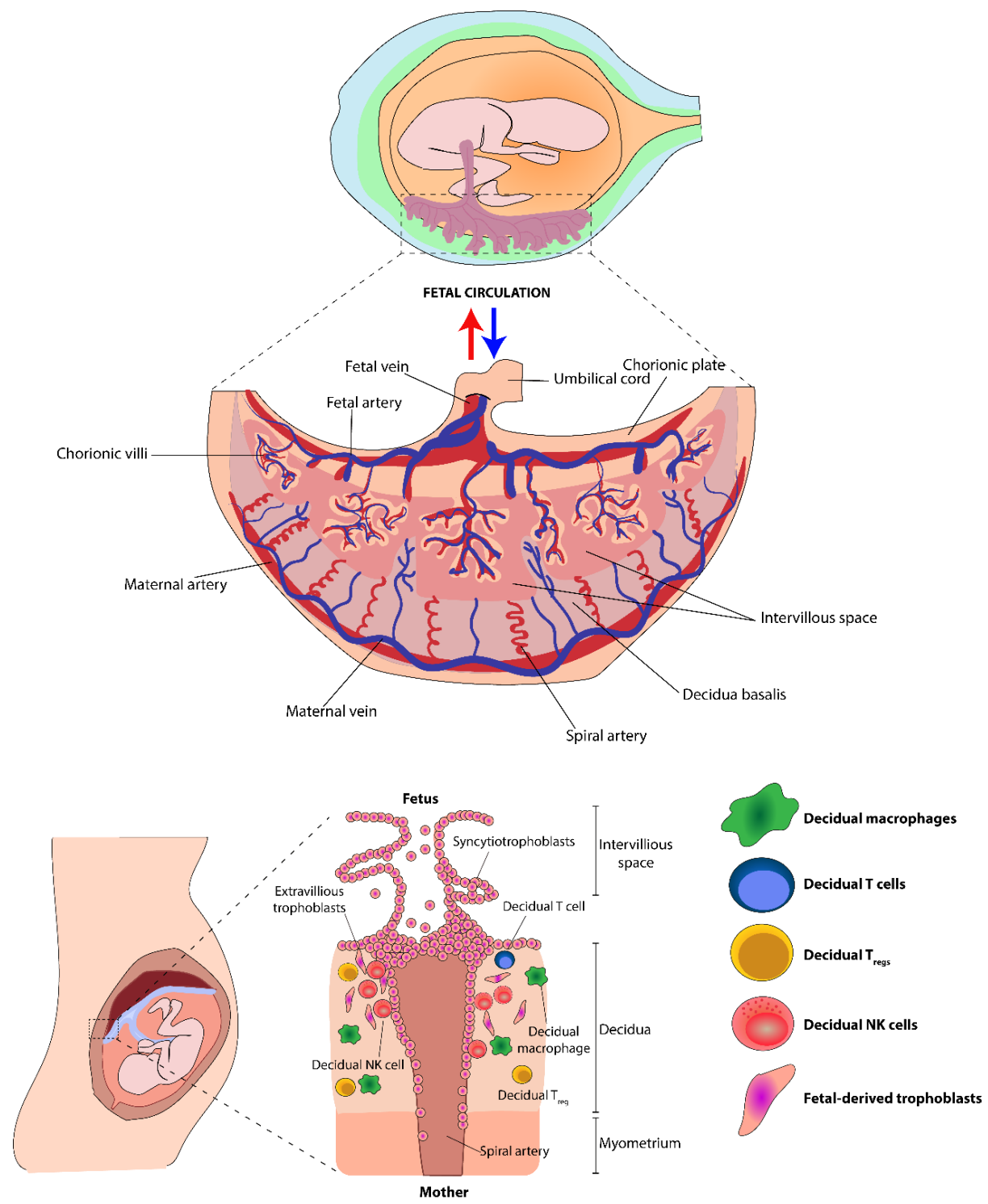

Figure 8. The fetal-maternal interface. During pregnancy, the developing fetus is dependent upon the maternal circulation for the exchange of nutrients, oxygen and waste. The placenta is a temporary organ connecting mother and fetus through the umbilical cord that performs this function during pregnancy. It is a chimeric organ, consisting of both maternal cells and fetal-derived trophoblast cells, that together forms the fetal-maternal interface. The main component of the placenta, the placental villous tree, consists of highly branching chorionic villi, the intervillous space and the decidua. Villious trophoblasts cover the villi through which the metabolic exchange occurs. Extravillious trophoblasts invade deep into the uterine wall, forming spiral arteries to allow for greater transport of maternal blood into the intervillous space and to provide adequate nutrition to the growing fetus. The immune response to the partly foreign trophoblasts is controlled and regulated by unique populations of immune cells infiltrating the decidua during early pregnancy. NK, Natural killer; $\mathrm{T}_{\text {reg, }}$, regulatory $\mathrm{T}$ cell. 
populations whereas only about $10 \%$ are T cells (Trundley and Moffett 2004). The immune cells present at the fetal-maternal interface display different phenotypic characteristics from their counterparts in blood and are more poised towards immune regulation and control of immune responses (Svensson-Arvelund et al. 2014). For example, the uterine decidual NK cells (CD56 bright) are less cytotoxic compared to the CD56 $6^{\mathrm{dim}} \mathrm{NK}$ cells that dominate in the peripheral circulation (Koopman et al. 2003) and the macrophages display M2-like characteristics with more immunomodulatory properties (Lidström et al. 2003, Gustafsson et al. 2008, Svensson et al. 2011). The importance of controlling immune responses during pregnancy is also evident by the relative exclusion of T cells at the fetal-maternal interface (Bulmer et al. 2010) as well by the enrichment of $\mathrm{T}_{\text {reg }}$ cells in the decidua with a more pronounced suppressive phenotype (Tilburgs et al. 2008, Mjösberg et al. 2010), further limiting potentially harmful T cell responses. Although pregnancy is mainly described as a state of tolerance, it is becoming increasingly more recognized that inflammatory features are required, particularly for implantation and tissue remodeling during early pregnancy but also during initiation of labor (Mor et al. 2017). It is evident that the dynamic physiological processes that follow pregnancy pose an immense immunological challenge for the local maternal immune system. Failure to timely and accordingly adapt to the changes induced during pregnancy could result in pregnancy complications.

\section{The influence of pregnancy on systemic immunity}

Although not as pronounced as the changes that occur locally at the fetal-maternal interface, it is evident that systemic alterations in response to pregnancy do take place (Svensson-Arvelund et al. 2014). The changes that occur during pregnancy are most likely the result of placenta-derived factors including cytokines, growth factors, hormones and fetal-derived microvesicles that shape systemic immune responses.

Characterization of peripheral immune cells throughout pregnancy has shown that the systemic changes induced by pregnancy are both gestational-age dependent and cell-type specific (Aghaeepour et al. 2017). Furthermore, the increased susceptibility to certain infections (Kourtis et al. 2014) and the improvement of some T cell-mediated diseases, like MS and RA (Confavreux et al. 1998, de Man et al. 2008) also confirm that 1) systemic adaptations in response to pregnancy occur and 2) it is not a general immune suppression but a tailored response to maintain the integrity of the maternal immune response while allowing tolerance towards fetal antigens. 
It has since long been established that the innate immune system changes during pregnancy, with increased number of circulating monocytes and granulocytes (Kraus et al. 2012). Moreover, there is also substantial evidence that not only is the number of innate immune cells increased but that they also show evidence of an activated phenotype (Svensson-Arvelund et al. 2014). Neutrophils have for example been shown to have increased production of reactive oxygen species (Sacks et al. 1998) and increased phagocytic activity (Barriga et al. 1994). Interestingly, pregnant women show decreased NK cell responses to non-specific stimulation but increased response to influenza virus as compared to non-pregnant women, suggesting that only specific innate immune responses are exacerbated (Kay et al. 2014). The increased activation of innate immune responses has been suggested as a mechanism to protect the mother against infections to compensate for the weakened adaptive immunity observed in the circulation (Sacks et al. 1999).

Pregnancy is evidently a much more dynamic state than "immunosuppressive", however certain parts of adaptive immunity are clearly altered and suppressed systemically, particularly certain aspects of the $T$ cell responses since triggering of fetal-specific $T$ cell responses could be detrimental to pregnancy. During pregnancy, when systemic immune tolerance is most evident, the in vitro response to recall antigens is altered in pregnant as compared to non-pregnant women, with less IFN- $\gamma$ and increased IL-10 production (Shah et al. 2017). Pregnant women have also been shown to have decreased T cell responses after non-specific stimulation (Kay et al. 2014). Wegmann et al. originally proposed that healthy pregnancy is characterized by a decreased $T_{H} 1 / T_{H} 2$ ratio (Wegmann et al. 1993) and since then pregnancy has been characterized as a " $T_{H} 2$ phenomenon" where $\mathrm{T}_{\mathrm{H}} 1$ responses have been considered incompatible with successful pregnancy (Raghupathy 1997). However, no differences in IL-4 and IFN- $\gamma$-producing cells have been observed between pregnant and non-pregnant women (Kraus et al. 2012). Clearly the $T_{H} 1 / T_{H} 2$ paradigm is a simplified view of pregnancy that needs to be revised (Chaouat et al. 2004) and expanded into the $T_{H} 1 / T_{H} 2 / T_{H} 17$ and $T_{\text {reg }}$ paradigm (Saito et al. 2010, Ernerudh et al. 2011). Although the switch between different $\mathrm{T}_{H}$ subsets might be most clear at the fetal-maternal interface (Saito et al. 2010, Ernerudh et al. 2011), the fact that $T_{H} 1 / T_{H} 17$-driven diseases like MS and RA improve during pregnancy suggests that alterations in these subsets also occur at a systemic level. Santner-Nanan et al. found decreased frequency of circulating $T_{H} 17$ cells during the third trimester as compared to non-pregnant women (Santner-Nanan et al. 2009), which correlates with the time point during pregnancy when MS improves the most (Confavreux et al. 1998), whereas others have reported no differences (Nakashima et al. 2010, Toldi et al. 2011). 
Despite the importance in controlling immune responses and promoting tolerance, circulating $T_{\text {reg }}$ numbers are unaltered or even decreased (Tilburgs et al. 2008, Mjösberg et al. 2009), which has been proposed to be due to specific migration of $T_{\text {reg }}$ cells to the decidua (Tilburgs et al. 2008).

\section{Endocrine regulation of immune cells during pregnancy}

Normal pregnancy is characterized by pronounced changes in pregnancy-related hormone concentrations, with elevated levels of several circulating steroid hormones which increase gradually throughout pregnancy (Figure 9). Progesterone (P4) is a naturally occurring steroid hormone, primarily produced by the corpus luteum during early pregnancy, but after about 8-12 weeks the placenta takes over as the major source of P4. The by far highest concentrations of P4 are found locally in the placental tissue and may exceed $10 \mu \mathrm{M}$ in the third trimester (Stites and Siiteri 1983, Arck et al. 2007). In contrast, circulating levels of P4 are much lower, starting from 3 nM in non-pregnant women to about 200-500 nM in late pregnancy (O'Leary et al. 1991, Soldin et al. 2005). P4 is essential for the establishment and maintenance of pregnancy as evident by the fact that administration of the P4-receptor antagonist Mifepristone (RU486) results in cessation of pregnancy (Couzinet et al. 1986). Furthermore, lowered circulating levels of P4 have been associated with several pregnancy complications (Arck et al. 2008, Okabe et al. 2014, Ku et al. 2018), and therapeutic use of P4 in pregnancy has been shown to reduce the risk of preterm birth in certain risk groups (Jarde et al. 2019).

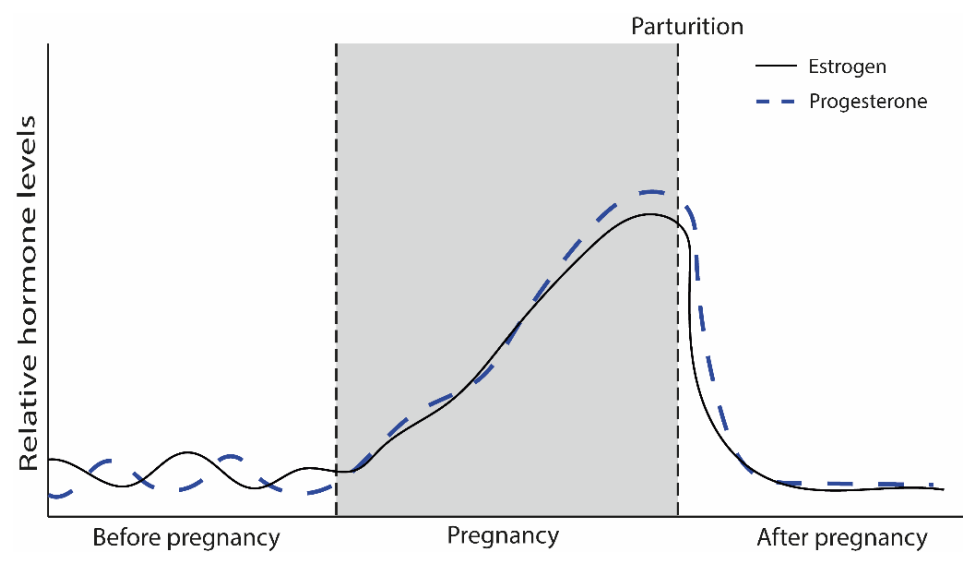

Figure 9. Schematic figure of the relative concentrations of progesterone and estrogen before, during and after pregnancy. The figure applies to both local (in the placenta) and systemic alterations in hormonal levels, although there are differences in the actual concentrations of the hormones locally versus systemically. 
In general, pregnancy hormones are believed to suppress maternal alloresponses while promoting fetal tolerance (Schumacher et al. 2014). Indeed, besides its effect on the uterus, it is becoming increasingly clear that P4 plays an important role in controlling immune-endocrine interactions that are essential for creating a tolerant immunological environment for the fetus. Indeed, P4 has been suggested as one of the main candidates for driving the "TH 2 dominance" in pregnancy (Piccinni et al. 1995). P4 has been shown to enhance IL-4 production in human CD4+ T cells (Piccinni et al. 1995, Lissauer et al. 2015) and could possibly suppress $T_{H} 1$ differentiation (Miyaura and Iwata 2002, Lissauer et al. 2015). There are conflicting results as to whether P4 can affect $T_{\text {reg }}$ differentiation, which could be related to differences in experimental settings and the species studied (Mjösberg et al. 2009, Lee et al. 2011, Lee et al. 2012). In humans, adult peripheral T cells were found to be largely unresponsive to P4 (Lee et al. 2011), whereas adult naive T cells from mice were readily converted to Foxp $3^{+} \mathrm{T}$ cells upon exposure to P4 (Lee et al. 2012). Furthermore, numerous studies have shown that P4 not only has the ability to affect $T$ cell differentiation but that it can also modulate the activity of the T cells by dampening their activation (Clemens et al. 1979, Chien et al. 2006, Chien et al. 2007, Hughes et al. 2013, Lissauer et al. 2015). This could be crucial during pregnancy since aberrant T cell activation could be detrimental (Arenas-Hernandez et al. 2019). Interestingly, P4 does not only appear to shape the T cell responses through direct effects on the T cells themselves but possibly indirectly, by modulating other immune cells. P4 has for example been shown to reduce the expression of costimulatory molecules on DCs and P4-treated DCs show reduced capacity to stimulate $\mathrm{CD} 4^{+} \mathrm{T}$ cells (Butts et al. 2007, Xu et al. 2011).

The role of estrogen in the immune system and in the immunological tolerance established during pregnancy is less clear since estrogen seems to have both immune regulatory and immune activating properties (Straub 2007, Walker 2011, Khan and Ansar Ahmed 2015). The IFN- $\gamma$ promoter contains estrogen response elements, suggesting that estrogen could be involved in driving IFN- $p$ production in T cells (Fox et al. 1991). Furthermore, ablation of the estrogen receptor- $\alpha$ attenuates the development of systemic lupus erythematosus (SLE) (Bynote et al. 2008) and markedly limited the inflammatory potential of the $C D 4^{+} T$ cells in a colitis mice model (Mohammad et al. 2018). Suggestively, the effects mediated by estrogen could be concentrationdependent (Priyanka et al. 2013).

The differential actions of sex hormones on immune cells are attributed to varying expression of the target receptors. P4 appears to be a promiscuous hormone that can interact with many 
different receptors: nuclear progesterone receptors (PR), membrane progesterone receptors (mPR) as well as glucocorticoid receptors (GR) (Dosiou et al. 2008, Engler et al. 2017. Tan et al. 2012; Figure 10). There are diverging findings regarding both the expression of different progesterone receptors on $\mathrm{CD}^{+} \mathrm{T}$ cells and also whether $\mathrm{P} 4$ works mainly by slower genomic or more rapid non-genomic actions through the nuclear or membrane receptors, respectively (Chien et al. 2006, Dosiou et al. 2008, Lee et al. 2012, Ndiaye et al. 2012). In addition, the expression of progesterone receptors has been shown to be activation-dependent (Szekeres-Bartho et al. 1985).

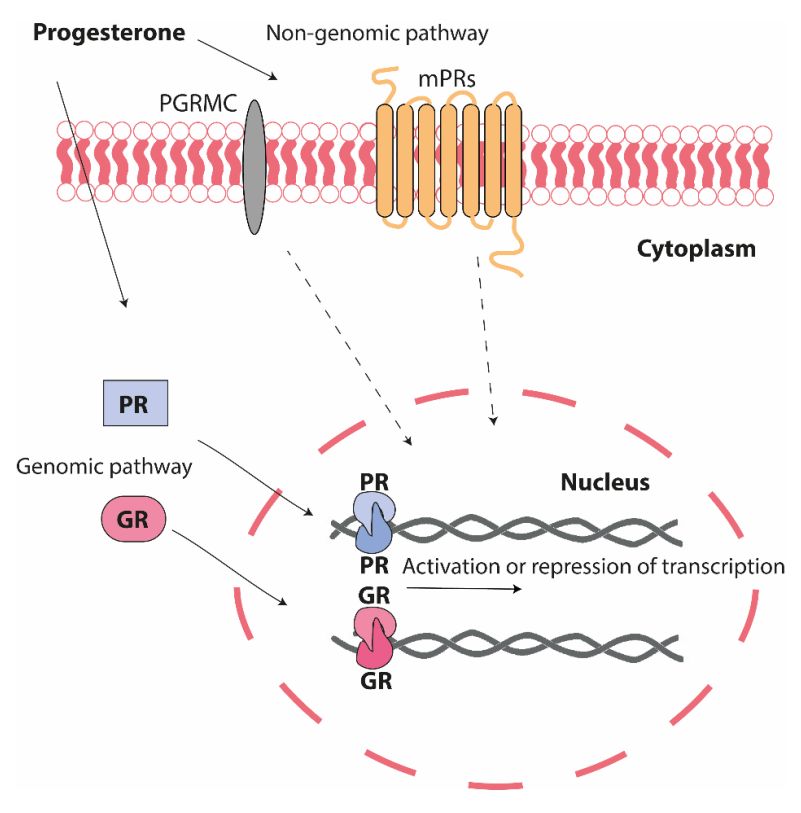

Figure 10. Overview of progesterone targets that induces both genomic (slower) and non-genomic (faster) pathways. GR, glucocorticoid receptor; $m$, membrane; PR, progesterone receptor; PGRMC, progesterone receptor membrane component.

\section{The effect of pregnancy on the thymus}

The thymus is a crucial organ in T cell immunity and is essential for maintaining the TCR repertoire that provides a crucial framework for the defense against the numerous pathogens that bombard our immune system on a daily basis (Germain 2002). It also serves as an important avenue for immunological tolerance, not only because most self-reactive T cells are deleted in the thymus, but also because $T_{\text {regs, }}$ which play a major role in peripheral tolerance, are generated there (Asano et al. 1996, Itoh et al. 1999, Cebula et al. 2013). As the thymus decreases in size with age, its 
relative contribution to the peripheral T cell pool remains poorly understood. Several studies support a significant role for the thymus in T cell regeneration, even during aging, most evidently during certain T cell-lymphopenic conditions (Douek et al. 1998, Ferrando-Martinez et al. 2017). Also, increased mortality in elderly is associated with failure of thymic function (FerrandoMartinez et al. 2013), and early life thymectomy increases the risk for certain autoimmune diseases, infections, cancer and asthma (Gudmundsdottir et al. 2018). Additional evidence for a continued importance of thymus in maintaining peripheral tolerance comes from observations of increased occurrence of systemic autoimmune diseases after thymectomy (Gerli et al. 1999, Park et al. 2004), as well as from the role of thymus-derived $T_{\text {regs }}$ in autoimmune diseases (Haas et al. 2007, Chen et al. 2009) and in tolerance towards commensal microbiota (Cebula et al. 2013).

During mammalian pregnancy, the thymus decreases in size (Clarke and Kendall 1994) and it has been speculated that this apparent evolutionary conserved mechanism reduces or alters the output of $T_{H}$ cells from the thymus, which could be an important component of maternal immune regulation (Tibbetts et al. 1999, Zoller et al. 2007). While thymic involution seems to be required for normal fertility in mice (Tibbetts et al. 1999), the functional importance of this pregnancyinduced involution is unclear. Indeed, thymus function in mice appears to be maintained to some extent during pregnancy (Kendall and Clarke 2000). However, in mice the naive T cell pool is sustained almost exclusively by thymic output throughout life whereas in humans the maintenance mostly relies on homeostatic proliferation of the existing peripheral T cell pool (den Braber et al. 2012). Thus, these differences in kinetics suggest that data from mice models should be extrapolated with caution. A role for thymic-derived $T_{\text {reg }}$ cells has been suggested in pregnancy complications (Wagner et al. 2015, Wagner et al. 2016), which supports the importance of the thymus in immune regulation during pregnancy.

\section{Identifying T cells with recent thymic origin}

Thymic function can be estimated by analyzing the output of T cells from the thymus. The T cells that have most recently completed thymic development and egress to join the circulating pool of peripheral T cells are called recent thymic emigrants (RTEs) (Fink 2013). RTEs are phenotypically and functionally distinct from their circulating mature naive (MN) counterparts (Kimmig et al. 2002, Berkley et al. 2013, Fink 2013). One of the major challenges in studying thymic output in humans has been the lack of unambiguous markers to reliably distinguish these cells from the rest of the peripheral T cell pool. To date, two markers have emerged as stable and consistent markers 
of RTEs; the expression of the surface marker CD31 (PECAM-1) (Kimmig et al. 2002), and an enrichment of intracellular episomal DNA fragments, T cell receptor excision circles (TREC), generated during the T cell receptor rearrangement in the thymus (Douek et al. 1998; Figure 11). As TRECs are not duplicated during mitosis, they are diluted with each cell division. Post-thymic homeostatic proliferation and priming of RTEs into memory T cells cause decreased TREC content, which is also paralleled by a loss of CD31 expression. Consequently, CD31+ naive T cells with a recent thymic origin have a higher TREC content as compared to CD31- naive T cells (Kimmig et al. 2002), which have persisted in the periphery for some time.

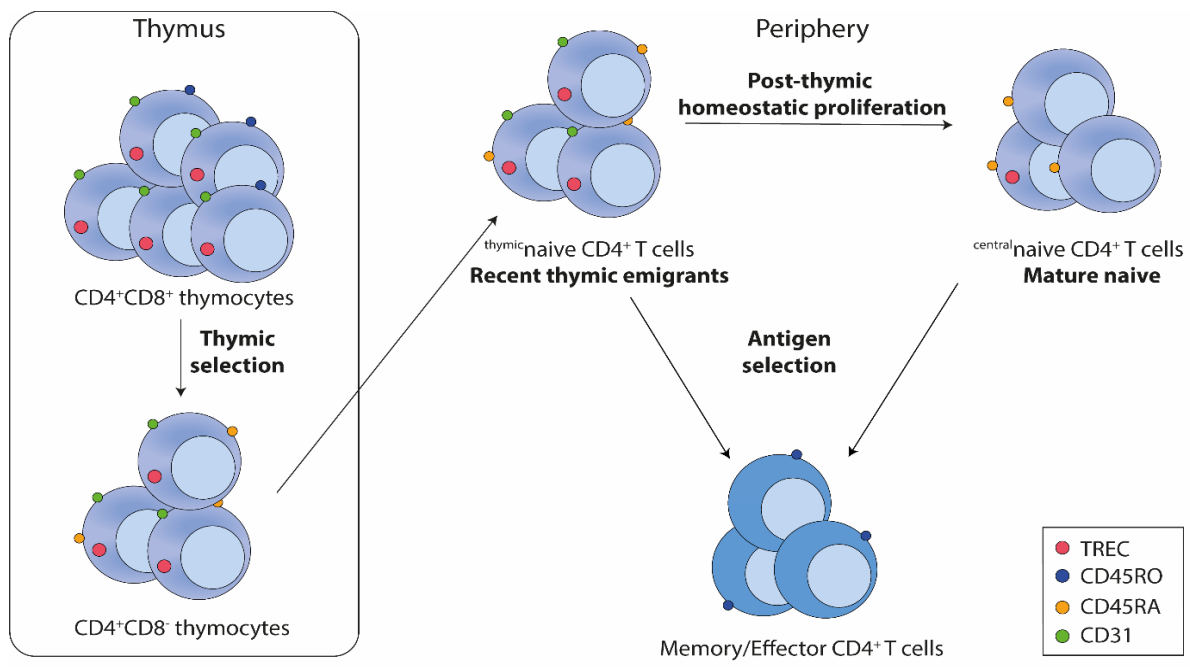

Figure 11. Dynamics of the circulating peripheral T cell pool.

\section{Multiple sclerosis and pregnancy}

The view of pregnancy and MS has changed since the 1950's, when women with MS were actually discouraged from having children and even recommended abortion in case of pregnancy because it was believed to worsen the disease (Sjögren and Lycke 2007). On the contrary, disease activity is typically decreased during pregnancy. In the seminal paper published in 1998 by Confavreux et al., the effect of pregnancy on disease activity in MS was investigated in a large prospective study, which revealed that pregnancy markedly reduced the relapse rate, particularly during the third trimester when there was an almost $70 \%$ reduction in relapse rate (mean 0.2 relapses/women /year as compared to 0.7 before pregnancy) (Confavreux et al. 1998; Figure 12). This is 
comparable to the effect achieved with Natalizumab, one of the best available treatments for MS today (Polman et al. 2006). However, a temporary worsening in the three months following delivery was also observed (1.2 relapses/women/year), after which the relapse rate returned to the pre-pregnancy rate. Several studies have since confirmed these findings (Saraste et al. 2007, Finkelsztejn et al. 2011, Hughes et al. 2014), which became classic and virtually undisputable. However, recent studies show that the natural history of pregnancy and MS is changing in the evolving treatment era where the large positive effect of pregnancy on disease activity is less clear (Alroughani et al. 2018, Das et al. 2018)

The long-term effects of parity in MS are less clear. Early observations showed protective effects of pregnancy on the risk of MS onset (Runmarker and Andersen 1995, D'Hooghe M et al. 2010), and parity has been associated with a better prognosis in MS (Runmarker and Andersen 1995, D'Hooghe M et al. 2010). However, other studies have failed to demonstrate long-term beneficial effects of pregnancy in MS (Thompson et al. 1986, Weinshenker et al. 1989, Stenager et al. 1994). One major caveat is that women with less severe disease choose to become pregnant more often than women with more severe disease, thus introducing a selection bias. However, a study including only women with a first demyelinating event still showed strong and significant effect of pregnancy to reduce the risk for subsequent development of MS (Ponsonby et al. 2012), although this was recently challenged (Zuluaga et al. 2019). Even though there are divergent findings regarding the effect of pregnancy in the long-term, it is at least evident that pregnancy does not have a negative long-term effect on the disease course.

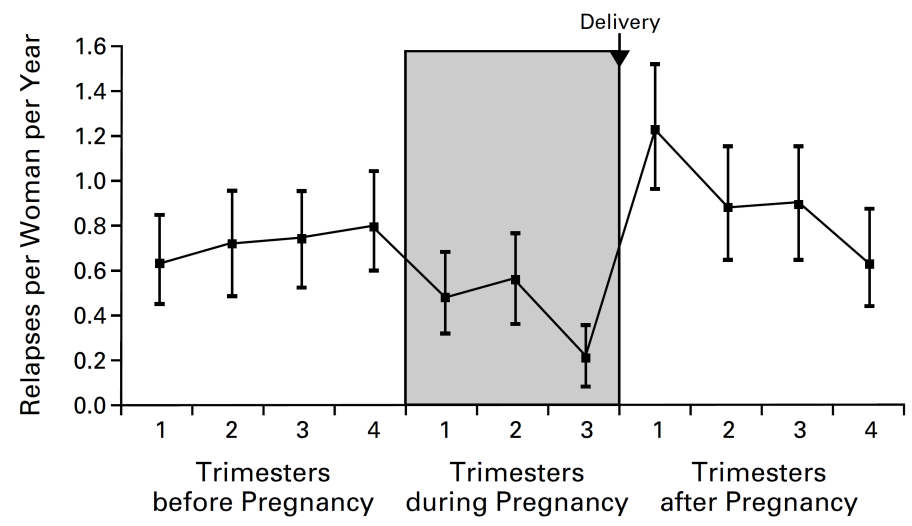

Figure 12. The natural history of MS during pregnancy (Confavreux et al. 1998). Picture printed with permission from Massachusetts Medical Society. 


\section{Why do patients with multiple sclerosis improve during pregnancy?}

It is evident from clinical data that pregnancy has a profound effect on the disease course, not only in MS but also in several other chronic inflammatory diseases (Confavreux et al. 1998, Raychaudhuri et al. 2003, de Man et al. 2008), which underscores the need to identify the underlying biological mechanisms responsible. The fact that autoimmune diseases like SLE may worsen during pregnancy (Petri et al. 1991) suggests that the beneficial effect of pregnancy on MS is most likely a consequence of immune-endocrine interactions and an altered maternal immune response during pregnancy. Indeed, there are many immunological changes that takes place during pregnancy that could be involved in mediating the pregnancy-induced effects such as the dramatic change in the levels of several hormones and changes in immune phenotype and function of many different immune cell populations (Patas et al. 2013). For example, a shift to more $T_{H} 2$ responses away from the disease-promoting $T_{H} 1 / T_{H} 17$ responses have been suggested as a possible explanation (Al-Shammri et al. 2004, Gilmore et al. 2004, Airas et al. 2008). Several studies have shown that alterations in immunological systemic parameters occur during pregnancy in MS (Saraste et al. 2007, lorio et al. 2009, Gilli et al. 2010, lannello et al. 2018, Spadaro et al. 2019), although the importance of these changes remains to be determined. In this thesis, we are adding to the knowledge and investigating mechanisms related to the immuneendocrine interactions and thymic regulation of $\mathrm{CD} 4^{+} \mathrm{T}$ cells that could potentially play a role in mediating some of the pregnancy-induced effects in the improvement of chronic inflammatory diseases like MS. 


\section{Aims}

The general aim of this thesis was to use pregnancy as a model of successful immune regulation to define mechanisms and factors responsible for the dysregulated immune system in MS to increase our understanding of how tolerance mechanisms induced during pregnancy could contribute to improvement of the disease. More specifically, the thesis focuses on immune regulatory mechanisms related to $\mathrm{CD}^{+} \mathrm{T}_{\mathrm{H}}$ cells.

\section{Specific aims}

- The aim of paper I was to characterize the response to $\mathrm{CD} 4^{+} \mathrm{T}$ cell activation in patients with MS to identify genes and molecules that were abnormally regulated upon activation.

Furthermore, we aimed to investigate if activated cells revealed the same or a different pattern of aberrations as compared to resting cells.

- The aim of paper II was to investigate how the pregnancy hormone progesterone affects $C D 4^{+}$ T cell activation to see if $\mathrm{P} 4$ promotes immune responses that could contribute to the pregnancy-induced improvement of MS.

- The aim of paper III was to explore the role of thymus in pregnancy by investigating if the output of $\mathrm{CD}^{+}$conventional $\mathrm{T}$ cells and $\mathrm{T}_{\text {reg }}$ cells is altered during pregnancy. 


\section{Study design and methodological considerations}

\section{Subjects}

\section{Subject characteristics}

In paper I, all MS patients (including early MS and CIS) were included at the Department of Neurology, Linköping University Hospital, Sweden. All patients with MS were diagnosed according to the McDonald criteria from 2010 (Polman et al. 2011). From the primary patient cohort, CD4 ${ }^{+}$ cells were isolated from 16 women (median age at inclusion $40.5 \mathrm{yrs}$, range 26-52). None of the patients had experienced a relapse within 3 months prior to sampling and none (except one) had received any immunomodulatory treatment for at least 2 months before. 16 age-matched controls, (median age 41.5, range 27-51) were recruited among healthy female blood donors at Linköping University Hospital. Plasma and/or CSF samples from three independent cohorts were used to validate the clinical relevance of our findings. The second cohort consisted of 41 patients with early MS ( $n=22, R R M S)$ or CIS (possible MS, n=19), median age 31 yrs (range 21-62) (Håkansson et al. 2017, Håkansson et al. 2018). None of the patients had received any previous treatment. The patients were followed for two years and classified into "no evidence of disease activity" (NEDA) (Rotstein et al. 2015) or not. Eleven age-matched controls (median age $30 \mathrm{yrs,}$ range 22-47) were recruited among healthy blood donors. CSF samples from a third cohort of MS patients ( $n=15$; median age $34 \mathrm{yrs}$, range 25-46) were included (from a larger cohort of $\approx 70$ patients, followed before and after treatment with Natalizumab, described in more detail in Mellergård et al. 2010, Mellergård et al. 2013, Gustafsson et al. 2014). Nine patients were chosen that did not fully respond to treatment (low responders) and were paired according to age, sex and EDSS to six patients that had not experienced a relapse at the follow-up after treatment with Natalizumab for 3 years (high responders). Further, an additional cohort of patients with RA $(n=40)$, SLE ( $n=43)$ and healthy controls $(n=40)$ were also included. Details regarding these patients have been described elsewhere (Ighe et al. 2015, Svärd et al. 2015). Further details regarding the study cohorts are found in paper $I$.

In paper II, blood samples were collected from healthy non-pregnant women ( $n=13$, median age 32 yrs, range 25-43), recruited at Linköping University or Linköping University Hospital. None of the women were taking hormonal contraceptives or any other medications. 
In paper III, blood samples were collected from $2^{\text {nd }}$ trimester $(n=30$, median age 28 yrs, range 2234 ) and $3^{\text {rd }}$ trimester ( $n=26$, median age 28 yrs, range 19-35) healthy pregnant women, recruited at the maternity care unit at Vrinnevi Hospital, Norrköping. All women were healthy and showed no signs of pregnancy complications at the time of inclusion. Review of medical records after delivery, 3 women were excluded because they were not considered as normal pregnancies. Healthy non-pregnant women ( $n=30$, median age 27.5 yrs, range 22-38) were recruited amongst students and personnel at Linköping University or Linköping University Hospital.

\section{Ethics statement}

Informed written consent was obtained from all participants prior to inclusion and sample collection. All the collected samples were anonymized (coded) and stored in biobanks owned by Region Östergötland. All results are presented at a group level and participants do not receive information regarding individual results. Any information about the study participants are handled in accordance with the General Data Protection Regulation (GDPR) and the subjects can at any time withdraw their participation from the study. All studies were approved by the Regional Ethics Committee in Linköping.

\section{Evaluation of disease status and activity}

In paper I, information regarding disease course and activity, past and current treatments was collected using medical records and the Swedish MS Registry. All included patients were clinically examined by a neurologist. EDSS was used to assess disability and multiple sclerosis severity score (MSSS) to determine disease severity. Disease scoring was performed in close proximity to inclusion except in the early MS/CIS cohort and in the response-to-treatment cohort where EDSS and MSSS were evaluated at multiple occasions following inclusion. Furthermore, patients included in the early MS/CIS cohort were also classified into NEDA (Rotstein et al. 2015) or not at the two-year follow-up.

\section{Expanded Disability Status Scale and Multiple Sclerosis Severity Score}

EDSS is one of the most commonly used method for measuring disease disability in MS (Kurtzke 1983). The evaluation of EDSS is based upon eight Functional Systems (FS): pyramidal tract function, cerebellar function, brain stem function, sensory function, bowel and bladder function, visual function, higher cerebral function and other functions where scoring is done based upon 
careful neurologic examination. The sum of the individual FS scores are used to define the actual EDSS score. The scale ranges from 0-10 where 0 is no sign of nerve damage and 10 is death caused by MS (Figure 13). The lower EDSS scores (0-4.5) refers to fully ambulatory patients and is based mainly on scoring of the FS whereas EDSS score 5.0-9.0 are defined as impairment in ambulation. Despite the general international acceptance of the EDSS, there are several limitations that needs to be taken into account (van Munster and Uitdehaag 2017). One caveat is that the clinical phenotypes are unevenly distributed across the scale and it is biased towards ambulatory function. Furthermore, there are several clinical symptoms that are not thoroughly assessed such as cognitive function and fatigue, common symptoms in MS patients. However, EDSS is still the most widely used outcome measure in clinical trials and if performed routinely at the clinic, it gives a rough estimate of the patient's functional level and disability that can be used to for example estimate and follow disease activity in relation to treatment.

MSSS is a measure that combines disease disability (as defined by EDSS) and disease duration to give an approximate rate of disease progression and severity (Roxburgh et al. 2005).

\section{No evidence of disease activity (NEDA)}

Disease-free status or NEDA is a currently evolving concept that has become a treatment goal and new outcome measure in MS (Rotstein et al. 2015). Clinically, NEDA status provides a valuable composite measure as an overall assessment of disease activity in individual patients, taking into account relapses, disability progression and MRI activity. NEDA is defined as the absence of new

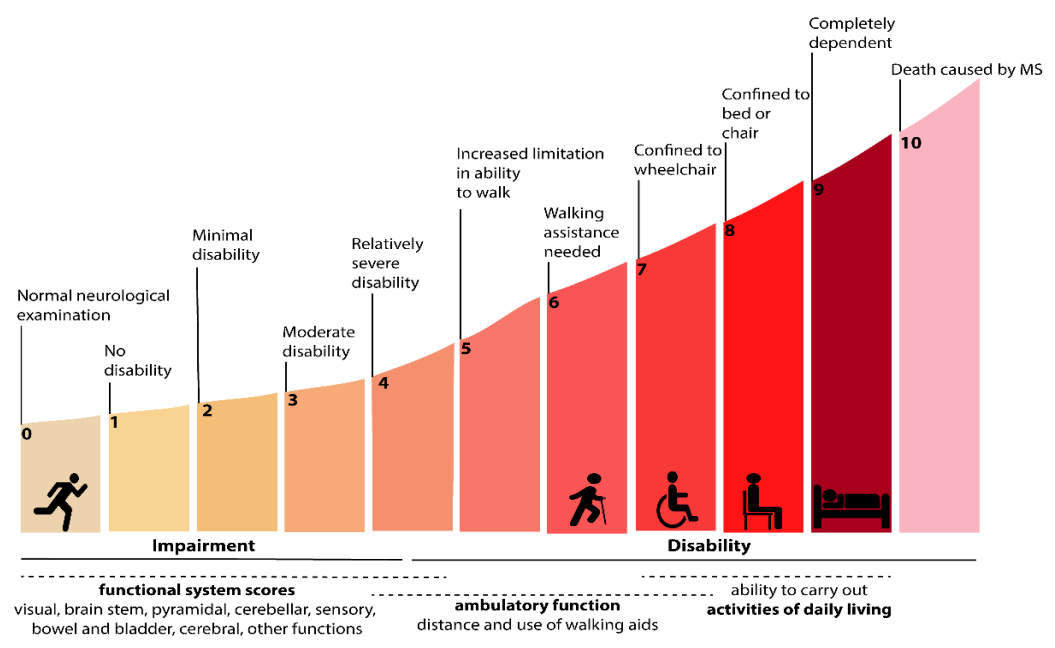

Figure 13. The Expanded Disability Status Scale. 
or enlarging T2 lesions or gadolinium enhancing lesions and no relapses or sustained EDSS score progression whereas patients with relapses, brain MRI activity or sustained disability worsening are classified as showing evidence of disease activity (EDA).

\section{Experimental design}

In the following sections, certain aspects of the experimental design and methods used in Paper IIII will be described and discussed. An overview of the different methods used in the thesis are shown in Table I. More detailed information regarding experimental and statistical procedures are described in the respective papers.

Table I. Overview of the methods used throughout paper I-III

\begin{tabular}{lccc}
\hline & Paper I & Paper II & Paper III \\
\hline MACS & & & \\
\hline Blood CD4 & & $x$ & $x$ \\
\hline FACS & $x$ & & $x$ \\
\hline Flow cytometry & $x$ & $x$ & \\
\hline Multiplex Bead Assay & $x$ & & \\
\hline Proximity Extension Assay & & & \\
\hline ELISA & $x$ & & \\
\hline RT-PCR & & & \\
\hline Microarray & $x$ & $x$ & \\
\hline RNA sequencing & & & \\
\hline
\end{tabular}

ELISA, enzyme-linked immunosorbent assay; FACS, fluorescence-activated cell sorting; MACS, magneticactivated cell sorting; RT-PCR, real time polymerase chain reaction.

\section{Peripheral blood as a tissue to study immunological mechanisms in MS}

In this thesis, we investigated peripheral mechanisms that could be involved in mediating the pregnancy-induced effects observed in MS. Although the detrimental inflammation occurs in the CNS, as previously mentioned there is ample evidence that during earlier stages of the disease, peripheral dysregulation of immune responses is a main driver of disease (Dendrou et al. 2015). Indeed, even though there has been an increasing need to identify more easily available biomarkers in blood as compared to CSF, it is clear that it is harder to identify biomarkers in peripheral blood that accurately reflect CNS inflammation (Hellberg et al. 2016, Håkansson et al. 2017, Håkansson et al. 2018). Thus, one could question if and how well the inflammatory processes in the brain is reflected in the systemic circulation. Furthermore, the effects induced 
during pregnancy are most likely mainly confined to the peripheral circulation, although one cannot rule of that pregnancy could directly affect the CNS itself. However, from a clinical point of view it is important to identify peripheral mechanisms and biomarkers that are involved in promoting disease at the earlier stages because once the inflammatory response becomes confined behind a sealed blood-brain barrier it becomes harder to target. Initiating treatment as early as possible is crucial to dampen disease activity and halt disease progression (Chalmer et al. 2018), which further supports the importance of peripheral mechanisms in driving disease as most current treatments mainly target the peripheral immune system. Thus, our overall design in the papers in the thesis allows us to identify and draw conclusions about potential peripheral mechanisms that could elucidate pathophysiological mechanisms in MS and why patients with MS improve during pregnancy. Although these mechanisms could be important for driving early disease, the design limits our ability to draw conclusions regarding possible CNS-related disease mechanisms or how systemic changes during pregnancy could affect the local inflammatory responses in the CNS.

\section{In vitro assay to study $T$ cell activation}

In paper I and II, we established and optimized an in vitro model to study CD4 ${ }^{+} \mathrm{T}$ cell activation. Isolated $\mathrm{CD}^{+} \mathrm{T}$ cells were cultured unstimulated (unactivated) or stimulated (activated) through the TCR (anti-CD3 antibodies) and the co-stimulatory CD28 receptor (anti-CD28 antibodies), mimicking the in vivo activation of T cells by antigen-presenting cells (Bretscher 1999, Sharpe and Freeman 2002; Figure 14). The unactivated $C D 4^{+} T$ cells were included in all experiments to define baseline characteristics and to be able to determine changes induced by the T cell activation. We used a low-moderate level of stimulation, based mainly on the level of expression of the T cell activation marker CD69 (Simms and Ellis 1996). In MS, only a few CD4+ $T$ cells are expected to be pathologically relevant and in pregnancy the situation of alloantigen "awareness" would be expected to result in a more moderate level of T cell activation. Thus, we aimed to mimic the level of activation that would be more physiologically relevant to both MS and pregnancy rather than inducing a strong and widespread activation of all T cells. One important aspect, particularly in paper I, is that we chose to use a generic T cell stimulation rather than an antigen-specific to study T cell activation. However, we hypothesized that patients with MS would display a dysregulated response to T cell activation irrespective of antigen-specificity. Furthermore, in MS, the nature of the disease-promoting T cells remains unclear and seems to vary between patients and hence, it is harder to study pathologically relevant $T$ cell responses in an individual context. 
The process of T cell activation, ranging from initial activation to proliferation and subsequent differentiation takes up to several days and depending on the length of stimulation the in vitro activation will reflect different aspects of this process. We stimulated the $C D 4^{+} T$ cells between 6 $24 \mathrm{hrs}$ to capture the events that occur early in the T cell activation, a central step as it shapes the subsequent T cell responses (Yamane and Paul 2013). Furthermore, the short time span of activation allowed us to study responses that occur before the T cells start to proliferate (Wells et al. 1997, Soares et al. 2010), which reduces potential in vitro effects that could impact the interpretation and generalization of the results. However, the shorter time of stimulation limits our ability to draw conclusions about processes that occur later during the T cell activation.

The relevance of using an in vitro model of T cell activation for studying in vivo processes is a central question. One major objection is that the in vitro model of isolated immune cells that we have used is an oversimplified system to mimic complex in vivo interactions, where many factors absent in vitro could play a major role in vivo. However, given the complexity of the immune system it would be difficult to capture and study all aspects simultaneously whilst also being able to pinpoint and draw conclusions about for example important disease-promoting mechanisms. Furthermore, the findings and the approaches we took in paper I validate the relevance of our in vitro model of T cell activation, as we were able to take our in vitro findings and validate them in more in vivo-like settings and in different patient cohorts.
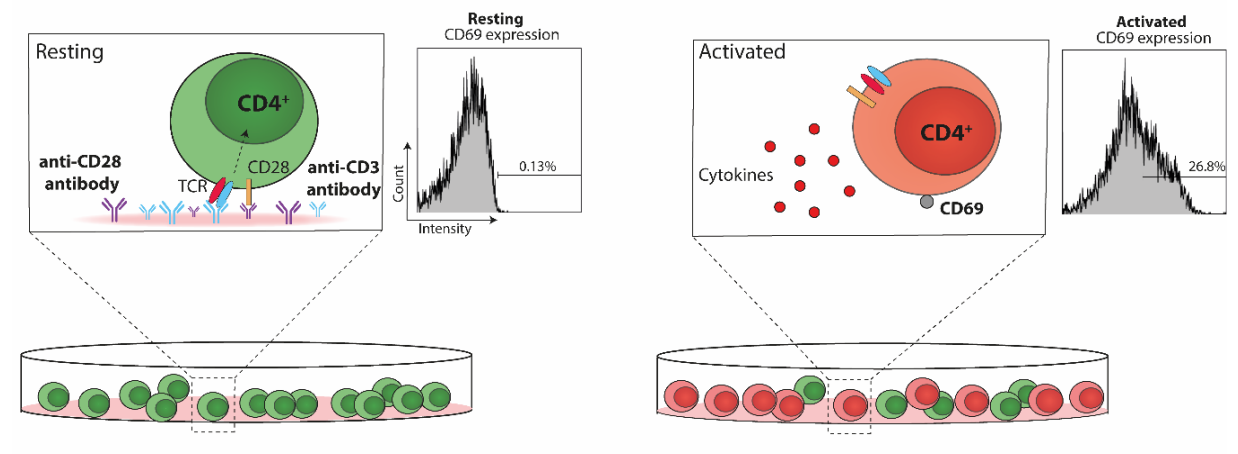

0 hrs

$6-24 \mathrm{hrs}$

Figure 14. In vitro model of $\mathrm{T}$ cell activation. $\mathrm{CD}^{+} \mathrm{T}$ cells were isolated from peripheral blood and cultured for up to $24 \mathrm{hrs}$ in the absence or presence of plate-bound anti-CD3 and anti-CD28 antibodies. The level of activation was determined based on flow cytometric analysis of CD69 expression. 


\section{T cell activation in the presence of progesterone}

In paper II, we used our established in vitro model to study T cell activation in the presence of P4. Freshly isolated $\mathrm{CD} 4^{+} \mathrm{T}$ cells were pre-incubated in the presence or absence of different concentrations of P4 prior to T cell activation (Figure 15). Many studies investigating the effect of P4 on T cells have performed the T cell activation while simultaneously adding P4 (Lee et al. 2012 Mjösberg et al. 2009, Lissauer et al. 2015). We decided to pre-incubate the cells with P4 prior to activation to resemble more the in vivo situation where the cells would be constantly exposed to P4 prior to antigen challenge.

We decided to use three different concentrations of $\mathrm{P} 4$ to be able to evaluate if $\mathrm{P} 4$ had a dosedependent effect on the $\mathrm{CD} 4^{+} \mathrm{T}$ cells. We used concentrations that are similar or slightly higher but still comparable to those found physiologically at the fetal-maternal interface during pregnancy (Arck et al. 2007). Of note, reliable information about local concentrations of P4 are scarce and most likely the concentrations in close proximity to the cells in the tissue are higher. We did observe an effect with the lowest concentration of P4 (10 $\mu \mathrm{M})$, corresponding to the highest concentration reported in the literature during pregnancy, although the observed effect was more pronounced with increased concentrations. Thus, we chose to perform a more in-depth analysis on the cells exposed to the highest concentration of P4. Although high hormone concentrations were needed to see a clear effect, we do believe that the results are physiologically transferable, which is strengthened by the observed dose-dependent response. It should also be noted that in many instances translating in vivo concentrations to an in vitro setting is challenging, particularly when using isolated cells.

\section{Microarray and RNA sequencing to study gene expression}

In paper I and paper II, we wanted to investigate the global gene expression profile in $\mathrm{CD}^{+} \mathrm{T}$ cells, not analysing single or a few groups of genes but investigating the expression of thousands of genes simultaneously. We used two different technologies, microarray (paper I) and next generation RNA sequencing (RNA-seq; paper II) for this purpose. In paper I, we compared the gene expression profile of unactivated and activated $\mathrm{CD}^{+} \mathrm{T}$ cells separately between patients and controls. However, since we also wanted to capture a potential difference in response to 


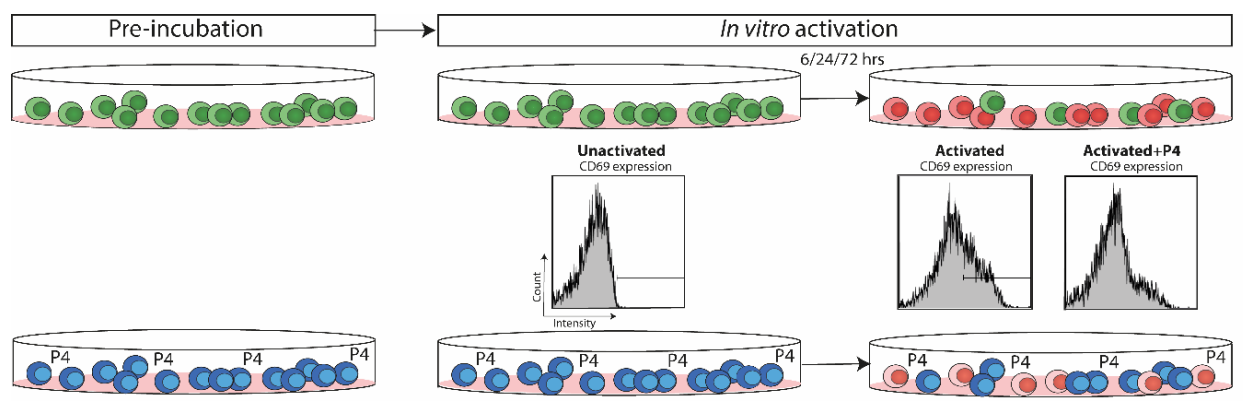

Figure 15. T cell activation in the presence of progesterone. Freshly isolated blood CD4+ $\mathrm{T}$ cells were preincubated for $20 \mathrm{hrs}$ with or without different concentrations of P4. Following pre-incubation, the cells were cultured unactivated or activated by plate-bound anti-CD3 and anti-CD28 antibodies in the absence or presence of P4 for 6, 24 and 72 hrs. 72 hrs were included for protein measurements only. Green colored cells represent those that were not exposed to P4, blue colored cells represent cells that have been exposed to P4 and red cells represent activated cells. The response to activation was characterized by flow cytometry, RNA sequencing and proximity extension assay for secreted proteins in culture supernatants. P4, progesterone.

activation between the groups, the gene expression in unactivated cells was subtracted from the expression in activated cells to capture the dynamics of the response to the T cell activation. Similar reasoning was applied in paper II but instead changes in gene expression were compared between $C D 4^{+} T$ cells activated in the presence of $\mathrm{P} 4$ as compared to $C D 4^{+} \mathrm{T}$ cells activated in the absence of P4.

Since the beginning of large-scale gene expression studies, microarray has been the most widely used technique and allowed for interrogation of a large number of genes in a more unbiased manner than what was previously possible at the time (Zhao et al. 2014). One of the major drawbacks with microarray technologies is that it is limited to investigation only of the genes for which the probes are designed, which in turn is based upon a priori knowledge regarding the sequence of the human genome. Similar to microarray, RNA-seq also allows for investigation of gene expression on a large scale, although in an even more unbiased manner, since it is not based upon the current state of knowledge. RNA-seq is now the technique to use for whole-genome transcriptome profiling and is rapidly replacing microarray platforms. Furthermore, RNA-seq also avoids a lot of the technical bias associated with hybridization-based approaches like microarray, which allows for more direct comparisons across different experiments (Wang et al. 2009). To minimize the technical bias when using microarray (paper I), samples between groups were evenly distributed across the arrays, and although not all samples were analysed at the same time, the same batch of arrays and the same machine was used for all samples. Although we used similar statistical approaches to investigate differentially expressed genes for data generated by 
both platforms, RNA-seq data poses additional challenges as it requires more thorough preprocessing of the data prior to analysis. Even though gene expression data is generated and processed in completely different ways between the two platforms there is still a high overlap in the identified differentially expressed genes (Marioni et al. 2008, Zhao et al. 2014). An overview of both microarray and RNA-seq is shown in Figure 16.

Regarding the statistical analysis of the data, analysing such a large number of genes in combination with rather few replicates presents a significant challenge in terms of mass significance. We used false discovery rate (FDR) to reduce the risk of mass significance. However, this rather strict statistical approach also increases the risk of not finding biologically relevant differences. Indeed, in paper I, we used the nominally differentially expressed genes instead of the FDR corrected p-values because we decided to replace the single gene analysis by instead analysing groups of genes and their functional and biological significance from a network-based perspective.

\section{Technical aspects and pre-processing of RNA sequencing data}

RNA-seq generates millions and millions of short reads. The length of the reads is determined by what you are interested in studying but for expression profiling around 100-150 base pairs (bp) is commonly used, depending on the sequencing platform (https://support.illumina.com) (Chhangawala et al. 2015). The samples included in paper II were sequenced 2x100 bp on the NovaSeq6000 (Illumina) at Science for Life Laboratory, the National Genomics Infrastructure (NGI), Stockholm Sweden. Paired end sequencing was chosen over single end because as the fragments are sequenced from both ends it enables more accurate read alignment. Unlike microarray data that requires relatively little pre-processing of the raw data prior to differential expression analysis, data generated from RNA-seq requires extensive pre-processing. One should be aware that there are as many different variations on how to process the data as there are applications of the technology and that no single analysis pipeline can be used in all cases. Therefore, it is important to choose the analysis tools that are most suitable for the data type generated, and the type of biological questions asked and to be aware of the advantages and disadvantages of using different pre-processing pipelines. The main components of the pre- 
Microarray

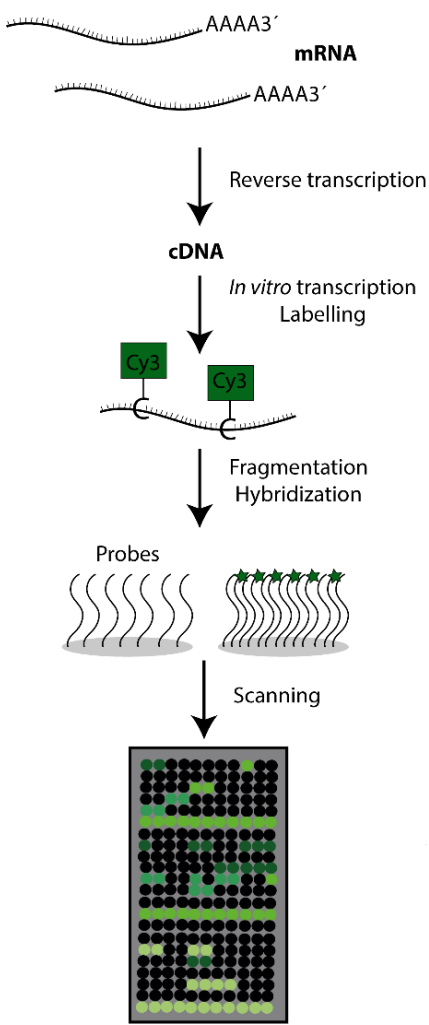

\section{RNA-seq}

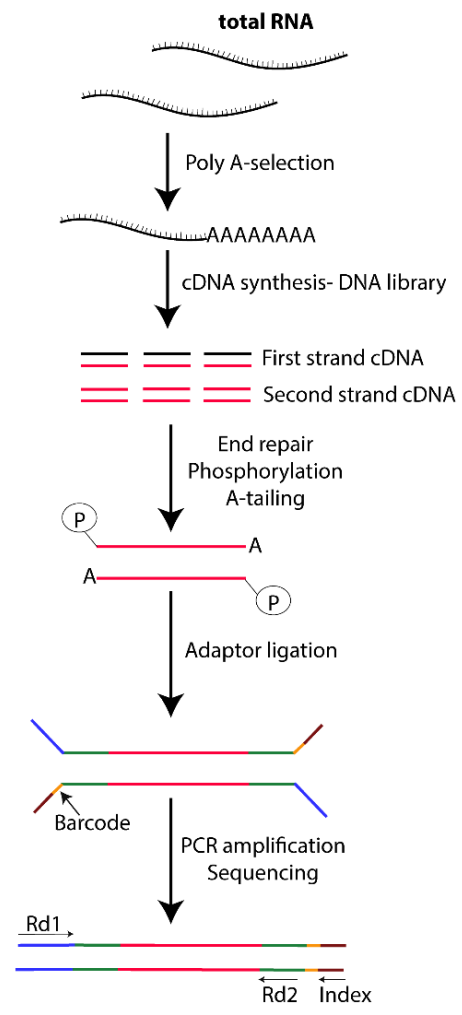

Sequencing
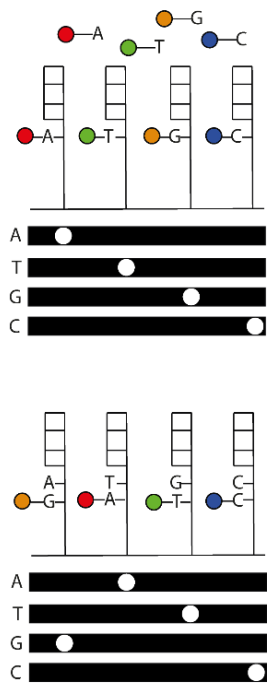

Read 1: AG

Read 2: TA

Read 3: GT Read 4: CC

Image showing fluorescence intensity

Figure 16. Microarray and RNA sequencing. Microarray: mRNA is converted into cDNA and labelled with a fluorescent dye, Cy3, and hybridized to the array (one color array). The array consists of DNA fragments of genes where the fragments of a gene are assigned to a specific location on the array. The fluorescent cDNA will bind to the complementary spot (probe) on the array. Differences in gene expression are revealed by the fluorescent patterns on the array. RNA-seq: from total RNA, mRNA is selected using poly-A-selection before first and second strand cDNA synthesis. The $5^{\prime}$ and $3^{\prime}$ ends are repaired and prepared for adapters, which contain a unique barcode (required for multiplexing) and primer binding sites. The adapters present on the cDNA fragments are covalently bound to complementary oligonucleotides attached on the surface of the flow cell. Several rounds of PCR amplification (bridge amplification) generate clusters of cDNA fragments that can be sequenced with the addition of one nucleotide per cycle. Fluorescence intensity values for each nucleotide are converted to nucleotide identity.

processing are quality control of the reads (including adapter removal and trimming of low-quality reads), read alignment to the reference genome, transcript assembly and identification and transcript quantification (Conesa et al. 2016; Figure 17). We used the RNA-seq Best Practice Pipeline (NGI-RNAseq) developed by NGI at SciLifeLab in Stockholm for processing the data (https://github.com/nf-core/rnaseq). Briefly, FastQC was used for read quality control and Spliced 
Transcripts Alignment to a Reference (STAR) (Dobin et al. 2013) was used to align the reads to the human reference genome (Genome Reference Consortium Human Build 37, GRCh37). When aligning the reads to the reference genome, it is important to consider that reads aligned at exonexon junctions will be split into two fragments and that the aligner of choice should take this into account in order to accurately identify novel transcripts generated by alternative splicing. Stringtie (Pertea et al. 2015) was used for transcriptome reconstruction and abundance estimation of the transcripts. Important to consider is that the number of reads overlapping with a particular gene cannot be directly translated into gene expression levels because read counts depend on 1) the transcripts own expression, 2) its length, 3) sequencing depth and 4) the expression of all other genes within the sample. Therefore, read counts need to be normalized against the fraction of reads assigned to each gene relative to the total number of reads and with respect to the entire RNA repertoire. The purpose with normalizing the read counts is to eliminate variations between samples that are not related to the biological differences of interest.

\section{Networks and modules for identifying disease-relevant genes}

In paper I, we investigated the difference in response to T cell activation between MS patients and healthy controls by analysing changes in gene expression. Besides using a traditional bioinformatic approach to look for differentially expressed genes, we also decided to use a network-based approach to look for disease-relevant genes, thereby shifting the focus from single genes to groups of related genes instead. The reasoning behind using these types of bioinformatic tools is that complex diseases like MS are not the result of an abnormality in one or a few genes but instead rather reflect the interplay between many genes and their corresponding proteins. Genes do not operate as independent units but form complex interacting systems where the function of one gene is defined by its interactions with other genes. Networks are a graphical representation of these complex interactions, where genes and proteins are represented as nodes and the interactions between them as edges (Figure 18). Networks are generated computationally by mapping gene expression data onto the protein-protein interaction (PPI) network, meaning that each corresponding gene is mapped to its matching protein product. One important property regarding networks is that functionally related nodes tend to be highly interconnected and colocalize within the network, forming distinct modules (Gustafsson et al. 2014). This is particularly 


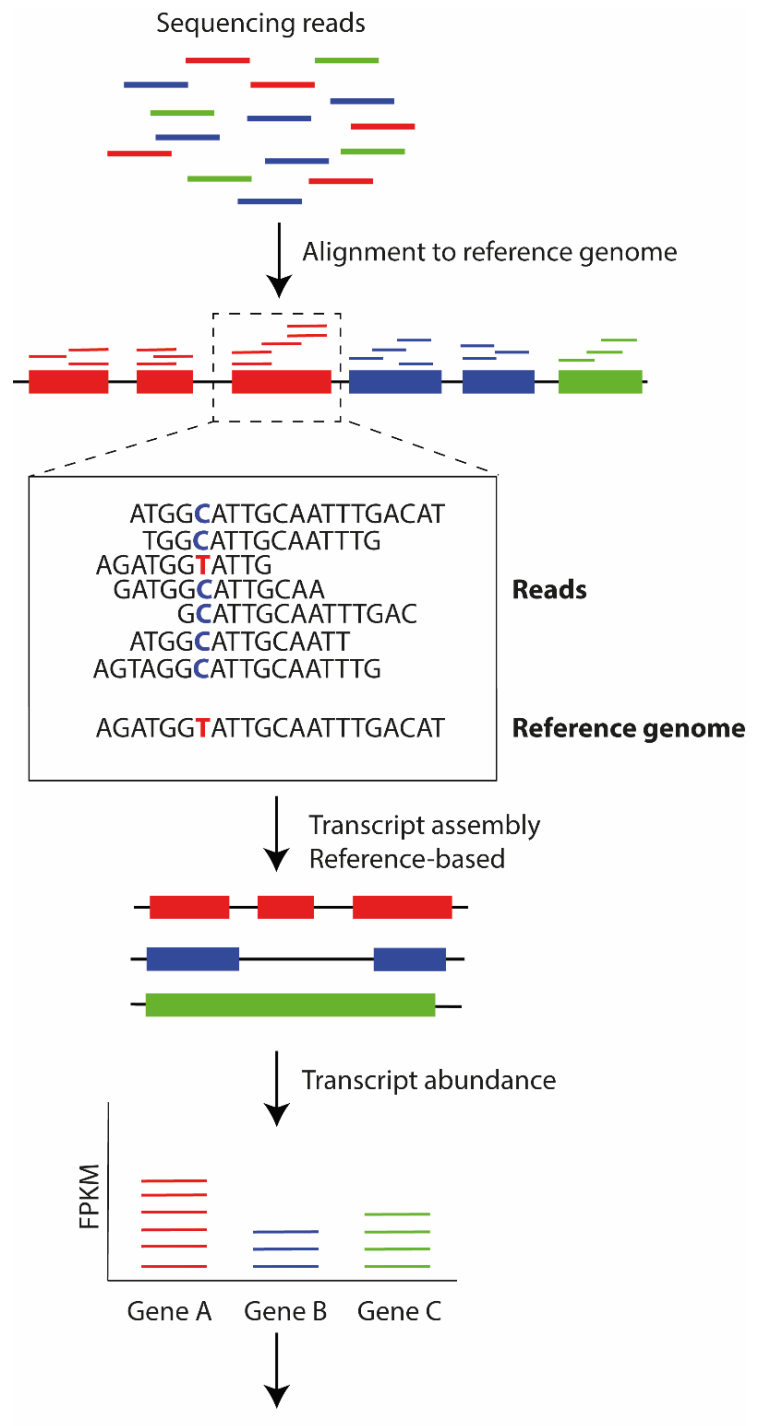

Differential expression analysis

Figure 17. Pre-processing of RNA-seq data prior to differential expression analysis.

true for diseases where proteins that are encoded by disease-associated genes tend to co-localize more often than expected by random and form distinct disease modules (Figure 18), indicating a functional relationship (Goh et al. 2007). The major advantage with using network-based approaches is to identify functional relationships among genes that most likely have a higher biological significance than just looking at individually differentially expressed genes by conventional statistical methods. Furthermore, in our module we also included not only gene 
products that were functionally interconnected in the PPI network, but also other tightly interconnected proteins, which include genes that were not present in our list of differentially expressed genes but that could still be of biological importance due to their close interactions with other genes. However, even though using a systems biology approach to analyse large scale data sets is an attractive option that is becoming increasingly used, it is still important to motivate that using these kinds of statistical methods is reasonable from a biological perspective.

There are several limitations in using networks based on the PPI network that should be considered when analysing and interpreting the results. One of the primary objections is that the networks rely on the PPI network which is estimated to cover about $20 \%$ of the complete interactome and thus, we are drawing conclusions regarding disease mechanisms based on a map of the interactome that is incomplete (Menche et al. 2015). Also, there is a large knowledge-bias where the interactome mainly reflects well-known, well-studied disease genes whereas unknown disease genes will be absent. However, despite the general incompleteness of the interactome, in terms of certain diseases like MS, the interactome seems to have sufficient coverage to allow for investigation of disease-related mechanisms (Menche et al. 2015).

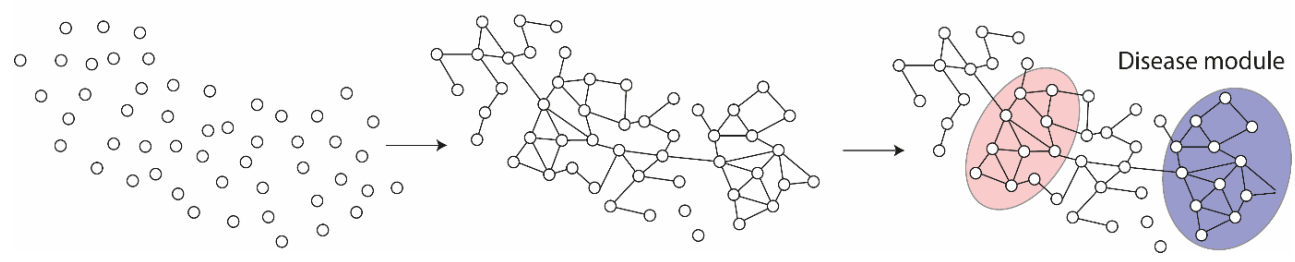

Figure 18. Networks and modules. Genes do not act as independent units but form intricate webs based on interactions with other genes, which are used as basis for constructing networks. Disease related genes/gene products form modules within the network that can be used to gain novel knowledge regarding disease mechanisms, biomarkers and potential treatment targets.

\section{RT-PCR for measuring TREC content in CD4 ${ }^{+} \mathrm{T}$ cells}

In paper III, we optimized a Taqman RT-PCR assay, based on the method previously published by Sairafi et al. (Sairafi et al. 2012), to measure TREC content in flow cytometry sorted populations of naive and memory conventional T cells ( $T_{\text {conv }}$ ) and $T_{\text {regs. }}$ TCR rearrangement has been reported to take place for all TCR genes and since TRECs are generated following each rearrangement there are several aspects that need to be considered when defining the optimal target TRECs; (1) it should detectable in peripheral T cells,; (2) be representative of thymic output and (3) should not be substantially diluted before the T cells enter the peripheral circulation (Hazenberg et al. 2001). 
Therefore, TRECs generated during early rearrangement of the TCR are not suitable because of the massive thymocyte expansion that follows these events. For example, TCRB TRECs are strongly diluted in the thymus and therefore detected at considerably lower levels in the circulation than TRECs produced during the late TCR gene rearrangements such as deletion of the TCRD gene or TCRA gene rearrangement. In $\alpha \beta$-T cells, deletion of the TCRD gene with the TCRA locus is required for productive rearrangement of the TCRA gene. This rearrangement results in a $\delta$ Rec- $\psi$ J $\alpha$ signal joint TREC (sjTREC) and a coding joint TREC (Figure 19). These TRECs are generated in approximately $70 \%$ of the rearrangements (Verschuren et al. 1997) and thus constitute the most common TRECs in $\alpha \beta$ - T cells, which makes them most suitable for assessing thymic output of this population. Also, the $\delta$ Rec- $\psi J \alpha$ TRECs are only minimally diluted in the thymus, because of the limited proliferation that takes place between the TCRD deletion and TCRA rearrangement, and thereby making them relatively easy to detect in peripheral T cells (Douek et al. 1998). We chose to analyze the $\delta$ Rec- $\psi J a$ sjTREC content since current PCR-based TREC methods cannot accurately distinguish between the $\delta$ Rec- $\psi \mathrm{J} \alpha$ coding joint that is found on one allele on genomic DNA and the $\delta$ Rec- $\psi J \alpha$ coding joint residing within the $V \alpha-J \alpha$ sjTREC. The primers and probes used have previously been validated by others and developed for screening of immunodeficiencies in newborns (Douek et al. 2000, Nobile et al. 2004, Chan and Puck 2005, Baker et al. 2009, Sairafi et al. 2012). To validate the PCR assay, we analyzed TREC levels in a

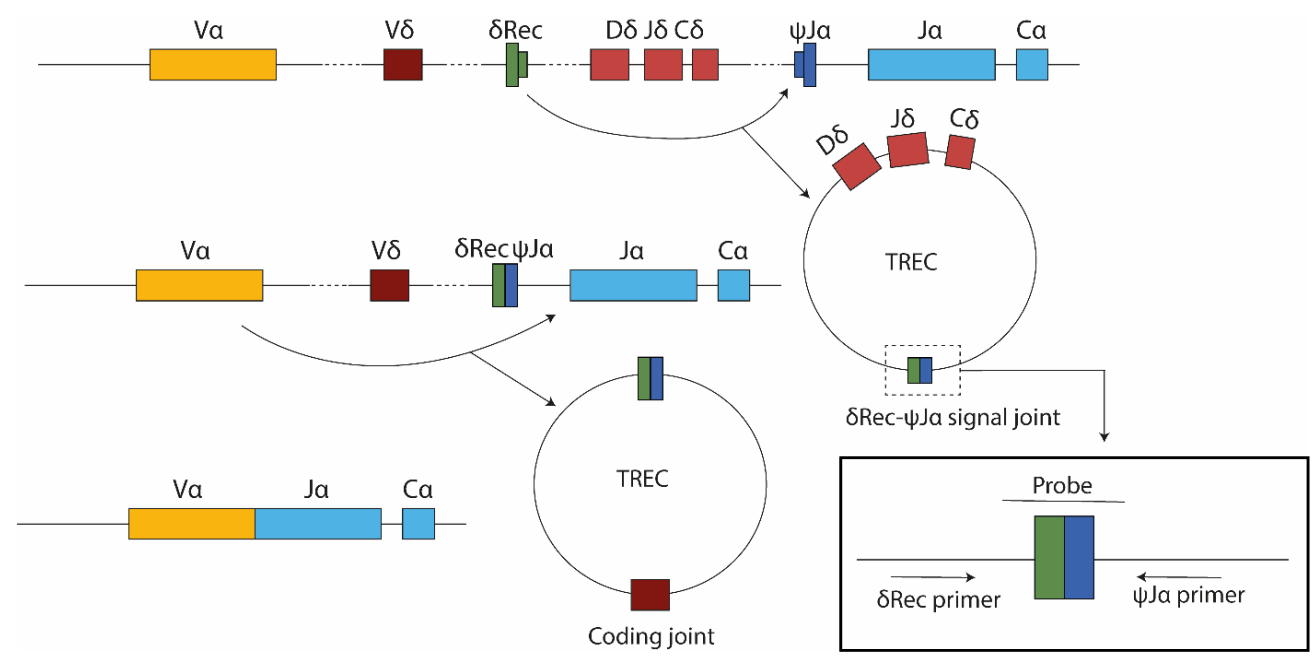

Figure 19. Molecular generation of $\delta$ Rec- $\psi J \alpha$ signal joint TREC. Rearrangement of the TCRAD locus results in the generation of signal joint and coding joint TRECs. The primers and probes used for detection of the $\delta R e c-$ UJa signal joint TRECs are shown in the figure. TREC, T cell receptor excision circle. 
subset of naive and memory $T_{\text {conv }}$ and $T_{\text {reg }}$ cells to show that TREC levels are as expected higher in cells with a naive phenotype (Paper III, Figure 1C). Because TREC levels are considerably affected by proliferation we also analyzed Ki67 expression, as a marker of proliferation, by flow cytometry. 


\section{Results and Discussion}

\section{Dysregulated response to $\mathrm{CD} 4^{+} \mathrm{T}$ cell activation in patients with MS}

$\mathrm{CD}^{+} \mathrm{T}$ cells are essential in the MS pathogenesis and T cell activation in itself is a crucial event for initiation and propagation of MS (Dendrou et al. 2015). Surprisingly, no studies have yet investigated the response to T cell activation in MS at the transcriptomic level, looking at changes in not only a few but on thousands of genes simultaneously. Previous gene expression profiling has mainly been performed on resting, i.e. unactivated immune cells, which has failed to show consistent results (Kemppinen et al. 2011). In paper I, we therefore decided to perform gene expression profiling of both unactivated and activated $\mathrm{CD}^{+} \mathrm{T}$ cells from MS patients and healthy controls as we hypothesized that the response to activation would better reveal new diseaserelevant genes that had not previously been discovered using conventional profiling of resting cells.

\section{Response to TCR-mediated stimulation in patients with MS}

Using an in vitro model of T cell activation, we investigated changes in gene expression in response to T cell activation in MS patients and healthy controls. There were no differences in response to activation based on the surface expression of CD69 (Figure 20A). There were many genes that were nominally differentially expressed ( $p<0.05$, not corrected for multiple testing) between patients and controls upon activation, suggesting that even though the T cells "appear" to respond similarly to activation, according to CD69 expression, it induces changes at the transcriptomic level that could alter the T cell response in patients versus controls (Figure 20B). Furthermore, in order to assess the dynamic changes that occur in response to T cell activation, which are not captured adequately when solely taking into account the gene expression levels in unactivated and activated cells separately as this represents two end-point measures, the gene expression in unactivated cells was subtracted from the gene expression in activated cells to find what is hereon referred to as the dynamic response (DR) genes (Figure 20B). However, when adjusting for genome-wide testing, no differentially expressed genes (DEGs) were found for any of 
A

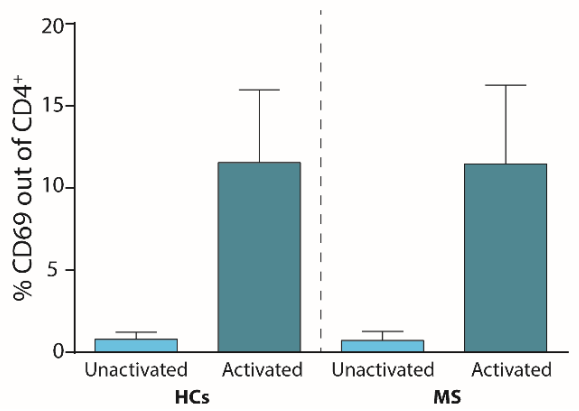

B

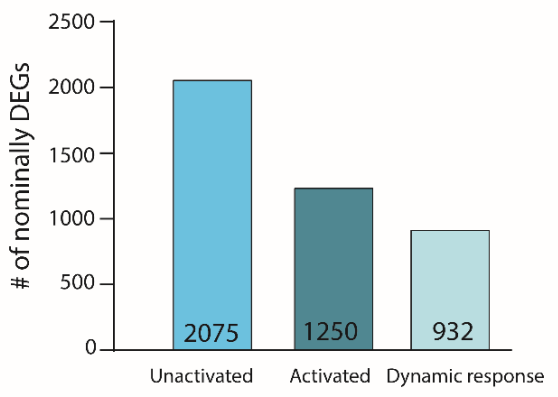

Figure 20. Characterization of the response to T cell activation in MS patients and healthy controls. (A) Flow cytometric characterization of the expression of the surface marker CD69 in unactivated and in anti$\mathrm{CD} 3 / \mathrm{CD} 28$ antibody activated CD4 ${ }^{+} \mathrm{T}$ cells after $24 \mathrm{hrs}$. Student's test was used to determine statistical differences between groups. Mean and standard deviations are shown. (B) Number of nominally differentially expressed genes determined by unpaired $t$-test ( $p<0.05$, not FDR corrected) in the different gene sets (unactivated, activated and dynamic response) when comparing MS patients and controls. Dynamic response genes were calculated by subtracting the gene expression in the unactivated cells from the gene expression in the activated cells. $n=14$ patients and $n=14$ healthy controls. DEGs, differentially expressed genes; HC, healthy control; MS, multiple sclerosis.

the three gene sets, which is in agreement with previous studies (Ratzer et al. 2013, Brorson et al. 2019), showing only few, if any, differences when comparing gene expression in $C D 4^{+} T$ cells from MS patients and controls.

\section{Differentially expressed genes in response to activation are enriched for MS- associated GWAS genes}

The nominally DEGs were used to investigate differences in groups of genes and their biological significance rather than focusing on differences in single genes. The biological significance of the DEGs were investigated by using previously known risk genes associated with MS from a large GWAS (Sawcer et al. 2011). In order to increase the chance to detect potential differences, a moderate stringency cut off $\left(p<10^{-5}\right)$ was used, which resulted in the identification of $760 \mathrm{MS}$ associated SNPs that mapped, through the closest transcription start site, to 216 unique MS genes. Both the unactivated and the DR genes were significantly enriched for these MS-associated genes (Figure 21). GWAS genes are associated with risk of developing disease and reasonably, considering we are studying patients with established disease, there are other genes that are not captured in the GWAS that could be central for propagation and progression of disease. However, as there is currently no consensus regarding which genes that are important during disease progression, which could also vary considering the large disease heterogeneity, using MS-GWAS genes that are derived from the interrogation of tens of thousands of patients and controls is the 
Unactivated

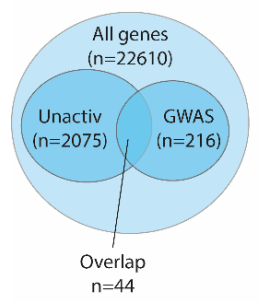

Activated

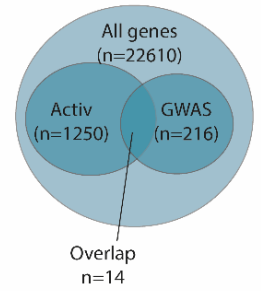

Dynamic response

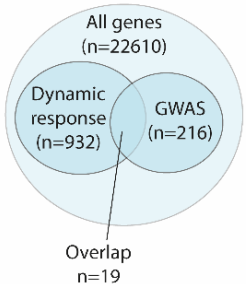

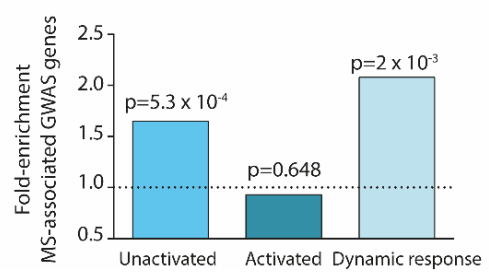

Figure 21. Enrichment of MS-associated GWAS genes. The differentially expressed genes from the three data sets were overlapped with 216 MS-associated genes (as determined by GWAS). Fold enrichment was calculated using Fisher's exact test. The dynamic response genes were defined as the gene expression in the unactivated subtracted from the activated cells. DR, dynamic response; GWAS, genome wide association study; MS, multiple sclerosis.

most unbiased and feasible approach to establish disease relevance. Also, considering the dominance of $\mathrm{T}_{\mathrm{H}}$-associated genes among the MS-GWAS genes, they are highly relevant in this context and disclose central disease processes. The enrichment of these genes among the identified DEGs highlights and supports their relevance in MS. Interestingly, the DR genes had the highest fold enrichment (Figure 21), supporting the hypothesis that taking into account the dynamic response to activation adds value in the understanding of the dysregulated response to activation in MS as compared to when investigating the steady state alone.

A similar approach has been applied in Crohn's disease, which also revealed more pronounced differences in gene expression following T cell activation (Quinn et al. 2015), further emphasizing that studying the response to T cell activation could be a better and more feasible approach for unveiling disease mechanisms. Speculatively, the activation of T cells could mirror the processes that occur in vivo in driving relapses, whereas the resting, unactivated cells would represent the steady-state condition during remission. Differences in gene expression during relapse and remission in peripheral immune cells have been found in patients with MS (Brynedal et al. 2010, Lindsey et al. 2011), although similar studies on isolated $C D 4^{+} T$ cells is, to our knowledge, missing. 


\section{A network-based modular approach identifies cell activation and chemotaxis as central components in the dysregulated response to T cell activation in MS}

A network-based modular approach was used to search for functionally related genes among the DR genes to broaden the biological significance and find relevant functional modules that could disclose central processes involved in driving the differential responses in patients versus controls. The resulting module consisted of 75 protein-coding genes that differed between patients and controls (Figure 22A and B). Pathway analysis revealed five submodules where the two largest submodules, containing the most significantly enriched pathways, were related to cell activation and chemotaxis. In line with our results, myelin-reactive $\mathrm{CD} 4^{+} \mathrm{T}$ cells have been shown to display a different transcriptomic profile in MS patients as compared to healthy controls (Cao et al. 2015). One significant difference is that we have investigated transcriptomic changes induced in response to general TCR-mediated stimulation and not antigen-specific. Using a generic stimulation could potentially make it more difficult to find significant differences between patients and controls, and also making it more difficult for direct comparisons with other studies where mostly myelin-reactive $\mathrm{CD}^{+} \mathrm{T}$ cell responses have been studied. Although it should also be noted that other auto-antigens of relevance to MS has been identified (Ayoglu et al. 2016, Planas et al. 2018). Nevertheless, the fact that cell activation appears as the largest submodule highlights its importance in the disease and suggests that there could be a more general dysregulated response to T cell activation in patients, not driven solely by antigen-specific responses. Interestingly, and less established, chemotaxis appeared in the module, which has not been suggested by previous GWAS analyses, but could be regarded as a downstream event of the T cell activation. Chemotaxis is a prerequisite for migration of T cells into the CNS and a role for chemokines in MS is supported by other gene expression studies in T cells (Satoh et al. 2006, Corvol et al. 2008).

Notably, the module itself was more significantly enriched for MS-associated GWAS genes than the actual DR genes (Figure 22C). One rational behind using a network-based approach to study differential gene expression is that it allows for investigation not only of the genes that are physically interconnected but also of other tightly interconnected genes. From the resulting module, two additional genes that were not present among the original DR genes were found: CXCL10 and FCGR2B. CXCL10 is highly relevant in MS considering its central role in the recruitment of $\mathrm{CXCR}^{+} \mathrm{T}_{\mathrm{H}} 1$ cells. 
A

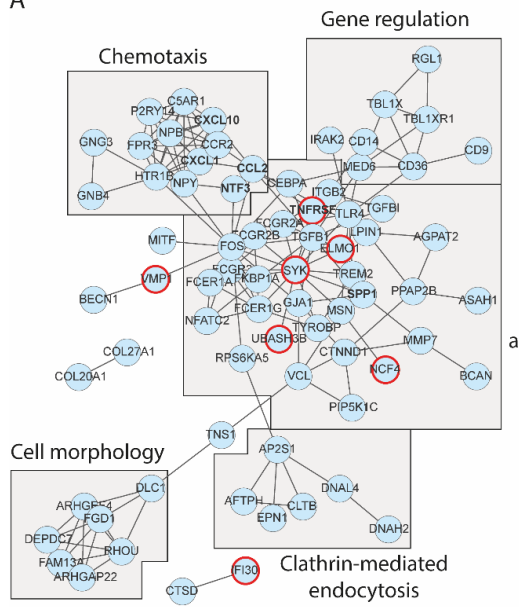

C

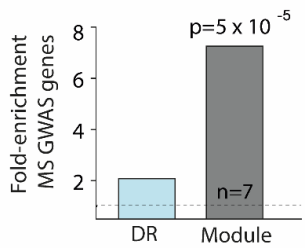

B
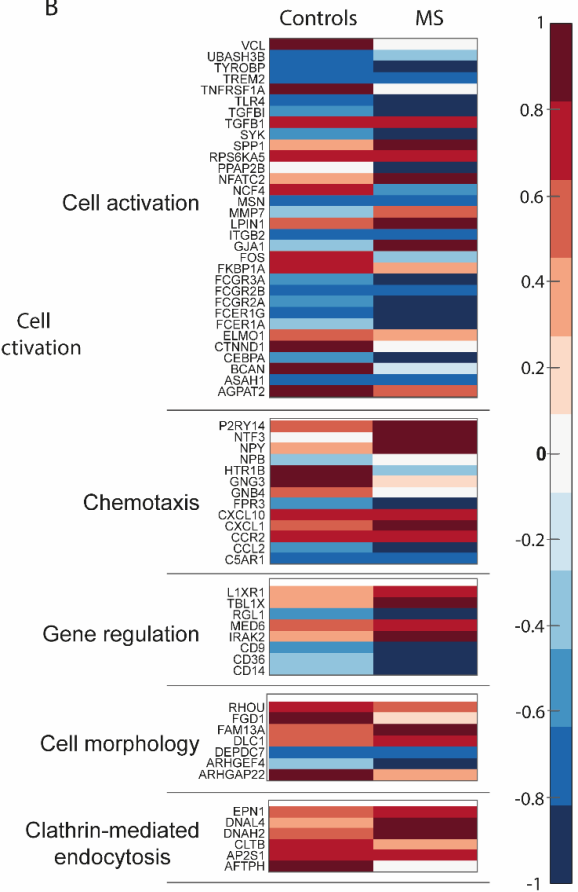

Figure 22. Network-based module of the dynamic response genes. (A) The resulting module of 75 genes derived from the 932 dynamic response (DR) genes, which differed between MS patients and controls in response to T cell activation. The module was divided into 5 different submodules based on DAVID GO analysis and red rings denote MS-associated GWAS genes. The module was constructed using the human PPI STRING database (including only high confidence interactions, above 0.7). (B) Heatmap of the dynamic response genes (activated-unactivated gene expression) in patients and controls. (C) Fold enrichment of MSassociated GWAS genes among the DR genes and in the module, calculated by Fisher's exact test. DR, dynamic response; MS, multiple sclerosis.

\section{Module proteins discriminate between patients and controls with high accuracy}

Since proteins constitute the functional output of differential gene expression, a set of proteins from the module were measured to validate its biological significance and to test whether the module accurately captured central aspects of the dysregulated response to T cell activation in patients. Four proteins (out of the six measured) could be detected in the culture supernatants from unactivated and activated CD4 ${ }^{+}$T cells in patients and controls: osteopontin (OPN), CXCL1-3, CXCL10 and CCL2 (Figure 23). Only OPN was significantly different between patients and controls, which is in agreement with other studies showing increased levels in MS patients compared to 


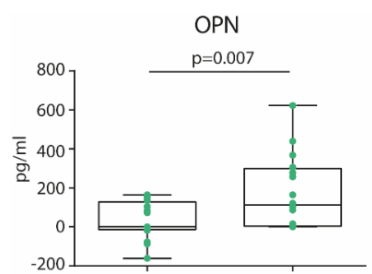

$\mathrm{HC}$

200

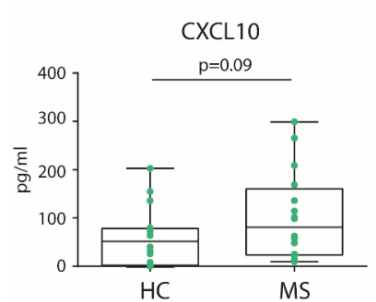

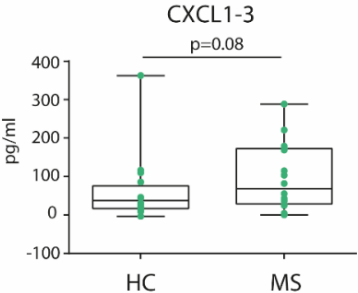

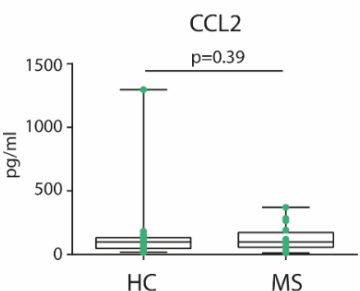

Figure 23. Protein levels in culture supernatants from $\mathrm{CD}^{+} \mathrm{T}$ cells from MS patients and controls. The levels of four secreted proteins from the module in culture supernatants measured by multiplex bead technology. Data is shown as the dynamic response levels, i.e. the levels from unactivated cells subtracted from the levels in cells activated with anti-CD3/CD28 antibodies. Statistical differences between groups were determined using Mann-Whitney test. $\mathrm{n}=16$ in each group. HC, healthy control; MS, multiple sclerosis; OPN, osteopontin.

controls (Agah et al. 2018). Interestingly, increased OPN levels have been associated with active disease compared to stable (Vogt et al. 2003, Comabella et al. 2005), highlighting again the reasoning of our in vitro model where activation could mimic relapsing, more active disease.

Next, we investigated the potential disease association of the identified proteins and found that the combination of OPN, CXCL1-3, CXCL10 and CCL2 could classify patients and controls. Notably, OPN, CXCL1-3 and CXCL10 added to the disease score whereas CCL2 levels decreased it (OPN+CXCL1-3+CXCL10-CCL2), i.e. patients had a higher disease score than controls (Figure 24A). Using a combination of the four proteins outperformed the use of a single or combinations of two or three proteins. Out of the four proteins, OPN and CXCL10 had the highest overall contribution to the disease score, where the combination of OPN+CXCL10 had an area under the curve (AUC) of 0.81 as compared with 0.84 for all of the combined proteins, and OPN in itself had an AUC of 0.75. The dominance of OPN and CXCL10 in comparison to the rest of the proteins is not surprising considering that they are both suggested as biomarkers in MS (Mahad et al. 2002, Håkansson et al. 2017, Agah et al. 2018). Interestingly, CCL2 was the only protein that contributed negatively to the combined disease score, suggesting a potential protective role of CCL2. Indeed, in line with what has been shown by others (Sorensen et al. 1999, Mahad et al. 2006, Moreira et al. 2006), CCL2 levels were lower in patients as compared to controls and could have a beneficial role in neuroinflammation (Kwon et al. 2015, Kaushansky et al. 2019). 
One could question the relative importance of these four proteins in the MS pathogenesis considering that they were selected based on proteins that were known to be secreted and that could be measured by commercially available methods. Still, their importance was validated by comparison of diseases scores generated by the expression of eight other secreted proteins (GMCSF, IFN-y, IL-10, IL-13, IL-17, CCL17, M-CSF and CCL20) that were not part of the original module but of immunological relevance (mean $A \cup C=0.54$ ). In further support, in a second cohort of patients with early MS, the combined disease score could still discriminate between patients and controls. However, it cannot be ruled out that other gene products in the module could add additional value to the overall understanding of the dysregulated response to activation. Interestingly, the same combination of proteins (OPN, CXCL10, CXCL1-3 and CCL2) could accurately classify patients and controls in two other autoimmune diseases, RA and SLE (see paper I), which suggests that these proteins are not specific to MS but might also reflect more general mechanisms of relevance in other autoimmune diseases.

\section{Disease-associated proteins can be used as potential biomarkers for predicting disease activity and response to treatment}

A lot of effort has been made into identifying proteins that could serve as potential biomarkers in MS (Comabella and Montalban 2014, Raphael et al. 2015), although previous work has mainly focused on biomarkers for detecting disease or ongoing disease activity rather than predicting disease activity. Biomarkers for prognosis would be extremely valuable when deciding treatment strategy for individual patients. To further validate the biological significance of the identified proteins and to evaluate their potential as biomarkers, we investigated their ability to predict disease activity and response to treatment. In a second cohort of patients with early MS, the combined score of OPN, CXCL10, CXCL1-3 and CCL2 could predict disease activity after two years (Figure 24C). There are several other proteins that have been suggested as potential biomarkers for predicting disease activity such as CXCL13 (Khademi et al. 2011, Alvarez et al. 2013), although the AUC for identifying CIS patients developing definite MS in 2 years was lower ( $A \cup C=0.64$ ) (Brettschneider et al. 2010). We also sought to determine if the combined protein score was pertained specifically to MS or relevant for predicting disease activity also in other autoimmune diseases. Notably, the combined protein score could not predict disease activity in patients with RA and SLE (see paper I), suggesting that the correlation to later disease activity is limited to MS. Surprisingly, the combined protein score could also predict high or low response to Natalizumab 
A

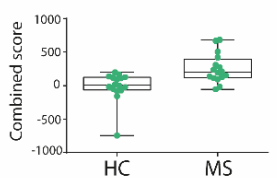

Presence of disease (culture supernatants)

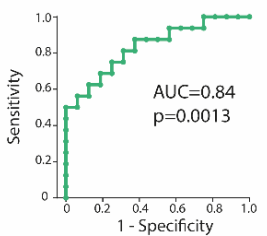

B

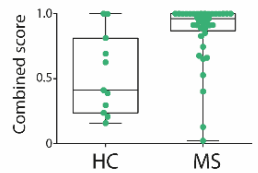

Presence of disease (cerebrospinal fluid)

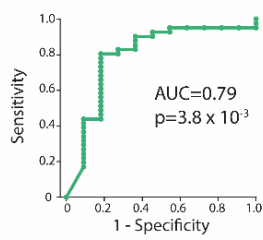

C

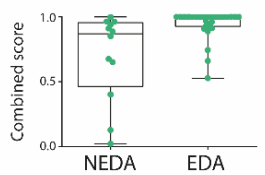

Evidence of disease activity

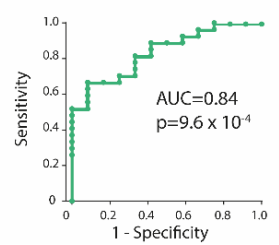

D

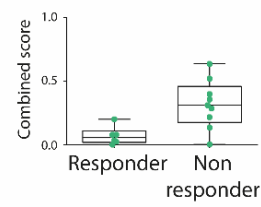

Response to treatment

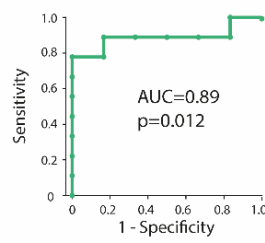

Figure 24. Combined protein score of the secreted module proteins. Each subplot shows discrimination of different cohorts. The top panel shows box plot of the combined score (OPN+CXCL1-3+CXL10-CCL2) and the lower panel shows the receiver operating characteristics (ROC) curves. (A) The combined score in culture supernatants discriminated patients from controls ( $n=16$ in each group). In a second cohort of patients with early MS the combined protein score, defined from the probability computed by leave-one-out crossvalidation and logistic regression of the four proteins, as measured in CSF discriminated between (B) patients $(n=41)$ and controls $(n=11)$ and (C) patients with signs of disease activity (EDA; $n=27)$ from those with no evidence of disease activity (NEDA; $n=12$ ) at 2 year follow-up. (D) In a third cohort of MS patients the combined score discriminated between high $(n=6)$ and low $(n=9)$ responders to natalizumab treatment. $\mathrm{AUC}$, area under the curve; $\mathrm{HC}$, healthy control; MS, multiple sclerosis.

treatment in a third cohort of MS patients (Figure 24D), which suggests that proteins of relevance in the disease processes also hold prognostic value in terms of response to treatment.

\section{Progesterone as an immunomodulator of T cell activation}

The pregnancy-related improvement and subsequent worsening of MS coincides with the time points during and after pregnancy when P4 concentrations are highest and lowest, respectively. P4 has been shown to modulate T cell activity (Chien et al. 2006, Chien et al. 2007, Hughes et al. 2013) and considering the central role of $\mathrm{CD}^{+}{ }^{+} \mathrm{T}$ cells and $\mathrm{T}$ cell activation in the disease pathogenesis (Dendrou et al. 2015), P4 is a potential candidate for being involved in mediating the pregnancy-induced effects. Arguably, estrogen levels increase and decrease in a similar pattern as P4 during pregnancy but we chose to focus specifically on P4 because estrogen (1) seems to have both immune-regulatory and immune-activating properties (unpublished data Papapavlou et al., Straub 2007) and (2) has been suggested as a major factor explaining the increased occurrence of autoimmune diseases in women (Mohammad et al. 2018). There are currently no in-depth studies on the precise effect of P4 on T cell activation. Understanding the effect of P4 on T cell activation is central not only for understanding disease mechanisms in MS but also in pregnancy tolerance. 


\section{P4 dampens $\mathrm{T}$ cell activation and alters the transcriptomic profile in activated CD4 ${ }^{+} \mathrm{T}$ cells}

As in paper I, we used an in vitro model of T cell activation where isolated $\mathrm{CD} 4^{+} \mathrm{T}$ cells from healthy female blood donors were activated in the absence or presence of P4 (Figure 15). Upon activation, T cells upregulate their expression of various cell surface markers that are needed for their continued activation and proliferation. $\mathrm{CD}^{+} \mathrm{T}$ cells activated in the presence of P4 displayed lower levels of CD69 and CD25 (Figure 25A), indicating that T cell activation is significantly dampened in the presence of P4. This is in agreement with previous findings (Stites et al. 1983, Ehring et al. 1998), and further reinforces the view of P4 as an immunosuppressive hormone. This dampening effect on the $T$ cell activation also resulted in large transcriptomic changes in the $C D 4^{+}$ T cells as evident from the clear clustering of cells activated in the presence or absence of P4 (Figure 25B and C), with many DEGs at both 6 and 24 hrs (Figure 25D and E). These findings support a role for $\mathrm{P} 4$ during early $\mathrm{T}$ cell activation, which is central since it shapes the subsequent T cell responses.

\section{Immune-related pathways are significantly down-regulated by P4}

More in-depth analysis of the P4-induced DEGs revealed that at both 6 and 24 hrs, P4 mainly exerted a down-regulatory effect on immune-related pathways. Several of these pathways corroborated our initial findings of a dampening effect of P4 on T cell activation, as several pathways associated with, or down-stream of, T cell activation were significantly down-regulated by P4, such as T cell receptor signaling, JAK-STAT signaling and cytokine-cytokine receptor interactions (Figure 26). Many immune-associated disease pathways were also significantly downregulated by P4, many of them related to viral infections. Increased susceptibility or severity among pregnant women have been found for several of these diseases (Kourtis et al. 2014). Speculatively, P4 could be involved in down-regulating immune responses required to maintain proper defense against some of these infections. This could be a "side effect" resulting from the immunosuppressive properties of $\mathrm{P} 4$ that is required for promoting and maintaining fetal tolerance. We could also observe that several pathways related to $T$ cell differentiation were also significantly affected by P4. Previous studies showed that P4 affects T cell differentiation and 
A
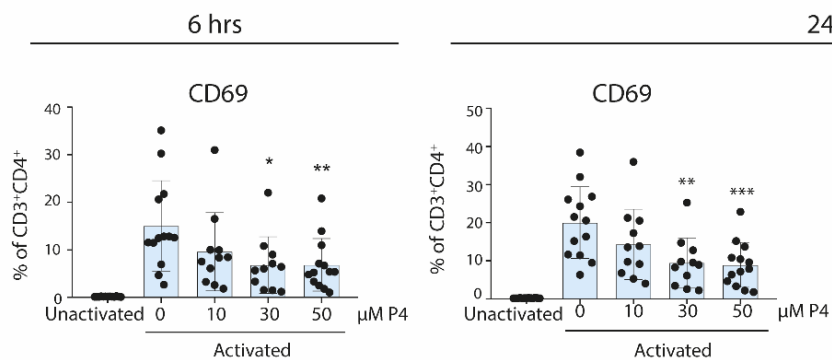

$24 \mathrm{hrs}$
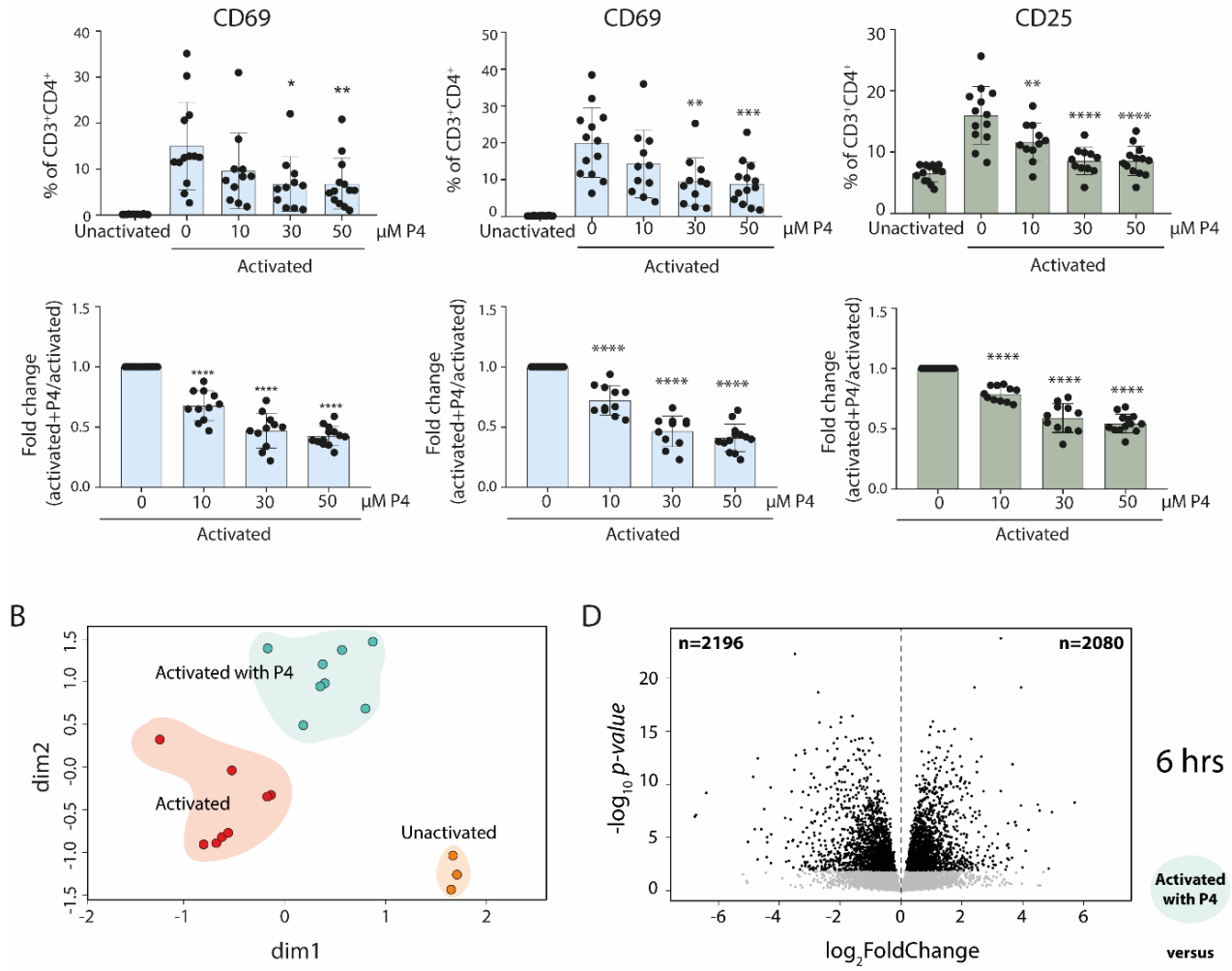

6 hrs
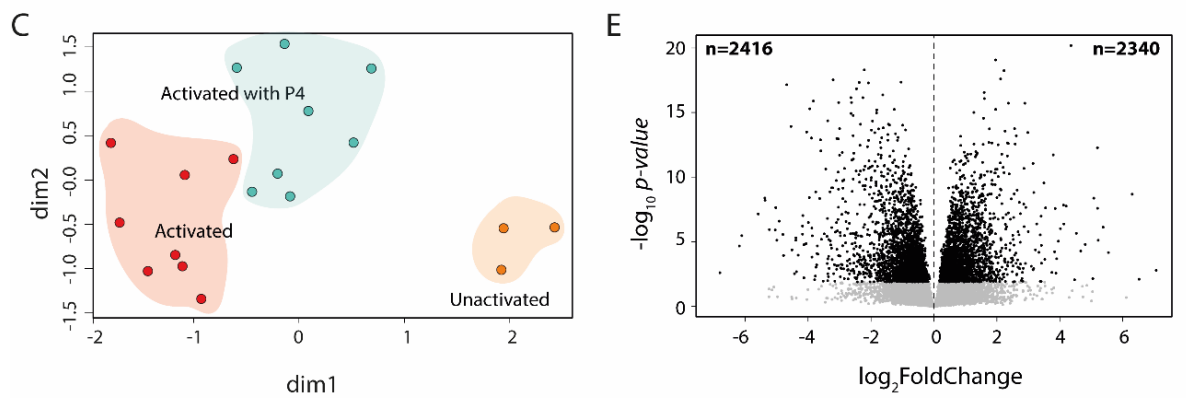

Activated
with P4

versus

Activated

$24 \mathrm{hrs}$

Figure 25. Phenotypic and transcriptomic profiling of $\mathrm{CD}^{+} \mathrm{T}$ cells activated in the absence or presence of P4. (A) Expression of CD69 and CD25 was analyzed by flow cytometry. The upper panel shows percentages of cells and lower panel shows fold change in expression in $\mathrm{CD} 4^{+} \mathrm{T}$ cells activated in the presence as compared to absence of $\mathrm{P} 4$. Data was analyzed with one-way ANOVA with Dunnett's multiple comparison test. ${ }^{*} p \leq 0.05,{ }^{* *} p \leq 0.01,{ }^{* * *} p \leq 0.001,{ }^{* * *} p \leq 0.0001$. (B,C) Multidimensional scaling analysis of gene expression data generated by RNA sequencing. The groups have been highlighted for visual purposes. (D,E) Volcano plots of differentially expressed genes in $C D 4^{+} T$ cells activated in the presence of $\mathrm{P} 4$ as compared to absence of P4. Black dots FDR $<0.05$. P4, progesterone. 
suggested to affect the polarization (Piccinni et al. 1995, Miyaura and Iwata 2002, Lee et al. 2012, Lissauer et al. 2015), although after only $24 \mathrm{hrs}$ it is too early to draw any affirmative conclusions about the exact effects of P4. Strikingly, although there was an almost equal proportion of up-and down-regulated DEGs, very few pathways were significantly up-regulated by P4 (Figure 26).

Perhaps even more surprising, none of the up-regulated were immune-related, clearly demonstrating that on the pathway-level, P4 mainly affects immune-related responses and that the effects are exclusively down-regulatory.

To further understand how P4 affected the T cell activation, we investigated if P4 could oppose the changes induced during the activation, in line with our hypothesis that immune responses upregulated during T cell activation are down-regulated/dampened by P4. Genes that were upregulated during $T$ cell activation (as compared to unactivated cells) were significantly downregulated by P4 and vice versa, showing that P4 significantly affects genes related to the actual T cell activation by mainly altering the changes induced during activation. Pathway analysis showed

A 6 hrs

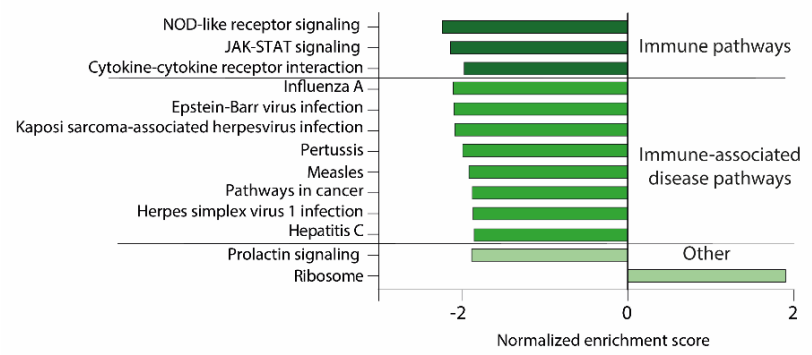

B

$24 \mathrm{hrs}$

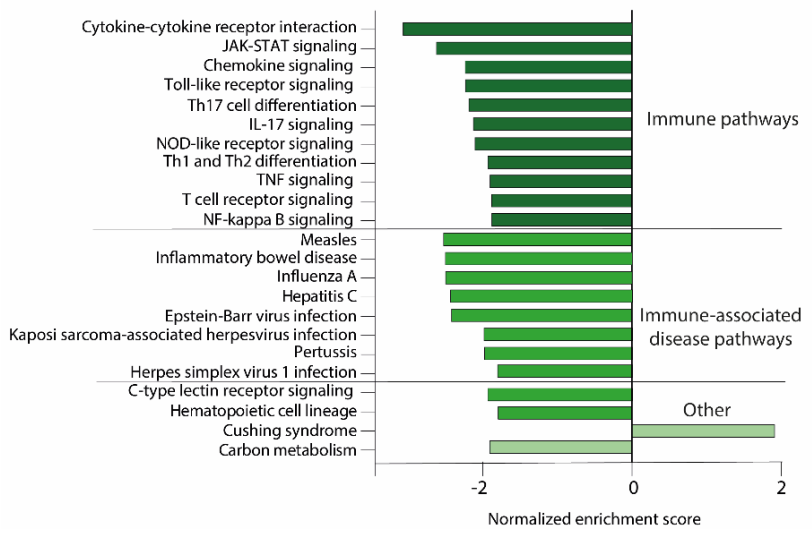

Figure 26. KEGG gene set enrichment analysis of differentially expressed genes induced by $\mathrm{P} 4$ (as compared to activation in the absence of P4) at (A) 6 and (B) $24 \mathrm{hrs}$. P4, progesterone. 
clusters of immune-related pathways among the intersecting genes that were up-regulated during $T$ cell activation and down-regulated by P4, whereas again, no immune-related pathways were found among the genes up-regulated by P4 (Figure 27). Many of the pathways present at the gene set enrichment (GSE) analysis of all P4-induced DEGs were also present in intersecting genes, indicating that the down-regulatory effect of $\mathrm{P} 4$ on the actual $\mathrm{T}$ cell activation plays a substantial role in the overall changes induced by P4.

A

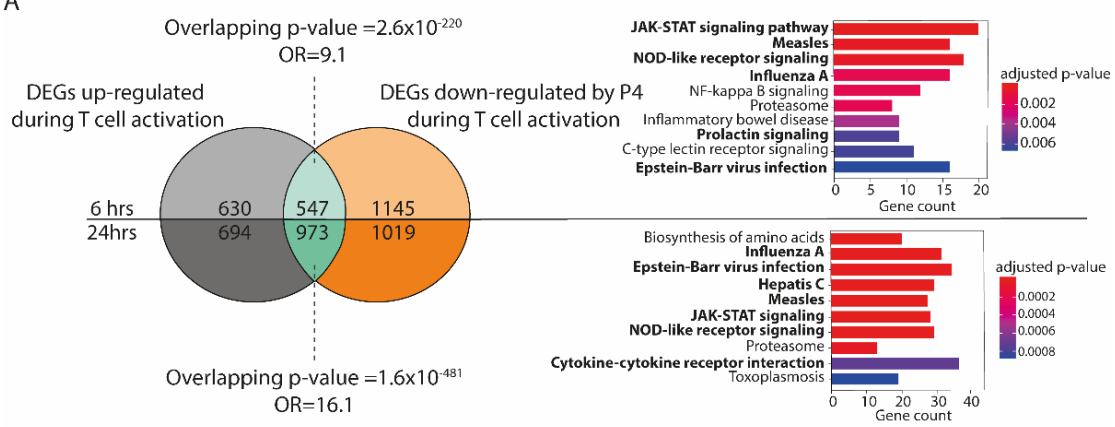

B

Overlapping $p$-value $=1.6 \times 10^{-125}$

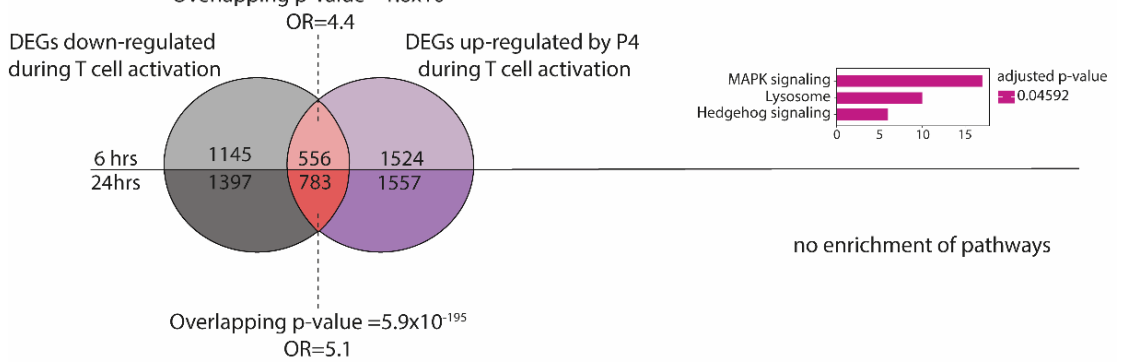

Figure 27. Venn diagrams of the overlapping DEGs between (A) genes up-regulated during $T$ cell activation and down-regulated by P4 and (B) genes down-regulated during T cell activation and up-regulated by $\mathrm{P} 4$, at 6 and $24 \mathrm{hrs}$. Bar graphs of the top 10 most significant KEGG pathways of the intersecting genes. Bold pathways were also present during GSE analysis of all P4-induced DEGs. Overlap statistics was performed using Fisher's exact test. DEGs, differentially expressed genes; GSE, gene set enrichment; OR, odds ratio; P4, progesterone.

\section{Genes associated with immune-related diseases are most significantly affected by P4}

The fact that P4 significantly dampened T cell activation suggests that P4 could be involved in the pregnancy-induced effects observed in patients with MS by modulating immune responses that could be central in the MS pathogenesis. The P4-induced genes were significantly enriched for MS-associated GWAS genes (Figure 28), showing that P4 significantly affects genes of relevance in 
MS. Because of the significant overlap and the predominance of immune-related pathways among the intersecting genes up-regulated during $T$ cell activation and down-regulated by $\mathrm{P} 4$, we also specifically investigated if these genes were significantly enriched for MS-associated GWAS genes. Not surprisingly, these genes were even more enriched for MS-associated genes, which not only supports the importance of T cell activation in MS but also that T cell activation is a central process that is significantly affected by P4. In light of our results from paper I, we also tested if P4 affected the identified dysregulated dynamic response genes and the resulting module. However, we found no enrichment for these genes neither at 6 nor at 24 hrs. Further studies are needed to delineate the effect of pregnancy on the dysregulated dynamic response in MS.

There are other diseases that are known to be affected during pregnancy (Piccinni et al. 2016) and to gain further insight and more support of a potential role for P4 in the pregnancy-induced modulation of autoimmune diseases, we investigated if $\mathrm{P} 4$ affected genes of relevance not only for other immune-mediated diseases, but also for neurodegenerative, psychiatric, cardiovascular and other diseases based on available GWAS data. The P4-induced genes were mostly enriched for immune-related diseases: MS, RA, Crohn's disease (CD) and ulcerative colitis (UC), where genes associated with MS were most significantly enriched at both 6 and 24 hrs (Figure 29). Both RA and MS are diseases that are well-known to improve during pregnancy (Confavreux et al. 1998, de Man et al. 2008). In terms of CD and UC, there are conflicting results as to whether they improve or worsen, where disease activity prior to pregnancy has been suggested to influence the Overlap with MS GWAS

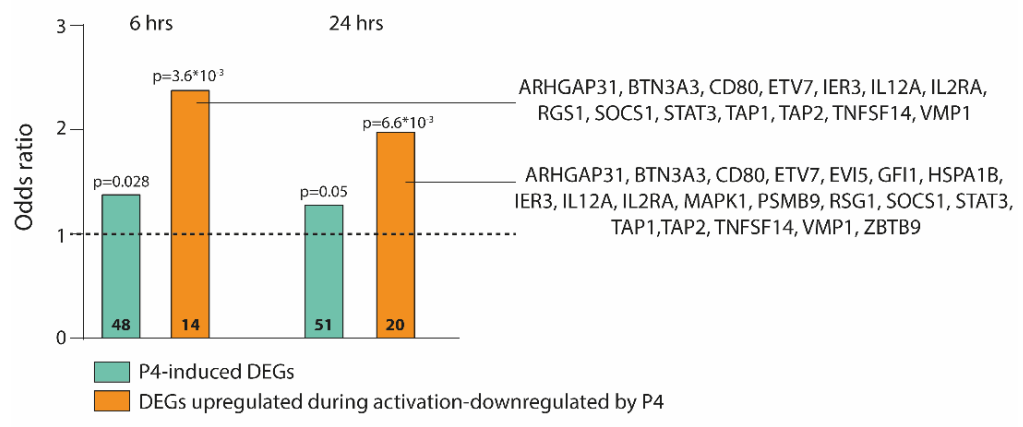

Figure 28. Enrichment of MS-associated GWAS genes. P-value and number of overlapping genes are shown in the graph. Enrichment was performed using Fisher's exact test. Green bar, P4-induced DEGs (as compared to activation in the absence of P4). Orange bar, intersecting DEGs between genes upregulated during $T$ cell activation and down-regulated by $\mathrm{P} 4$. The names of the overlapping genes are shown to the right. DEGs, differentially expressed genes; GWAS, genome-wide association studies; MS, multiple sclerosis; P4, progesterone. 


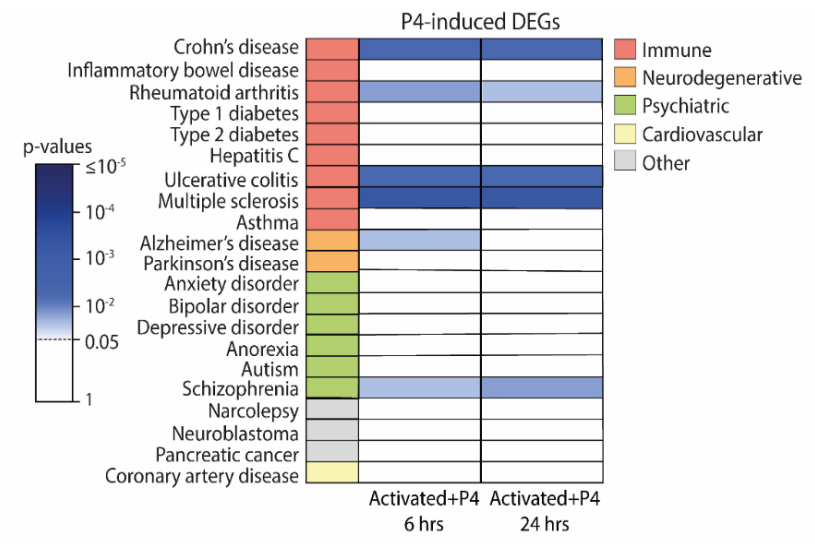

Figure 29. Effect of P4 on disease-associated GWAS genes. Pathway scoring algorithm (PASCAL) was performed on 21 different GWAS studies on the P4-induced DEGs. Blue color represents the significant $p$-values, $p<0.05$.

disease course during pregnancy (Hashash and Kane 2015). Irrespectively, most studies indicate that the disease activity is modulated during pregnancy and thus, P4 seemingly affects diseases that are influenced by pregnancy, which further highlights P4 as a plausible candidate for being involved in these pregnancy-induced effects.

The enrichment of disease-associated GWAS genes for MS and RA was even more significant in the intersecting genes that were upregulated during T cell activation but downregulated by P4, where again MS was most significantly enrichment for GWAS-associated genes (Figure 30). Both MS and RA are considered to be classical T cell-mediated diseases so it might not be so surprising that the genes involved in T cell activation are more significantly enriched for these two diseases but again, it reinforces the central role for $\mathrm{T}$ cell activation and that P4 significantly affect diseaseassociated genes related to this process. The genes affected by P4 that did not overlap with the genes induced during T cell activation (exclusive P4 genes) were not significantly enriched for any of the diseases.

\section{Transcriptomic changes induced by P4 are mirrored at the protein level}

In order to verify central transcriptomic changes at the protein level, culture supernatants collected after 6, 24 and $72 \mathrm{hrs}$ were analyzed for the presence of 92 inflammation-associated proteins (Olink inflammation panel: https://www.olink.com/products/inflammation/). Almost all 


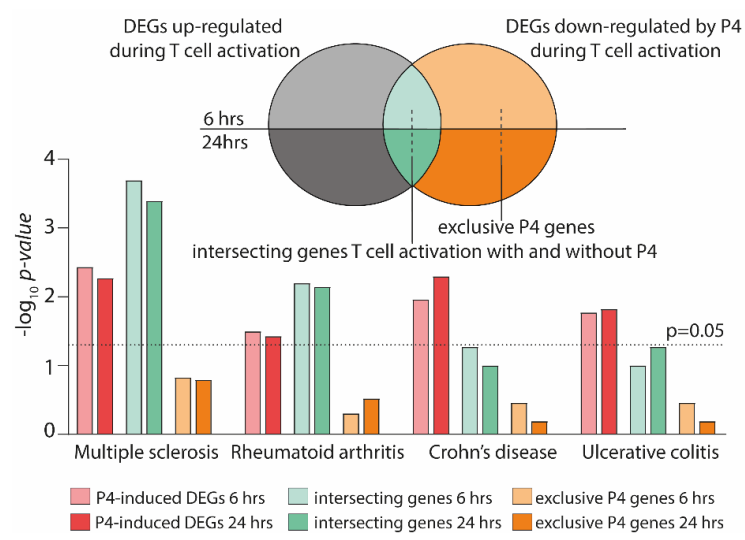

Figure 30. Effect of P4 on disease-associated GWAS genes related to multiple sclerosis, rheumatoid arthritis, Crohn's disease and ulcerative colitis. Disease enrichment was performed using the pathway scoring algorithm (PASCAL). Red bars, P4-induced DEGs (as compared to activation in the absence of P4); green bars, intersecting genes between genes up-regulated during $T$ cell activation and down-regulated by $\mathrm{P} 4$; orange bars, genes that were down-regulated by P4 that did not overlap with $\mathrm{T}$ cell activation (exclusive P4 genes). GWAS, genome-wide association studies; P4, progesterone.

of the proteins that were differentially expressed at any given time point were down-regulated, consistent with the transcriptomic findings, again showing a mainly dampening effect of P4 on immune responses (Figure 31). Many of the pathways that were significantly down-regulated at the transcriptomic level were also down-regulated at the protein level, which was particularly evident at 24 hrs (Figure 31A and B), showing that the changes induced by P4 at the transcriptomic level are also, on the pathway level, to some extent mirrored at the protein level. The changes induced by P4 in the profile of secreted proteins were maintained at 72 hrs (Figure 31C), where all of the overlapping gene-protein pathways at 6 and $24 \mathrm{hrs}$ were also present among the KEGG pathways at 72 hrs. Most of the proteins that were differentially expressed were overlapping with at least one other time point, also showing that most changes induced by P4 are preserved over the chosen time points. There were 6 proteins that were significantly downregulated at both 6, 24 and 72 hrs: CCL8, CXCL8, CXCL9, FLT3LG, IL17A and TNF (Figure 31D). Interestingly, IL-17A has been proposed as a major player in the MS pathogenesis and IL-17A blockade has been suggested as potential treatment (Setiadi et al. 2019). Taken together, it seems that most of the changes induced by P4 at the earlier stages 
A $6 \mathrm{hrs}$

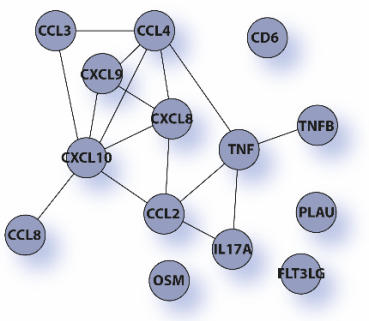

Protein pathways overlap with GSE pathways: $31 \%$

Cytokine-cytokine receptor interaction Influenza A Pertussis Hepatitis C

C 72 hrs

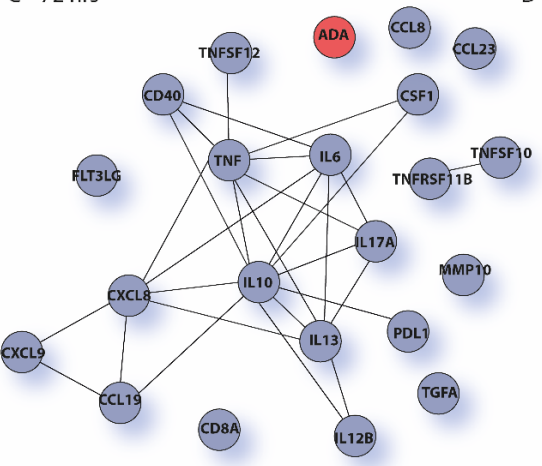

B $\quad 24$ hrs

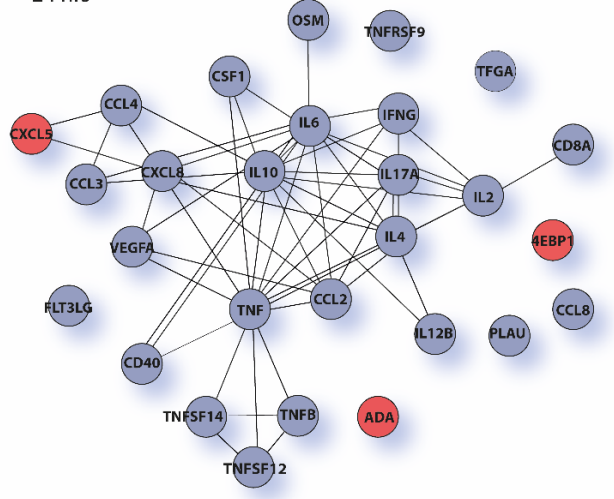

Protein pathways overlap with GSE pathways: $\mathbf{8 3} \%$
Cytokine-cytokine receptor interaction Inflammatory bowel disease IL-17 signaling
NF-kappa B signaling Toll-like receptor signaling Pertussis
JAK-STAT signaling Hematopoietic cell lineage T cell receptor signaling TNF signaling

$$
\begin{gathered}
\text { Influenza A } \\
\text { Chemokine signaling } \\
\text { Th17 cell differentiation } \\
\text { Measles } \\
\text { Th1 and Th2 differentiation } \\
\text { NOD-like receptor signaling } \\
\text { Kaposi's sarcoma-associated } \\
\text { herpesvirus infection } \\
\text { Epstein-Barr virus infection } \\
\text { Hepatitis C }
\end{gathered}
$$

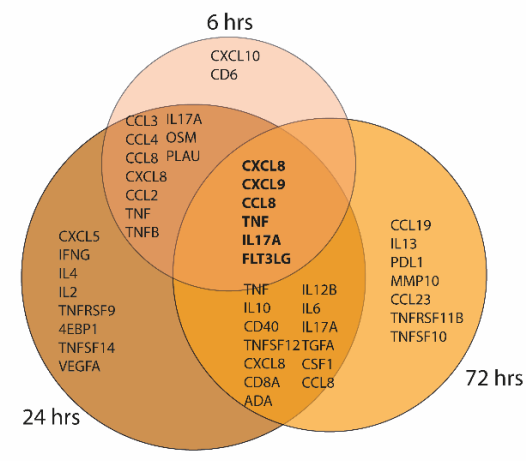

Figure 31. Protein levels in culture supernatants collected from $\mathrm{CD} 4^{+} \mathrm{T}$ cells activated in the absence or presence of $50 \mu \mathrm{M} \mathrm{P} 4$ for 6,24 and $72 \mathrm{hrs}$. The levels of proteins were measured by proximity extension assay. $(A, B, C)$ The differentially secreted proteins, where the lines between proteins represents interactions that were denoted from the STRING database (only including the highest confidence interactions. Blue circles represent down-regulated protein expression and red circles represents up-regulated protein expression. For 6 and 24 hrs, overlapping KEGG pathways between the gene set enrichment analysis on the differential expressed genes induced by P4 and the differentially expressed proteins are shown below. The percentages were calculated based on how many of the protein pathways that were also found at the gene level. (D) Venn diagram of the overlapping proteins at 6, 24 and $72 \mathrm{hrs}$. Statistical differences were determined using Friedman test with Benjamini-Hochberg for FDR correction. FDR $<0.05 . n=9-10$ paired samples in each group. GSE, gene set enrichment. 
of the T cell activation are also still apparent after $72 \mathrm{hrs}$ although one should take into account that we have measured a selected panel of proteins of which all are not secreted to a large extent by $T$ cells.

\section{Re-evaluating the role of thymus during pregnancy}

It is generally believed that the thymic involution that in many species occurs during pregnancy leads to decreased thymic function, proposed as a mechanism to protect the fetus from potentially harmful $T_{H}$ cell responses. This general "dogma" is almost exclusively based on studies in mice where thymic involution has been paralleled with decreased thymic function (Zoller et al. 2007, Laan et al. 2016). In contrast, there are conflicting results in humans, challenging the notion of the across-species thymic involution and function during pregnancy (Swami et al. 2012). Considering the central role of the thymus in both immunity and tolerance, its function during human pregnancy needs to be further clarified. Thus, in paper III, we investigated the role of the thymus in pregnancy by analyzing the output of $\mathrm{T}_{\text {conv }}$ and $\mathrm{T}_{\text {reg }}$ from the thymus, utilizing both CD31 and TREC as markers of $T_{H}$ cells with recent thymic origin.

\section{TREC levels are increased in naive $T_{\text {reg }}$ cells during $2^{\text {nd }}$ trimester pregnancy}

As T cells with a more recent thymic origin have a higher TREC content as compared with the rest of the naive T cell pool (Kimmig et al. 2002), it can serve as an indirect measure of thymic function defined by the output of $T_{H}$ cells. Because different $T_{H}$ subpopulations can display differential output from the thymus and have very different functional characteristics, we decided to investigate the output of both $\mathrm{T}_{\text {conv }}$ cells and $\mathrm{T}_{\text {reg }}$ cells. Speculatively, under different circumstances such as pregnancy, the output of one over the other may increase or decrease, which would not be accurately reflected by investigating the bulk $\mathrm{CD} 4^{+} \mathrm{T}$ cell population. Naive $\mathrm{T}_{\text {regs }}$ (defined as $C D 45 R A^{+} C D 25^{++}$) from $2^{\text {nd }}$ trimester pregnant women were found to have significantly higher TREC content as compared to healthy non-pregnant controls (Figure 32A), suggesting an increased output of $\mathrm{T}_{\text {reg }}$ cells during pregnancy. On the other hand, there was no differences in the TREC levels in the naive $\mathrm{T}_{\text {conv }}$ cells $\left(C D 45 R A^{+} C D 25^{-}\right.$) (Figure 32B) between pregnant and non-pregnant women, which is line with a maintained output of this population during pregnancy. 
A

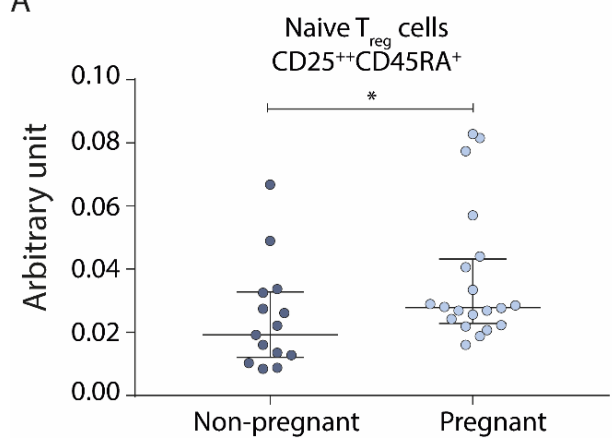

B

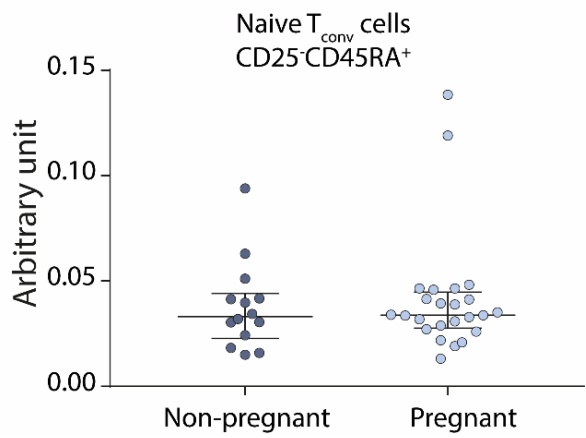

Figure 32. TREC levels during pregnancy. TREC levels were measured by RT-PCR in flow cytometry sorted naive $(A) T_{\text {reg }}$ cells (non-pregnant $n=14,2^{\text {nd }}$ trimester pregnant $=20$ ) and $(B) T_{\text {conv }}$ cells (non-pregnant $n=14$, $2^{\text {nd }}$ trimester pregnant $n=24$ ). The TREC levels in each sample was calculated using the delta $C t-m e t h o d$ where the $\mathrm{Ct}$ values for sjTREC was subtracted from the housekeeping gene glyceraldehyde 3-phosphate

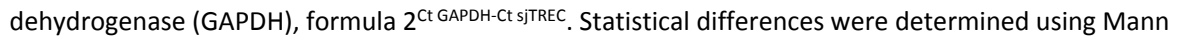
Whitney $\mathrm{U}$ test. Median and interquartile ranges are shown. ${ }^{*} \mathrm{p}<0.05$. $\mathrm{T}_{\text {conv, }}$ conventional T cell; TREC, T cell receptor excision circle; $T_{\text {reg, }}$, regulatory $T$ cell.

\section{Pregnancy does not alter the proportion or absolute numbers of CD31+RTES}

As an additional measure of thymic output, CD31 expression on naive CD45RA ${ }^{+} T_{\text {conv }}$ and $T_{\text {reg }}$ cells was analysed by flow cytometry (Figure 33A for gating strategy for identification of RTEs). There are several lines of evidence that support the use of CD31 as a marker of RTEs: (1) CD31 $1^{+} C D 45^{+} T$ cells have a higher TREC content than CD45RA ${ }^{+}$cells lacking CD31 expression (Kimmig et al. 2002); (2) $C D 31^{+} C D 45 R A^{+}$decreases with age in line with the decreased contribution of the thymus to the peripheral T cell pool (Kimmig et al. 2002) and (3) its expression is lost upon repetitive TCR stimulation in vitro (Demeure et al. 1996). Overall, pregnant women had similar proportions and absolute numbers of RTE $T_{\text {conv }}$ cells as non-pregnant women (Figure 33), which suggests maintained output of the bulk of T cells during pregnancy. A significantly higher RTE $T_{\text {conv }}$ cell count was observed in $3^{\text {rd }}$ trimester pregnant women, although this most likely corresponds to the noted increase in total $C D 4^{+} T$ cell counts in the $3^{\text {rd }}$ trimester (compared to $2^{\text {nd }}$ trimester; data not shown). We found no differences in the proportion or absolute numbers of RTE $T_{\text {regs }}$ between pregnant and non-pregnant women (Figure 33), in contrast to the TREC-based differences in $T_{\text {reg }}$ cells.

In the pioneering studies by Wagner et al. (Wagner et al. 2015, Wagner et al. 2016), RTE Treg cells, defined by CD31 expression, were evaluated during pregnancy. However, their focus was on differences in the composition of subsets within the $T_{\text {reg }}$ population, rather than involving the global assessment of proportions and total numbers of both RTE $T_{\text {reg }}$ and $T_{\text {conv }}$ cells that we 
A

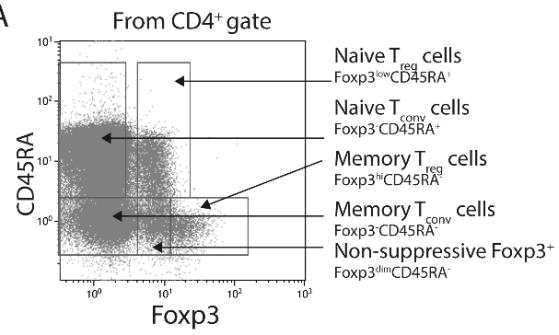

B

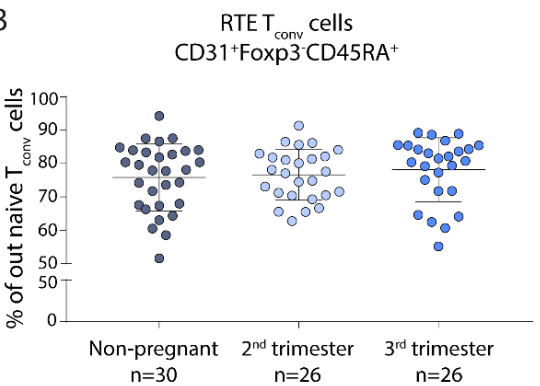

$\mathrm{D}$

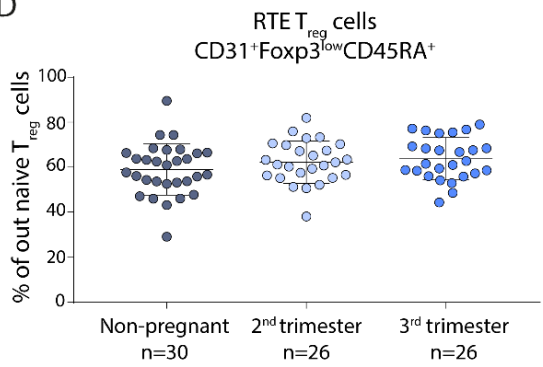

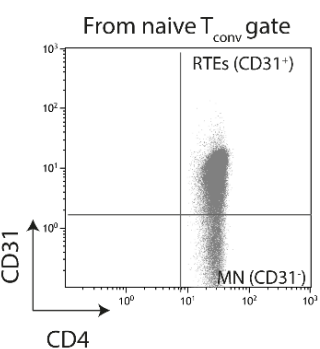

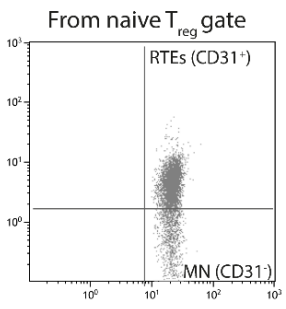

C

RTE T conv $_{\text {cells }}$ CD31 ${ }^{+}$Foxp3-CD45RA ${ }^{+}$

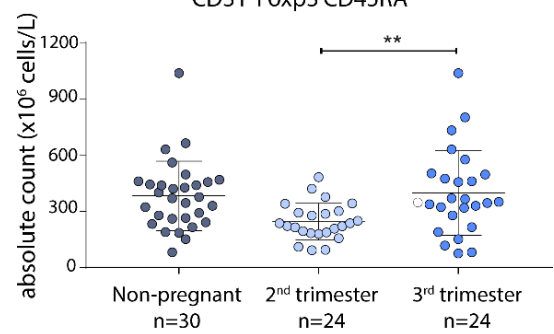

$\mathrm{E}$

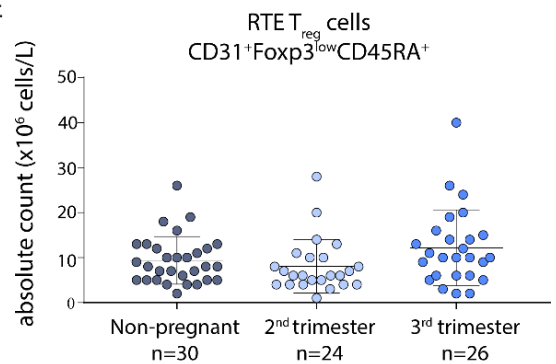

Figure 33. Recent thymic emigrants in pregnant and non-pregnant women. $C D 31^{+} C D 45 R A^{+}$RTEs was analyzed by flow cytometry in $2^{\text {nd }}$ and $3^{\text {rd }}$ trimester pregnant and healthy non-pregnant controls. (A) Representative dot plots of the gating strategies for phenotyping. Proportion and absolute numbers of RTE $T_{\text {conv }}$ cells $(B, C)$ and RTE $T_{\text {reg }}$ cells $(D, E)$. Missing values are due to limited availability in the number of cells required for analysis. Statistical differences were determined by Student's unpaired t-test, ${ }^{*}{ }^{*} \mathrm{P}<0.01$, mean and standard deviations are shown. $M N$, mature naive; RTE, recent thymic emigrants; $T_{\text {conv, }}$ conventional $T$ cell; $T_{\text {reg, }}$ regulatory $T$ cell.

performed. Also, we used TREC-based detection of RTEs in addition to the CD31-based approach. One notable difference in findings was that, in contrast to our finding of a possible maintained output of $T_{\text {reg }}$ cells, Wagner et al. reported a decreased proportion of RTE $T_{\text {reg }}$ cells within the $T_{\text {reg }}$ population during pregnancy (Wagner et al. 2015). In addition to the different approaches of the studies, one major difference is that we evaluated RTE frequencies in whole blood, and not in isolated lymphocytes. Unmanipulated whole blood more closely resembles the state of the circulating cells in vivo as compared to isolated mononuclear cells (Mallone et al. 2011), which may have contributed to the differences. Also, although the same definition of RTE was used, 
somewhat different gating strategies were used to avoid inclusion of non-suppressive Foxp3expressing cells, where we relied on the strategy according to Miyara et al. (Miyara et al. 2009, Boij et al. 2015).

\section{Peripheral consumption of $T_{H}$ cells does not affect the distribution of cells with recent thymic origin}

When evaluating thymic output by measures of TREC levels, it is important to also consider the peripheral cell turnover since TREC levels are largely affected by proliferation (Douek et al. 1998, Hazenberg et al. 2001). In healthy adults, however, the proliferation of naive T cells is assumed to be too low to significantly affect TREC content (Douek et al. 1998). During pregnancy, there are indications of an activated maternal immune system, for instance by findings of increased systemic soluble HLA-DR levels (Steinborn et al. 2003). We therefore evaluated proliferation in the naive $\mathrm{CD}^{+} \mathrm{T}$ cell subpopulations in terms of expression of the T cell proliferation marker Ki67. There was no increased expression of Ki67; hence, no signs of increased proliferation in the naive T cell subsets (Figure 34 ). The expression of Ki67 on RTE $T_{\text {conv }}$ cells was significantly lower in $2^{\text {nd }}$ and $3^{\text {rd }}$ trimester pregnant women as compared to the non-pregnant state, albeit Ki67 expression was very low in all groups (Figure 34). Hence, a higher proliferation in non-pregnant women could
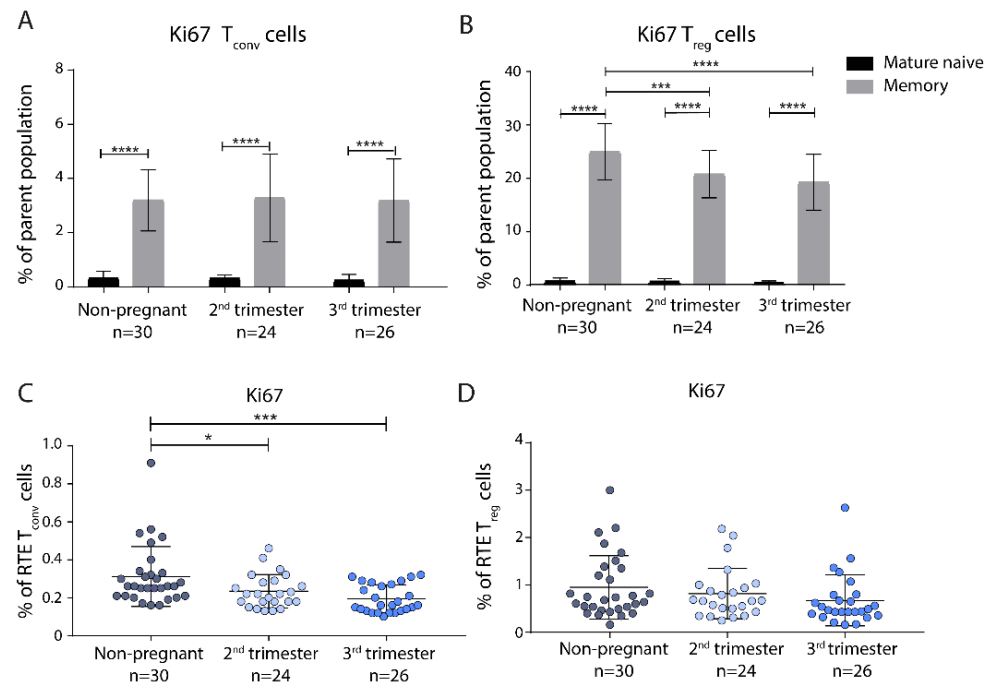

D

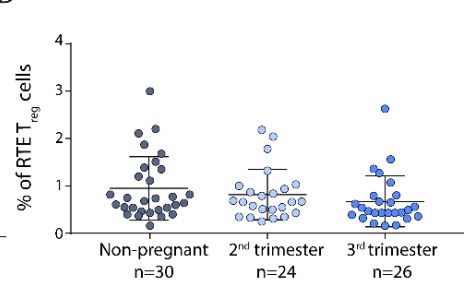

Figure 34. Ki67 expression on $\mathrm{CD}^{+} \mathrm{T}$ cell subsets. Expression of the proliferation marker Ki67 analyzed in whole blood by flow cytometry on $(A, B)$ mature naive and memory $T_{\text {conv }}$ and $T_{\text {reg }}$ cells and (C,D) RTE $T_{\text {conv }}$ and $T_{\text {reg }}$ cells. Statistical differences were determined by Student's unpaired t-test. Mean and standard deviations are shown. ${ }^{*} \mathrm{P}<0.05, * * * \mathrm{P}<0.001, * * * * \mathrm{P}<0.0001$. 
potentially "dilute" the measured TREC levels, which could represent an underestimation of the "true" TREC levels and suggest a decreased output of $T_{\text {conv }}$ cells, including potentially allo-reactive T cells, during pregnancy.

Another factor that could also affect measured RTE frequencies, and thus also TREC content, is alterations in the peripheral homeostasis that could potentially be due to recruitment of cells from the circulation to the tissues, for example to important sites of immune regulation during pregnancy like the decidua, which would affect their distribution in blood. We and others have demonstrated an accumulation of $\mathrm{T}_{\text {reg }}$ cells in the decidua (Tilburgs et al. 2006, Mjösberg et al. 2010), and since they are preferentially recruited from blood (Tilburgs et al. 2008), the process could alter the balance in the circulating T cell pool. However, CD4 ${ }^{+} \mathrm{T}$ cells are scarce in the decidua (Vassiliadou and Bulmer 1996) and since the decidua makes up a small portion of tissue circulated by lymphocytes, it is unlikely that migration of cells to the decidua would have a major

A

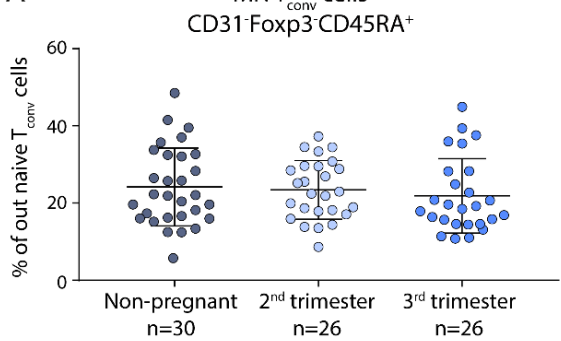

C Memory $T_{\text {conv }}$ cells

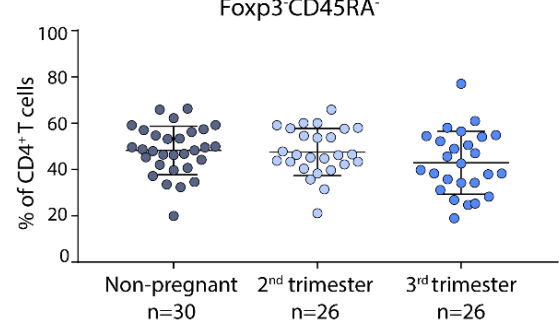

E

Non-suppressive Foxp $3^{+} T_{H}$ cells

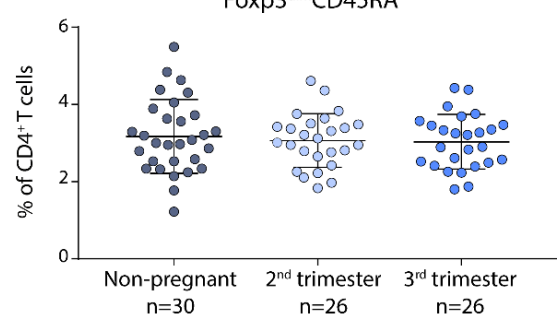

B $\quad \mathrm{MNT}_{\text {reg }}$ cells

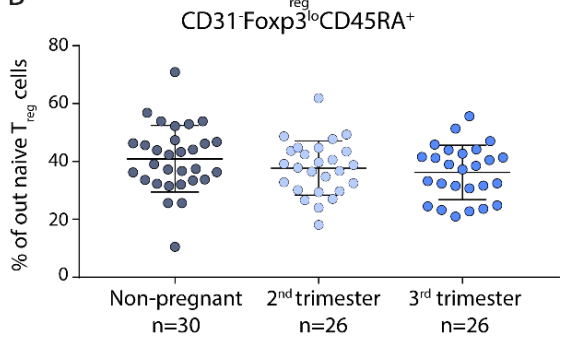

D

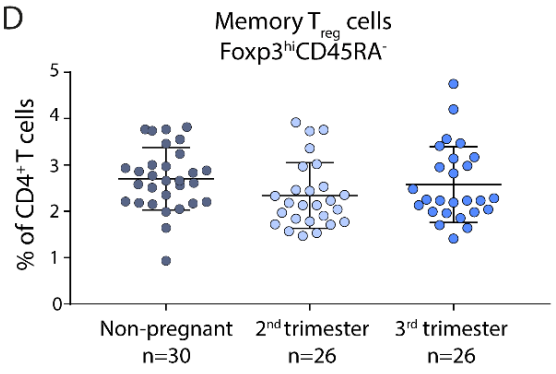

Figure 35. Proportion of $T_{H}$ cell subsets analyzed by flow cytometry in $(A, B)$ mature naive $T_{\text {conv }}$ and $T_{\text {reg }}$ cells, $(C, D)$ memory $T_{\text {conv }}$ and $T_{\text {reg }}$ cells and (E) non-suppressive Foxp $3^{+} T_{H}$ cells. $M N$, mature naive; $T_{\text {conv, }}$ conventional $\mathrm{T}$ cell; $\mathrm{T}_{\mathrm{H}}, \mathrm{T}$ helper cell; $\mathrm{T}_{\text {reg, }}$ regulatory $\mathrm{T}$ cell. 
impact of the distribution of cells in the circulation. The proportion of both $T_{\text {conv }}$ and $T_{\text {reg }}$ subsets were unaltered during pregnancy, indicating that altered peripheral homeostasis did not significantly affect our findings.

\section{CD31 and TREC as markers of T cells with recent thymic origin}

The presence of CD31 and high TREC levels are the most well-established markers of cells with recent thymic origin (Fink 2013). We used both methods and obtained similar findings in that both methods falsified the general conception of decreased output of T cells during pregnancy. Instead, both measures showed maintained output of $\mathrm{T}_{\text {conv }}$ cells, and based on TREC levels even indicated an increased output of $\mathrm{T}_{\text {reg }}$ cells. In general, in agreement with our findings, CD31 and TREC levels are known to correlate (Figure 36), for example both decline with age (Junge et al. 2007, Ravkov et al. 2017). Nevertheless, there is a slight dis-concordance between CD31 and TREC during aging since the decrease in TREC levels is disproportionally greater compared with the decline in CD31 ${ }^{+}$naive T cells (Douek et al. 1998, Kilpatrick et al. 2008). Furthermore, TREC levels in $\mathrm{CD}_{3} 1^{+}$naive T cells also tend to decline with age, indicating different dynamics with a slower turnover of CD31 (Kilpatrick et al. 2008). Indeed, CD31 expression was shown to be maintained for several rounds of homeostatic proliferations, while proliferation would decrease TREC levels despite a maintained CD31 phenotype (Kilpatrick et al. 2008, Azevedo et al. 2009). Still, although CD31 and TREC show somewhat different dynamics, CD31+ naive T cells definitely reflect a recent

A

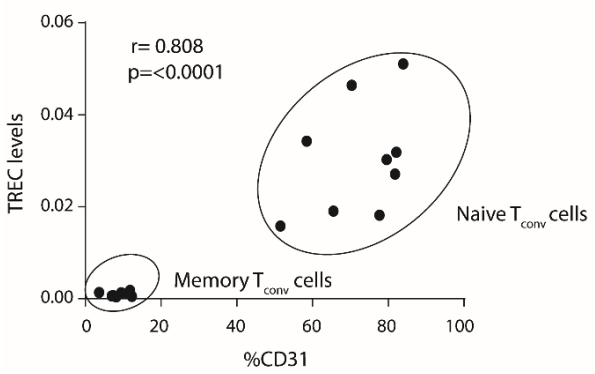

B

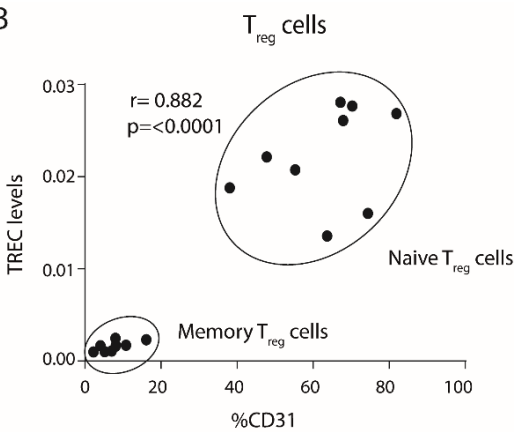

Figure 36. Correlation between TREC levels and CD31 expression. TREC levels and CD31 expression in flow cytometry sorted (A) naive and memory $T_{\text {conv }}$ cells (pregnant $n=4$, non-pregnant $n=5$ ), (B) naive and memory $T_{\text {reg }}$ cells (pregnant $n=5$, non-pregnant $n=4$ ). TREC levels were determined by RT-PCR and CD31 expression on naive $\left(\mathrm{CD}^{2} 5 \mathrm{RA}^{+}\right)$and memory $\left(\mathrm{CD} 45 \mathrm{RA} \mathrm{A}^{-}\right) \mathrm{T}$ cell subsets was analyzed by flow cytometry. Correlation analysis was performed using Spearman rank correlation. TREC, $T$ cell receptor excision circles; $T_{\text {conv, }}$ conventional $\mathrm{T}$ cells; $\mathrm{T}_{\mathrm{reg}}$, regulatory $\mathrm{T}$ cell. 
thymic origin, as shown for example by their decrease following neonatal thymectomy (den Braber et al. 2012), and after high dose chemotherapy with autologous hematopoietic stem-cell transplantation (Batorov et al. 2017). These differences in kinetics between the markers could explain the discrepancies in our findings and hence it is still plausible with a higher output of $\mathrm{T}_{\text {regs }}$ during pregnancy, than in the non-pregnant state. 


\section{Summary and future perspectives}

Today, there are more and more effective and targeted treatments for MS, which have improved the situation for many patients (Tintore et al. 2019). However, we are also faced with increased risk of serious adverse side effects and increasing costs of treatment. Furthermore, despite the array of treatments available, many patients still continue to deteriorate. Clearly, we do not yet have all the answers needed to give the best care and treatment for individual patients. One of the major obstacles is that MS is a very complex and heterogenous disease, both in terms of clinical presentation and disease course as well as in its pathophysiology (Lassmann et al. 2001). Furthermore, there are large inter-individual variations in response to treatment. We need a better understanding of the underlying disease mechanisms to find new treatment targets as well as biomarkers for personalized medicine.

Why use pregnancy to understand MS and what can we learn from it? During pregnancy, the maternal immune system is faced with a tremendous immunological challenge, the presence of the semi-allogenic fetus (Mor et al. 2017). Balancing the need for tolerance whilst maintaining effective immunity can only be accurately described as an immunological paradox and the success of pregnancy requires extensive immune-endocrine interactions and an altered maternal immune response. Pregnancy therefore represents an excellent model of natural immunological tolerance and since MS improves and worsens during pregnancy (Finkelsztejn et al. 2011), it can also be viewed as a dynamic model of immunological changes that can be used to understand not only disease-alleviating but also disease-promoting mechanisms. Indeed, it is not only important to understand why patients improve, but also why there could be increased risk of worsening following delivery. This is not only relevant from a disease mechanistic perspective but also for a better understanding of how to manage patients in the post-pregnancy period. In this thesis, we chose to focus on one of the major central aspects in MS, T cell activation, to gain a deeper understanding of how $\mathrm{CD}^{+} \mathrm{T}$ cells can contribute to the disease pathogenesis (paper I) and how pregnancy-related mechanisms could be involved in altering disease activity in MS during pregnancy (paper II and III). 


\section{Deciphering the dynamic responses to T cell activation holds promise for the future}

We initially set out to investigate the response to T cell activation to understand, from a more global perspective, if MS patients responded differently to activation and if that could give insights into important disease-promoting mechanisms. Paper I was designed as a pilot, a benchmark study for understanding potentially important aspects of the disease pathogenesis and more importantly, how they are most accurately captured. From this, several important key aspects emerged: (1) as hypothesized, the dynamic response to activation is pivotal for studying deviating immune responses in MS; (2) using a network-based modular approach is central for identifying disease-relevant genes; (3) the above mentioned methodology can be used to give mechanistical insights about the disease pathogenesis that can be translated into potentially clinically useful biomarkers. Furthermore, our findings provide continued support of the importance of $C D 4^{+} \mathrm{T}$ cells and T cell activation in MS. Future studies will be aimed at understanding how this dysregulated response is affected during pregnancy, where we hypothesize that the identified disease module will be normalized during pregnancy. We have a cohort of MS patients that have been followed prospectively and longitudinally before, during and after pregnancy together with a cohort of healthy pregnant women that will serve as the basis for these studies. In this cohort, we will not only study the dysregulated network identified here but also other changes that could give additional knowledge on how pregnancy alters the $C D 4^{+} \mathrm{T}$ cells in MS. A similar approach was performed by Gilli et al., although they were studying gene expression changes before, during and after pregnancy in resting/unactivated PBMCs (Gilli et al. 2010). Based on our findings, it will be interesting to see how our network-based modular strategy of the dynamic response to T cell activation can give further insights. Furthermore, one of the major findings in paper I was that the dynamic response genes resulted in the identification of potential future biomarkers in MS. This is important since the implementation of personalized medicine in MS is limited by the lack of robust biomarkers and detailed understanding of the disease pathogenesis (Rotstein and Montalban 2019). Our identified biomarkers could not only distinguish between patients and controls but could also be used to predict disease activity and response to treatment, which are corner aspects in personalized medicine and needed to treat the right patient with the correct treatment at the appropriate time. The importance and relevance of our biomarkers will need to be verified in other settings but holds promise for the future. Currently, as in our study, biomarkers in CSF seems to, as of yet, be superior to potential biomarkers found in blood 
(Håkansson et al. 2018). However, with the technical advances and increased sensitive of the available techniques it will be interesting to see if future studies will find promising blood biomarkers (Lycke and Zetterberg 2017, Håkansson et al. 2018).

\section{Progesterone as future treatment for multiple sclerosis?}

The prominent hormonal changes that occur during pregnancy are believed to play an important role in the pregnancy-induced effects observed in MS where P4 constitutes a likely candidate for playing a substantial role in this. Understanding how P4 can affect such a central process as T cell activation is crucial to get a deeper understanding on how P4 can be involved in shaping the immunological tolerance established during pregnancy and how that subsequently can influence mechanisms of importance to MS. To our knowledge, this is the first study (paper II) to show that P4 specifically affects T cell responses of relevance in MS, and also other immune-related diseases that are affected during pregnancy, which supports a role for P4 in the pregnancy-induced immunomodulation. Speculatively, since MS relapses are proposed to be initiated in the periphery (Brynedal et al. 2010), higher circulating P4 levels during pregnancy could make the pathogenic T cells less responsive to T cell activation and/or dampen their activation, which could make them less prone to enter the CNS and initiate inflammation.

Our findings provide an incentive to continue to explore the effect of P4 on the immune system as it constitutes a very attractive potential treatment option that has not yet been fully explored. Administration of P4 significantly reduces disease severity in the EAE model (Garay et al. 2009, Yates et al. 2010) and has further been shown to have neuroprotective and repairing properties (El-Etr et al. 2015). The ability to affect processes in the CNS is an important component for future treatments in MS as current treatments seem unable to stop the ongoing neurodegenerative processes and hence, have little or no effect on the progressive disease state. There are many studies investigating the effect of hormonal contraceptives and MS, which could give indications of potential beneficial effect of use of P4 or synthetic progestins. However, the results are so far inconclusive (Hellwig et al. 2016, Zapata et al. 2016) and in most studies combined hormonal contraceptives are evaluated, containing both an estrogen and a progesterone component, which makes it harder to draw conclusions regarding the exclusive effects of P4. High dose of progestins as treatment for preventing post-partum relapses failed to show convincing results (Vukusic et al. 2012). However, considering the overall dramatic changes in the immune system that occurs following delivery, it is not surprising that no clear effect was observed. As potential treatment, 
hormonal therapy alone might not be sufficient but could be combined with current treatment regimens. Clearly, further studies are warranted, deciphering the potential beneficial role of P4 in MS and its potential use a treatment. Considering that progestins are more potent than progesterone, with varying properties but generally without serious side effects, they could make an even more attractive treatment option. We currently plan studies to see if synthetic progestins could mimic the effects of P4 observed here. Further, our study was limited to evaluating the direct effect of $\mathrm{P} 4$ on $\mathrm{CD}^{+} \mathrm{T}$ cells and further studies will need to address more specifically the effect of P4 and progestins in a broader sense. Our preliminary data suggests that P4 could affect both $\mathrm{CD}^{+}, \mathrm{CD}^{\circ} 6^{+}$and $\mathrm{CD} 19^{+}$cells, whereas we have previously not seen any effect on macrophages (Svensson et al. 2011, unpublished data). Indeed, the effect of P4 on CD4 ${ }^{+}$T cells could even be further enhanced in the presence of other immune cells.

Polarization of $T_{H}$ cells is important in the MS pathogenesis, where $T_{H} 1 / T_{H} 17$ are clearly involved in driving the disease (Dendrou et al. 2015). Since P4 is suggested as one of the main candidates driving the " $T_{H} 2$-bias" during pregnancy while dampening $T_{H} 1 / T_{H} 17$ responses (Polese et al. 2014), it could explain its role in the pregnancy-related alterations in MS. Indeed, a shift from $T_{H} 1$ to $T_{H} 2$ has been observed in MS patients during pregnancy (Al-Shammri et al. 2004, Airas et al. 2008, Lopez et al. 2006). Our in vitro model of T cell activation was not designed with the purpose of evaluating the effect of $\mathrm{P} 4$ on $\mathrm{T}_{H}$ polarization. Based on pathways analysis of the DEGs and protein expression, we did not see any indications of a polarizing effect of P4 although clearly, the short time span (6-72 hrs) plays a major role here. It is possible that even during early $T$ cell activation, P4 could have a polarizing effect that is not evident from our analysis since it was not designed to specifically evaluate those aspects. One potential future application would be to do a more detailed investigation of our identified P4-induced DEGs to gain more insight into a possible polarizing ability of P4 already during the early T cell activation. Indeed, one could use publicly available RNA-seq data from differentiated $T$ cells to define " $T_{H}$-signatures" for each $T_{H}$ subset and investigate if one or some of these signatures appear to be more or less affected by P4. However, studying the effect of P4 on a longer time scale is desirable, going from early T cell activation to its effect during the later stages of T cell differentiation and polarization, to get a more complete picture of the role of P4. Speculatively, based on our data and others, the initial and early effect of P4 is mainly dampening the T cell activation, thereby making disease-promoting T cells less prone to become activated and to initiate inflammation. Further, in the longer perspective, T cells activated in the presence of $\mathrm{P} 4$ will possibly be less poised towards detrimental $T_{H} 1 / T_{H} 17$ 
responses. Taken together, these mechanisms could collectively be involved in mediating some of the observed pregnancy-induced effects in MS.

Importantly, our findings are not only limited to important immunomodulatory effects of P4 on T cells of potential relevance in MS but also for understanding normal pregnancy and pregnancyrelated complications. Low circulating levels of P4 have been associated with several pregnancy complications (Arck et al. 2008, Ku et al. 2018) and the importance of P4 for controlling T cell activation during pregnancy is evident as administration of P4 could prevent T cell activationinduced preterm labor and birth in an animal model (Arenas-Hernandez et al. 2019). The benefit of using of progesterone as an intervention to prevent preterm birth are inconclusive (Norman et al. 2016, Jarde et al. 2019) and further studies regarding the role of P4 in pregnancy complications and as potential future treatment are needed.

\section{Thymus-the forgotten organ revisited}

The importance of the thymus throughout life has for a long time been overlooked simply because of its age-associated involution together with its decreased contribution to the peripheral T cell pool (Lynch et al. 2009). However, over the years it has become increasingly clear that the thymus still plays a significant role, also at a higher age, as evident for example from the increased prevalence of certain autoimmune diseases in children that underwent early thymectomy (Gudmundsdottir et al. 2018). In MS, disturbed T cell homeostasis as a result of thymic dysfunction has been reported (Haegert et al. 2011), where patients with MS have decreased frequency of circulating RTE $T_{\text {regs }}$ (Haas et al. 2007, Venken et al. 2010). Considering the effect of pregnancy on MS, our finding of a maintained output of T cells during normal pregnancy offers a potential mechanism that could be important for the pregnancy-induced improvement. Indeed, decreased thymic output has also been reported in RA (Koetz et al. 2000), which lends additional support for a role of the thymus in the improvement of certain diseases during pregnancy. Hypothetically, the disturbed thymic output noted in MS and RA may be restored during pregnancy, which could play a role in the pregnancy-induced improvement. This will be further investigated in our prospective longitudinal cohort of MS patients followed throughout and after pregnancy.

Previously, RTEs were considered functionally immature and simply "defective" versions of their mature counterparts. However, accumulating evidence suggests that RTEs could play an important role in maintaining immune tolerance (Cunningham et al. 2018). However, in humans, 
studies on thymic function are limited due to the inaccessibility of the target organ and thus, much of the available information regarding functional characteristics of RTEs stems from animal models. Interestingly, single cell sequencing of isolated RTEs and MN T cells is an approach that have not yet been applied in humans and could provide more insight into potential functional differences of the RTEs in different contexts.

Boosting thymic function is emerging as a concept to reduce the risk of infections and cancer associated with loss of regular thymic function (Holländer et al. 2010). Currently proposed strategies are aimed at reducing thymic atrophy, thereby enhancing the output T cells, which is essential for immune reconstitution. Several promising interventions have been tested such as IL7 (Majumdar and Nandi 2018). Potentially, in the future, stimulating thymus function could provide a potential therapeutic approach in MS. 


\section{Concluding remarks}

The profound effects of pregnancy on MS underscore its relevance as a model of natural tolerance for understanding important disease mechanisms in MS and how they can be improved. A deeper understanding of the MS pathogenesis is needed for identification of biomarkers and new treatment strategies. In this thesis we have studied the dysregulated immune system in MS and potential factors that could be involved in the pregnancy-induced improvement of MS. The findings are concluded below and shown in Figure 37.

- In paper I, we show that $\mathrm{CD} 4^{+} T$ cells display a dysregulated gene response upon activation in MS, further supporting the importance of $C D 4^{+} T$ cells and particularly, $T$ cell activation, in the disease pathogenesis. A network-based modular approach disclosed chemotaxis and cell activation as central components in the dysregulated response. From the resulting module, a set of proteins were identified that could be measured and combined be used to classify patients and controls, predict disease activity after 2 years, and distinguish between high and low responders to treatment. Our results highlight the importance of studying the dynamic response to activation to find disease-relevant aberrations instead of steady state resting cells. Further, our study shows a useful principle for studying the dynamic response that could be translated into potentially clinically relevant biomarkers.

- In paper II, progesterone was shown to significantly dampen T cell activation and immune responses, confirming its previously proposed role as an immunoregulatory hormone important for controlling T cells responses during pregnancy. Further, genes associated with inflammatory diseases that are known to be modulated during pregnancy were significantly affected by $\mathrm{P} 4$, in particular genes related to MS, which clearly points towards a prominent role for P4 in the immunomodulation of certain diseases, like MS, during pregnancy.

- In paper III, we challenged the general dogma of an inactive thymus during pregnancy by showing that the output of both $T_{\text {conv }}$ and $T_{\text {reg }}$ cells is maintained during pregnancy, instead supporting a maintained and important function of the thymus during pregnancy. The output of $T_{\text {regs }}$ might even be increased, which would fit with the demand for fetal tolerance during pregnancy and could also speculatively be involved in the pregnancy-induced improvement of MS, which is associated with defects in thymic function. 
This thesis adds and extends the knowledge of the importance of $\mathrm{CD}^{+} \mathrm{T}$ cell and $\mathrm{T}$ cell activation in MS and provides possible mechanisms that could be responsible for the pregnancy-related improvement of MS. Clearly, there are many changes induced during pregnancy where the studies included in this thesis only cover some of those aspects. Still, our results provide an important framework for continued investigations and further studies are needed to understand more specifically how these mechanisms can be used to for example identify new treatments and treatment targets.

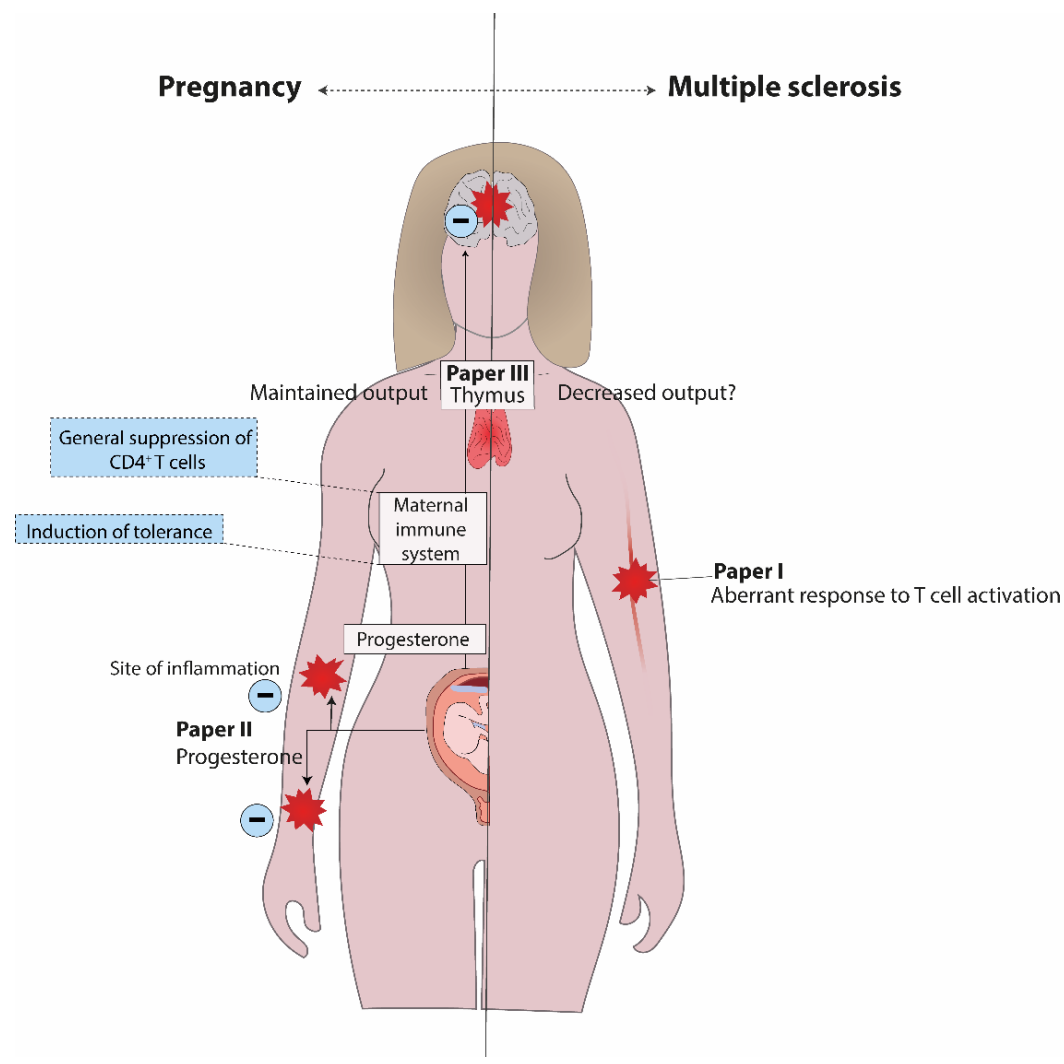

Figure 37. Graphical summary of the thesis projects. In paper I, a dysregulated dynamic gene response to $\mathrm{CD}^{+} \mathrm{T}$ cell activation in MS was found that could be translated into potentially clinically relevant biomarkers for predicting disease activity and response to treatment. We hypothesize that this aberrant response will be normalized during pregnancy, which in part could be a contributing factor to why patients with MS improve during pregnancy. Our findings of a dampening effect of T cell activation by progesterone in paper II together with the fact that progesterone significantly affected genes of relevance in MS, support its role in the pregnancy-induced modulation of MS. Speculatively the high levels of progesterone during pregnancy could make the pathogenic T cells less responsive to T cell activation, dampening their inflammatory disease-promoting capacity. The maintained output of $T$ cells from the thymus during pregnancy observed in paper III offers an additional potential mechanism that could be of importance for the pregnancy-induced improvement as thymic dysfunction has been reported in MS. 


\section{Acknowledgements}

It has been a crazy, fun, exciting, challenging, frustrating, awe-inspiring and truly amazing journey. I finally made it to the other side! I have met so many fantastic people throughout the years that have helped me along the way and has really made this the best time of my life, so to all of you, I thank you from the bottom of my heart $\bigcirc$ There are a few (!) people that I especially would like to thank:

First and foremost, I would like to thank Jan Ernerudh, my main supervisor. I could not think of a better supervisor and you have been a great mentor throughout the years. You have always been very supportive, and you have allowed me to really "test my wings", which has helped me grow into a more confident and independent researcher. You have always included me in all aspects of your research, which I have really appreciated. Thank you for opening my eyes to the wonderful and fascinating world of immunology (starting with Immunologi I in 2009). And perhaps most importantly, thank you for letting me "ha rätt" most of the time (-).

Thank you to Maria Jenmalm (assistant supervisor) for being such an inspiration to me throughout the years. Your passion for research and science is a true source of inspiration. Your knowledge in immunology is mind-boggling and you are always so eager to learn and know more. You have been a great support to me over the years and your thoroughness, insightful comments and attention to details have been very appreciated. You always find the time to respond to emails, look at standard curves, read manuscripts and everything else in between. Thank you for everything.

Magnus Vrethem (assistant supervisor) for valuable clinical input and for help with recruiting patients. Thank you for showing me the ropes around the clinic, I can only agree with your patients...you are a great clinician.

Thank you to Jan Brynhildsen (assistant supervisor), for all the help with untangling the complicated world of sex hormones and for always offering a helping hand if needed.

Tomas Olsson (assistant supervisor) for great collaboration with GraMS over the years.

To all co-authors, Danuta Gawel, Mattias Köpsén, Huan Zhang, Colm Nestor, Ingrid Kockum, Ola Winqvist and Mikael Benson, for fruitful collaborations. A special thanks to Ratnesh B. Mehta for all the help on paper III, taking care of samples and sorting T cells at late hours. Also, to Thomas Skogh, Alf Kastbom and Christopher Sjöwall for nice collaboration on paper I.

The GraMS-study was initiated during my first year as a PhD student, a multicenter collaboration between Linköping, Jönköping, Kalmar and Karolinska, Stockholm. In the end it did not make it into my thesis as planned, but a huge thank you to all of the people who were involved in GraMS; recruiting patients, taking care of samples and just making sure that everything ran smoothly. Without all of your help GraMS would not have been possible and now we have lots of material to do exciting research on in the future. From Karolinska, a special thanks to Mohsen Khademi, for organizing and keeping track of everything and for putting up with all of my emails about all the little details. Tomas Olsson and fellow neurologists at Karolinska for recruiting patients. Therese Pollack and Gunn Jönsson at Neurologmottagningen, KS, for keeping track of patients, taking care of samples and collecting all the clinical data. From Kalmar, all of the nurses and midwives at 
Familjecentrum and in particular Carina Nilsson for your positive attitude and for all the help with keeping GraMS going over the years. At Klinisk Kemi, Ivar Tjernberg and, in particular, Hanna Carlsson who worked tirelessly with taking care of samples whilst working with many other things. You went above and beyond to help us taking care of samples, thank you! Maria Svenvik, thank you for always being so positive about everything and for having a "no problem" attitude when I need your help. It is always nice to work with you and you really are an eldsjäl in research. Thank you for all your help! From Ryhov, Jönköping: Jonas Lind, Helena Bruhn and Henriett Ronnemo at Neurologmottagningen for recruiting patients and taking samples. Andreas Matussek, Annette Nilsson Bowers and to tjejerna at Medicinsk diagnostik flödescytometri for help with taking care of samples. To the nurses and neurologists at Neurologen, US, Linköping for all the help with recruiting patients. A big thanks to Gunn Johansson for all the help from start to finish. For being so organized and thorough, for taking samples and keeping track of all patients. It could not have been done without you. A special thanks to Lars Fugger and Hayley Evans, Oxford University, for nice and interesting present and future collaborations with GraMS.

Charlotte Dahle for always being so positive and curious about how everything is going. Your appetite for learning and understanding science is inspiring. Thank you for all the help with going through medical records and recruiting patients for GraMS. I will always remember our trips to Stockholm (buying Italian food in a basement ()) . Johan Mellergård, for taking the time and showing me that reading medical records is darn hard. Thank you and Irene Håkansson for all the help with recruiting patients to GraMS, nice collaborations and for valuable clinical input during our MS lunches.

To Mika Gustafsson, thank you for letting me be part of your team and introducing me to the world of bioinformatics. I finally learnt what a neural network is. It is always nice to collaborate with you. I like how you never see problems but always possibilities in all data and your research enthusiasm is contagious. Looking forward to working with you!

Göran Berg for all the clinical expertise, help with going through medical records and general wisdom. I have really appreciated all your support and help throughout the years, not to say the least with help carrying fruit baskets.

Thank you to the personnel at Kvinnokliniken, Vrinnevisjukhuset, for always being so positive and eager to participate in our studies. Research cannot be done without your invaluable help. In particular, the midwives, for all the help with recruiting women and collecting samples. It has been a pleasure collaborating with you.

Thank you to the staff at Blodcentralen for always finding the time to help taking blood samples. I do not dare the count the number of tubes that have been collected throughout the years. To both past and present personnel at the flow unit: Karin Backteman, Carina Andersson, Marie Abrahamsson, Emelie Blixt, Ida Bergström, Linda Åkerman and Annie Persson for always being so nice and friendly and for keeping the machines happy and running. A special thanks to Maria Hjorth for always having the time to answer all my flow cytometry-related questions. To Adam and Elof, we have spent a lot of happy (and sometimes boring) times together throughout the years. You have served me well, may your retirement (sad face) be awesome!

Judit Svensson-Arvelund, I do not know where to begin...probably Oppan gangnam style $\mathbf{q}_{\mathbf{2}}$ First supervisor, then colleagues to most importantly- friends. We have had so many fun and crazy 
times together both at work and outside of work. Miss dancing with you $\mathrm{R}$ Your work ethics and organization skills inspire me (might sound boring but you know how much I do love to organize). Whenever I feel lost at work, I just ask myself: What would Judit do? Cannot wait til you come back to Sweden! Anna Forsberg, you were there from the beginning and we were office mates for a long time and you have also been part of the fun times outside of work. Måns Edström, you scared me to death when I was a young student until I learnt that you are probably the nicest guy there is. I miss you at AIR and the place has not been the same since you left. I never understood how someone so disorganized could be so organized (?) You always helped when I needed help and your "det löser sig-inga problem" attitude was most often just what I needed. I have safely been taking care of your favorite pipette (still hoping you will come back one day). Daniel Eklund, working together with you was a pleasure and the MS-gene signature project would not have been the same without you. Working with you in the lab was always fun (although I sometimes yelled at you) and I would like to think that I won you over to the bright (T cell) side $;-$ Örebro is lucky to have you! Daniel Appelgren, for always being so positive...the glass is always half full with you. Could not think of a better companion to travel with, always a pleasure.

AIR is truly a great place to work and I think everyone who has ever walked through the corridors can attest to that; it is always "högt i taket" and most days are filled with laughter and if you need help there is always someone there to help. Helena Enocsson, I am so glad that you came back to AIR. You are so wise and I love talking to you about work and life in general. You also followed me half way around the world to eat falafel at Time Square, if that isn't friendship I don't know what is. I owe you one visit to Orla Kiely. Johanna Raffetseder, I love discussing science and practical matters with you, you are a great bollplank. Georgia Papapavlou, a welcomed addition to team Jan. Thank you for helping out in the lab when needed. I like how you take charge of things and make them happen. Lina Tingö, you are a breath of fresh air and welcomed addition to AIR and esteemed member of Träningsbrudarna (although we haven't been inside the gym for a looong time now (-)). I admire your "pannben" and how you find opportunities at every corner. Marie Rubér for being so genuinely nice and helpful. Klara Martinsson, for having such a straightforward attitude that I genuinely appreciate. Hammoudi Alkaissi, for inspiring me to stand up for what I believe in and that you should not be afraid to speak your mind. And also, for just being such a nice and funny person with a little bit of extra swag 0 . You, me and Robert would have made awesome roommates, who knows in the future maybe...? Petra Cassel, thank you for always taking care of everything small and big and for always answering my questions. Your humor (mostly the same as mine) can brighten up any fika. Jonas Wetterö, for lending out a helping hand to me and everyone else at AIR whenever needed. Your laughter is contagious, which is the best remedy for a boring workday. Thank you for always laughing at my craziness!

Thanks to Johanna Huoman, Camilla Janefjord, Ratnesh B. Mehta, Mattias Magnusson, Jaya Prakash Chalise, Sudeep Chenna Narendra, Sophie Biggs, Per Hultman, Said Havarinasab, Linda Fryland, Martina Abelius, Ammi Fornander, Mari-Anne Åkesson, Ylva Billing, Christer Bergman, Dhanapal Govindaraj, Purnika Damindi Ranasinghe, Mehdi Amirhosseini, Magalí Martí Generó, Pratheek Bellur Marthanda, Karin Söderman, Gunnel Almroth, Thomas Skogh, Alf Kastbom, Mimmi Persson, Marie Malander, Valentina Bruno and Christina Ekerfelt who have all been a part of filling AIR with fun, laughter and nice discussions throughout the years. 
To my musketeers: Robert Lindau, college, roomie, friend and first hand-holder (-). Lina Wirestam, former college, virtual shopping buddie, first line support and just truly awesome friend 2 . Thank you for just being amazing and kick-ass and for making me feel kiss-ass right along with you. Thank you both for always supporting me and encouraging me in life and at work, small and big...Words cannot explain what your friendship has meant to me...so much messenger...so many GIFs...so much laughter.

Rasmus Magnusson, my work hubbie $\Theta$. It is truly a blessing to work and share office with you and we have so much fun together. Thank you for all the morning coffee chats and for just making me laugh all the time. Here, you can have the orange ${ }^{-}$. Cracking jokes with you is amazing. We truly can "make fun out of nothing" (quote Alberto Zenere). And Rasmus, pecksniffian will only ever be funny with you. Alberto Zenere, who would have known that the strange little Italian man with the confused expression would become one of my closest friends. Good or bad, morning coffee or lunch walks, in or outside of work, you are always there...although sometimes it takes

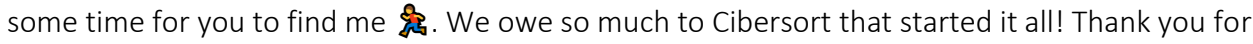
being the most amazing snail tamer ever $\mathscr{B}^{3}$ and for putting up with me and Rasmus when we spin out of control.

To the rest of the Deep Learning Research Section $\{$ Thank you for letting me be a part of your little bioinformatics family. Fika and lunch is never boring with you guys. I will never forget el uturno and our trip to Örebro. Heeey Macarena! My former office buddies, Tejaswi Badam for all help with anything related to R and David Martínez for just being hilarious and Spanish. Olé! Olof Rundquist for all bioinformatics support for which without it I would be lost on the cluster and still using sbash instead of sbatch. To Julia Åkesson for bringing some girl power to the group and Sanjiv Kumar Dwivedi for just being so enthusiastic about neural networks.

I am thankful to all the students Karolina Hjortswang, Edvin Ström, Mina Hovland, Anna Sundin, Zaid Mansur, Claudia D'Amario and Amanda Lundén that have worked on my projects over the years.

To all the people in the National Clinical Research School in Chronic Inflammatory Diseases that was a big part of my initial years as a PhD student. To Jan Alvar Lindencrona and Helena

Erlandsson Harris for organizing courses, amazing trips and workshops and for inspiring us to always strive higher in the pursuit of knowledge. To all (I guess now mostly former) PhD students for all scientific discussions (and non-scientific), laughter and good times. I will always remember our trip to Iceland. Look forward to working with you sometime in the future ().

Livet är inte bara jobb och det finns många underbara människor som förgyllt livet utanför jobbet och som ständigt undrar vad jag pysslar med på jobbet och när jag ska bli klar (-). Nu är jag klar! Petra (Love is always wicked med dig) och Emelie som var med från början i en mörk källarlokal. Saknar er i Linkan men det är alltid lika underbart när vi väl ses och våra galna eskapader från under och efter studentlivet kan fortfarande ljusa upp en grå dag. Angeliqa (Alle, lqa), vi har varit vänner sen långt innan vi kunde gå. Även om vi inte ses så ofta längre så finns du alltid där. Tack ○ Till "nya" vänner, Anders och Hanna med lilla Walther, Jonas, Ida och sötaste Tyra för roliga stunder i livet både med och utan barn. Någon gång inom en överskådlig framtid kommer vi alla 
sitta där i lugnan ro och dricka vin...nästa (eller näst näst nästa?) sommar...när barnen är större \#barnblirintemindrejobbmedåren

Till farmor och farfar, som var med när resan började men som tyvärr inte fick vara med till slutet. Tack för att ni var så nyfikna på vad jag pysslade med och alltid undrade hur det gick med forskeriet. Denna bok är till er. Ta hand om Sally! ir?

Stort tack till "tarmor" Ingmari och "dada" Stefan som alltid ställer upp som barnvakt i vått och torrt och till resten av klanen Ibbe/Jonsson-Hyllman för roliga äventyr genom åren.

Till min familj mamma, pappa och Johan för att ni finns där och alltid undrar över vad jag sysslar med på jobbet och om vi hittat någon ny behandling. För hjälp och stöd i allt, smått som stort. Och tack till hela tjocka släkten: Berntsson, Stawreberg och Pettersson.

Mathias, du är min klippa. Du hjälper mig att fokusera på det som är viktigt i livet och att se den stora bilden och inte fastna i de små detaljerna (vilket jag oftast gör). Tack för att du alltid lyssnar när jag pratar jobb, jobb och jobb vid köksbordet och för att du säger åt mig att hålla tyst ibland. Och kanske viktigast, att du får mig att skratta. Till Nils, du gör livet till ett äventyr. Att leva med dig i nuet är balsam för själen

Goodbye..?

Oh no, please. Can't we go back to page one and do it all over again?

Winnie the Pooh 


\section{References}

Abbas, A., Lichtman, A. and Pillari, S. (2017). Cellular and Molecular Immunology, 9th ed (Elsevier Saunders).

Abrahamsson, T. R., Jakobsson, H. E., Andersson, A. F., Björksten, B., Engstrand, L. and Jenmalm, M. C. (2012). Low diversity of the gut microbiota in infants with atopic eczema. J Allergy Clin Immunol 129, 434-440, 440 e431-432.

Agah, E., Zardoui, A., Saghazadeh, A., Ahmadi, M., Tafakhori, A. and Rezaei, N. (2018). Osteopontin (OPN) as a CSF and blood biomarker for multiple sclerosis: A systematic review and meta-analysis. PLoS One 13, e0190252.

Aghaeepour, N., Ganio, E. A., Mcllwain, D., Tsai, A. S., Tingle, M., Van Gassen, S., Gaudilliere, D. K., et al. (2017). An immune clock of human pregnancy. Sci Immunol 2.

Aharoni, R., Aricha, R., Eilam, R., From, I., Mizrahi, K., Arnon, R., Souroujon, M. C. and Fuchs, S. (2013). Age dependent course of EAE in Aire-/- mice. J Neuroimmunol 262, 27-34.

Ahlgren, C., Lycke, J., Oden, A. and Andersen, O. (2010). High risk of MS in Iranian immigrants in Gothenburg, Sweden. Mult Scler 16, 1079-1082.

Ahlgren, C., Oden, A. and Lycke, J. (2011). High nationwide prevalence of multiple sclerosis in Sweden. Mult Scler 17, 901-908.

Ahlgren, C., Oden, A. and Lycke, J. (2012). A nationwide survey of the prevalence of multiple sclerosis in immigrant populations of Sweden. Mult Scler 18, 1099-1107.

Airas, L., Saraste, M., Rinta, S., Elovaara, I., Huang, Y. H. and Wiendl, H. (2008). Immunoregulatory factors in multiple sclerosis patients during and after pregnancy: relevance of natural killer cells. Clin Exp Immunol 151, 235-243.

Al-Shammri, S., Rawoot, P., Azizieh, F., AbuQoora, A., Hanna, M., Saminathan, T. R. and Raghupathy, R. (2004). Th1/Th2 cytokine patterns and clinical profiles during and after pregnancy in women with multiple sclerosis. J Neurol Sci 222, 21-27.

Alonso, A. and Hernan, M. A. (2008). Temporal trends in the incidence of multiple sclerosis: a systematic review. Neurology 71, 129-135.

Alroughani, R., Alowayesh, M. S., Ahmed, S. F., Behbehani, R. and Al-Hashel, J. (2018). Relapse occurrence in women with multiple sclerosis during pregnancy in the new treatment era. Neurology 90, e840-e846.

Alvarez, E., Piccio, L., Mikesell, R. J., Klawiter, E. C., Parks, B. J., Naismith, R. T. and Cross, A. H. (2013). CXCL13 is a biomarker of inflammation in multiple sclerosis, neuromyelitis optica, and other neurological conditions. Mult Scler 19, 1204-1208.

Anderson, M. S., Venanzi, E. S., Klein, L., Chen, Z., Berzins, S. P., Turley, S. J., von Boehmer, H., et al. (2002). Projection of an immunological self shadow within the thymus by the aire protein. Science 298, 1395-1401.

Annunziato, F. and Romagnani, S. (2009). Heterogeneity of human effector CD4+ T cells. Arthritis Res Ther 11, 257.

Arck, P., Hansen, P. J., Mulac Jericevic, B., Piccinni, M. P. and Szekeres-Bartho, J. (2007). Progesterone during pregnancy: endocrine-immune cross talk in mammalian species and the role of stress. Am J Reprod Immunol $58,268-279$. 
Arck, P. C., Rucke, M., Rose, M., Szekeres-Bartho, J., Douglas, A. J., Pritsch, M., Blois, S. M., et al. (2008). Early risk factors for miscarriage: a prospective cohort study in pregnant women. Reprod Biomed Online 17, 101-113.

Arellano, G., Acuna, E., Reyes, L. I., Ottum, P. A., De Sarno, P., Villarroel, L., Ciampi, E., et al. (2017). Th1 and Th17 Cells and Associated Cytokines Discriminate among Clinically Isolated Syndrome and Multiple Sclerosis Phenotypes. Front Immunol 8, 753.

Arenas-Hernandez, M., Romero, R., Xu, Y., Panaitescu, B., Garcia-Flores, V., Miller, D., Ahn, H., et al. (2019). Effector and Activated T Cells Induce Preterm Labor and Birth That Is Prevented by Treatment with Progesterone. J Immunol 202, 2585-2608.

Asano, M., Toda, M., Sakaguchi, N. and Sakaguchi, S. (1996). Autoimmune disease as a consequence of developmental abnormality of a T cell subpopulation. J Exp Med 184, 387-396.

Ayoglu, B., Mitsios, N., Kockum, I., Khademi, M., Zandian, A., Sjöberg, R., Forsström, B., et al. (2016). Anoctamin 2 identified as an autoimmune target in multiple sclerosis. Proc Natl Acad Sci U S A 113, 2188-2193.

Azevedo, R. I., Soares, M. V., Barata, J. T., Tendeiro, R., Serra-Caetano, A., Victorino, R. M. and Sousa, A. E. (2009). IL-7 sustains CD31 expression in human naive CD4+ T cells and preferentially expands the CD31+ subset in a PI3K-dependent manner. Blood 113, 2999-3007.

Baecher-Allan, C., Kaskow, B. J. and Weiner, H. L. (2018). Multiple Sclerosis: Mechanisms and Immunotherapy. Neuron 97, 742-768.

Baecher-Allan, C. M., Costantino, C. M., Cvetanovich, G. L., Ashley, C. W., Beriou, G., Dominguez-Villar, M. and Hafler, D. A. (2011). CD2 costimulation reveals defective activity by human CD4+CD25(hi) regulatory cells in patients with multiple sclerosis. J Immunol 186, 3317-3326.

Baker, M. W., Grossman, W. J., Laessig, R. H., Hoffman, G. L., Brokopp, C. D., Kurtycz, D. F., Cogley, M. F., et al. (2009). Development of a routine newborn screening protocol for severe combined immunodeficiency. J Allergy Clin Immunol 124, 522-527.

Barriga, C., Rodriguez, A. B. and Ortega, E. (1994). Increased phagocytic activity of polymorphonuclear leukocytes during pregnancy. Eur J Obstet Gynecol Reprod Biol 57, 43-46.

Bates, M. D., Quenby, S., Takakuwa, K., Johnson, P. M. and Vince, G. S. (2002). Aberrant cytokine production by peripheral blood mononuclear cells in recurrent pregnancy loss? Hum Reprod 17, 2439-2444.

Batorov, E. V., Tikhonova, M. A., Kryuchkova, I. V., Sergeevicheva, V. V., Sizikova, S. A., Ushakova, G. Y., Batorova, D. S., et al. (2017). CD4+ memory T cells retain surface expression of CD31 independently of thymic function in patients with lymphoproliferative disorders following autologous hematopoietic stem-cell transplantation. Int J Hematol 106, 108-115.

Belkaid, Y. and Hand, T. W. (2014). Role of the microbiota in immunity and inflammation. Cell 157, $121-141$.

Bennett, C. L., Christie, J., Ramsdell, F., Brunkow, M. E., Ferguson, P. J., Whitesell, L., Kelly, T. E., et al. (2001). The immune dysregulation, polyendocrinopathy, enteropathy, $\mathrm{X}$-linked syndrome (IPEX) is caused by mutations of FOXP3. Nat Genet 27, 20-21.

Berer, K., Gerdes, L. A., Cekanaviciute, E., Jia, X., Xiao, L., Xia, Z., Liu, C., et al. (2017). Gut microbiota from multiple sclerosis patients enables spontaneous autoimmune encephalomyelitis in mice. Proc Natl Acad Sci U S A 114, 10719-10724.

Berer, K., Mues, M., Koutrolos, M., Rasbi, Z. A., Boziki, M., Johner, C., Wekerle, H. and Krishnamoorthy, G. (2011). Commensal microbiota and myelin autoantigen cooperate to trigger autoimmune demyelination. Nature 479, 538-541. 
Berg-Hansen, P. and Celius, E. G. (2015). Socio-economic factors and immigrant population studies of multiple sclerosis. Acta Neurol Scand 132, 37-41.

Bergamaschi, R. (2006). Prognosis of multiple sclerosis: clinical factors predicting the late evolution for an early treatment decision. Expert Rev Neurother 6, 357-364.

Berkley, A. M., Hendricks, D. W., Simmons, K. B. and Fink, P. J. (2013). Recent thymic emigrants and mature naive T cells exhibit differential DNA methylation at key cytokine loci. J Immunol 190, 6180-6186.

Bhela, S., Kempsell, C., Manohar, M., Dominguez-Villar, M., Griffin, R., Bhatt, P., Kivisakk-Webb, P., et al. (2015). Nonapoptotic and extracellular activity of granzyme B mediates resistance to regulatory T cell (Treg) suppression by HLA-DR-CD25hiCD127lo Tregs in multiple sclerosis and in response to IL-6. J Immunol 194, 2180-2189.

Billington, W. D. (1992). The normal fetomaternal immune relationship. Baillieres Clin Obstet Gynaecol 6, 417438.

Bluestone, J. A. and Abbas, A. K. (2003). Natural versus adaptive regulatory T cells. Nat Rev Immunol 3, 253257.

Boij, R., Mjösberg, J., Svensson-Arvelund, J., Hjorth, M., Berg, G., Matthiesen, L., Jenmalm, M. C. and Ernerudh, J. (2015). Regulatory T-cell Subpopulations in Severe or Early-onset Preeclampsia. Am J Reprod Immunol 74, 368-378.

Borsellino, G., Kleinewietfeld, M., Di Mitri, D., Sternjak, A., Diamantini, A., Giometto, R., Hopner, S., et al. (2007). Expression of ectonucleotidase CD39 by Foxp3+ Treg cells: hydrolysis of extracellular ATP and immune suppression. Blood 110, 1225-1232.

Boström, I., Stawiarz, L. and Landtblom, A. M. (2013). Sex ratio of multiple sclerosis in the National Swedish MS Register (SMSreg). Mult Scler 19, 46-52.

Breij, E. C., Brink, B. P., Veerhuis, R., van den Berg, C., Vloet, R., Yan, R., Dijkstra, C. D., van der Valk, P. and Bo, L. (2008). Homogeneity of active demyelinating lesions in established multiple sclerosis. Ann Neurol 63, 16-25.

Bretscher, P. A. (1999). A two-step, two-signal model for the primary activation of precursor helper T cells. Proc Natl Acad Sci U S A 96, 185-190.

Brettschneider, J., Czerwoniak, A., Senel, M., Fang, L., Kassubek, J., Pinkhardt, E., Lauda, F., et al. (2010). The chemokine CXCL13 is a prognostic marker in clinically isolated syndrome (CIS). PLoS One 5, e11986.

Brorson, I. S., Eriksson, A., Leikfoss, I. S., Celius, E. G., Berg-Hansen, P., Barcellos, L. F., Berge, T., Harbo, H. F. and Bos, S. D. (2019). No differential gene expression for CD4(+) T cells of MS patients and healthy controls. Mult Scler J Exp Transl Clin 5, 2055217319856903.

Brynedal, B., Khademi, M., Wallström, E., Hillert, J., Olsson, T. and Duvefelt, K. (2010). Gene expression profiling in multiple sclerosis: a disease of the central nervous system, but with relapses triggered in the periphery? Neurobiol Dis 37, 613-621.

Bulmer, J. N., Williams, P. J. and Lash, G. E. (2010). Immune cells in the placental bed. Int J Dev Biol 54, $281-294$.

Butts, C. L., Shukair, S. A., Duncan, K. M., Bowers, E., Horn, C., Belyavskaya, E., Tonelli, L. and Sternberg, E. M. (2007). Progesterone inhibits mature rat dendritic cells in a receptor-mediated fashion. Int Immunol 19, 287296.

Bynote, K. K., Hackenberg, J. M., Korach, K. S., Lubahn, D. B., Lane, P. H. and Gould, K. A. (2008). Estrogen receptor-alpha deficiency attenuates autoimmune disease in (NZB x NZW)F1 mice. Genes Immun 9, 137-152. 
Cao, Y., Goods, B. A., Raddassi, K., Nepom, G. T., Kwok, W. W., Love, J. C. and Hafler, D. A. (2015). Functional inflammatory profiles distinguish myelin-reactive T cells from patients with multiple sclerosis. Sci Transl Med 7, 287 ra274.

Cebula, A., Seweryn, M., Rempala, G. A., Pabla, S. S., Mclndoe, R. A., Denning, T. L., Bry, L., et al. (2013). Thymus-derived regulatory T cells contribute to tolerance to commensal microbiota. Nature 497, $258-262$.

Cekanaviciute, E., Yoo, B. B., Runia, T. F., Debelius, J. W., Singh, S., Nelson, C. A., Kanner, R., et al. (2017). Gut bacteria from multiple sclerosis patients modulate human $T$ cells and exacerbate symptoms in mouse models. Proc Natl Acad Sci U S A 114, 10713-10718.

Chalmer, T. A., Baggesen, L. M., Norgaard, M., Koch-Henriksen, N., Magyari, M., Sorensen, P. S. and Danish Multiple Sclerosis, G. (2018). Early versus later treatment start in multiple sclerosis: a register-based cohort study. Eur J Neurol 25, 1262-e1110.

Chan, K. and Puck, J. M. (2005). Development of population-based newborn screening for severe combined immunodeficiency. J Allergy Clin Immunol 115, 391-398.

Chaouat, G., Ledee-Bataille, N., Dubanchet, S., Zourbas, S., Sandra, O. and Martal, J. (2004). TH1/TH2 paradigm in pregnancy: paradigm lost? Cytokines in pregnancy/early abortion: reexamining the TH1/TH2 paradigm. Int Arch Allergy Immunol 134, 93-119.

Chen, L. and Flies, D. B. (2013). Molecular mechanisms of T cell co-stimulation and co-inhibition. Nat Rev Immunol 13, 227-242.

Chen, X., Fang, L., Song, S., Guo, T. B., Liu, A. and Zhang, J. Z. (2009). Thymic regulation of autoimmune disease by accelerated differentiation of Foxp3+ regulatory T cells through IL-7 signaling pathway. J Immunol 183, 6135-6144.

Chhangawala, S., Rudy, G., Mason, C. E. and Rosenfeld, J. A. (2015). The impact of read length on quantification of differentially expressed genes and splice junction detection. Genome Biol 16, 131.

Chien, E. J., Chang, C. P., Lee, W. F., Su, T. H. and Wu, C. H. (2006). Non-genomic immunosuppressive actions of progesterone inhibits PHA-induced alkalinization and activation in T cells. J Cell Biochem 99, 292-304.

Chien, E. J., Liao, C. F., Chang, C. P., Pu, H. F., Lu, L. M., Shie, M. C., Hsieh, D. J. and Hsu, M. T. (2007). The nongenomic effects on $\mathrm{Na}+/ \mathrm{H}+-$ exchange 1 by progesterone and 20alpha-hydroxyprogesterone in human T cells. J Cell Physiol 211, 544-550.

Clarke, A. G. and Kendall, M. D. (1994). The thymus in pregnancy: the interplay of neural, endocrine and immune influences. Immunol Today 15, 545-551.

Clemens, L. E., Siiteri, P. K. and Stites, D. P. (1979). Mechanism of immunosuppression of progesterone on maternal lymphocyte activation during pregnancy. J Immunol 122, 1978-1985.

Codarri, L., Gyulveszi, G., Tosevski, V., Hesske, L., Fontana, A., Magnenat, L., Suter, T. and Becher, B. (2011). RORgammat drives production of the cytokine GM-CSF in helper T cells, which is essential for the effector phase of autoimmune neuroinflammation. Nat Immunol 12, 560-567.

Comabella, M. and Montalban, X. (2014). Body fluid biomarkers in multiple sclerosis. Lancet Neurol 13, 113126.

Comabella, M., Pericot, I., Goertsches, R., Nos, C., Castillo, M., Blas Navarro, J., Rio, J. and Montalban, X. (2005). Plasma osteopontin levels in multiple sclerosis. J Neuroimmunol 158, 231-239.

Comi, G., Radaelli, M. and Soelberg Sorensen, P. (2017). Evolving concepts in the treatment of relapsing multiple sclerosis. Lancet 389, 1347-1356. 
Conesa, A., Madrigal, P., Tarazona, S., Gomez-Cabrero, D., Cervera, A., McPherson, A., Szczesniak, M. W., et al. (2016). A survey of best practices for RNA-seq data analysis. Genome Biol 17, 13.

Confavreux, C., Hutchinson, M., Hours, M. M., Cortinovis-Tourniaire, P. and Moreau, T. (1998). Rate of pregnancy-related relapse in multiple sclerosis. Pregnancy in Multiple Sclerosis Group. N Engl J Med 339, 285291.

Confavreux, C., Vukusic, S. and Adeleine, P. (2003). Early clinical predictors and progression of irreversible disability in multiple sclerosis: an amnesic process. Brain 126, 770-782.

Corvol, J. C., Pelletier, D., Henry, R. G., Caillier, S. J., Wang, J., Pappas, D., Casazza, S., et al. (2008). Abrogation of T cell quiescence characterizes patients at high risk for multiple sclerosis after the initial neurological event. Proc Natl Acad Sci U S A 105, 11839-11844.

Couzinet, B., Le Strat, N., Ulmann, A., Baulieu, E. E. and Schaison, G. (1986). Termination of early pregnancy by the progesterone antagonist RU 486 (Mifepristone). N Engl J Med 315, 1565-1570.

Crome, S. Q., Wang, A. Y. and Levings, M. K. (2010). Translational mini-review series on Th17 cells: function and regulation of human Thelper 17 cells in health and disease. Clin Exp Immunol 159, 109-119.

Cunningham, C. A., Helm, E. Y. and Fink, P. J. (2018). Reinterpreting recent thymic emigrant function: defective or adaptive? Curr Opin Immunol 51, 1-6.

D'Hooghe M, B., Nagels, G. and Uitdehaag, B. M. (2010). Long-term effects of childbirth in MS. J Neurol Neurosurg Psychiatry 81, 38-41.

Das, G., Damotte, V., Gelfand, J. M., Bevan, C., Cree, B. A. C., Do, L., Green, A. J., Hauser, S. L. and Bove, R. (2018). Rituximab before and during pregnancy: A systematic review, and a case series in MS and NMOSD. Neurol Neuroimmunol Neuroinflamm 5, e453.

de Man, Y. A., Dolhain, R. J., van de Geijn, F. E., Willemsen, S. P. and Hazes, J. M. (2008). Disease activity of rheumatoid arthritis during pregnancy: results from a nationwide prospective study. Arthritis Rheum 59, 12411248.

Demeure, C. E., Byun, D. G., Yang, L. P., Vezzio, N. and Delespesse, G. (1996). CD31 (PECAM-1) is a differentiation antigen lost during human CD4 T-cell maturation into Th1 or Th2 effector cells. Immunology 88 , 110-115.

den Braber, I., Mugwagwa, T., Vrisekoop, N., Westera, L., Mogling, R., de Boer, A. B., Willems, N., et al. (2012). Maintenance of peripheral naive T cells is sustained by thymus output in mice but not humans. Immunity 36 , 288-297.

Dendrou, C. A., Fugger, L. and Friese, M. A. (2015). Immunopathology of multiple sclerosis. Nat Rev Immunol $15,545-558$

Dobin, A., Davis, C. A., Schlesinger, F., Drenkow, J., Zaleski, C., Jha, S., Batut, P., Chaisson, M. and Gingeras, T. R. (2013). STAR: ultrafast universal RNA-seq aligner. Bioinformatics 29, 15-21.

Dosiou, C., Hamilton, A. E., Pang, Y., Overgaard, M. T., Tulac, S., Dong, J., Thomas, P. and Giudice, L. C. (2008). Expression of membrane progesterone receptors on human T lymphocytes and Jurkat cells and activation of Gproteins by progesterone. J Endocrinol 196, 67-77.

Douek, D. C., McFarland, R. D., Keiser, P. H., Gage, E. A., Massey, J. M., Haynes, B. F., Polis, M. A., et al. (1998). Changes in thymic function with age and during the treatment of HIV infection. Nature 396, 690-695. 
Douek, D. C., Vescio, R. A., Betts, M. R., Brenchley, J. M., Hill, B. J., Zhang, L., Berenson, J. R., Collins, R. H. and Koup, R. A. (2000). Assessment of thymic output in adults after haematopoietic stem-cell transplantation and prediction of T-cell reconstitution. Lancet 355, 1875-1881.

Dutta, R. and Trapp, B. D. (2014). Relapsing and progressive forms of multiple sclerosis: insights from pathology. Curr Opin Neurol 27, 271-278.

Ebers, G. C. (1998). Randomised double-blind placebo-controlled study of interferon beta-1a in relapsing/remitting multiple sclerosis. PRISMS (Prevention of Relapses and Disability by Interferon beta-1a Subcutaneously in Multiple Sclerosis) Study Group. Lancet 352, 1498-1504.

Ehring, G. R., Kerschbaum, H. H., Eder, C., Neben, A. L., Fanger, C. M., Khoury, R. M., Negulescu, P. A. and Cahalan, M. D. (1998). A nongenomic mechanism for progesterone-mediated immunosuppression: inhibition of $\mathrm{K}+$ channels, Ca2+ signaling, and gene expression in T lymphocytes. J Exp Med 188, 1593-1602.

El-Behi, M., Ciric, B., Dai, H., Yan, Y., Cullimore, M., Safavi, F., Zhang, G. X., Dittel, B. N. and Rostami, A. (2011). The encephalitogenicity of $T(H) 17$ cells is dependent on IL-1- and IL-23-induced production of the cytokine GMCSF. Nat Immunol 12, 568-575.

El-Etr, M., Rame, M., Boucher, C., Ghoumari, A. M., Kumar, N., Liere, P., Pianos, A., Schumacher, M. and SitrukWare, R. (2015). Progesterone and nestorone promote myelin regeneration in chronic demyelinating lesions of corpus callosum and cerebral cortex. Glia 63, 104-117.

Engler, J. B., Kursawe, N., Solano, M. E., Patas, K., Wehrmann, S., Heckmann, N., Luhder, F., et al. (2017). Glucocorticoid receptor in T cells mediates protection from autoimmunity in pregnancy. Proc Natl Acad Sci U S A 114, E181-E190.

Ernerudh, J., Berg, G. and Mjösberg, J. (2011). Regulatory T helper cells in pregnancy and their roles in systemic versus local immune tolerance. Am J Reprod Immunol 66, 31-43.

Ferrando-Martinez, S., De Pablo-Bernal, R. S., De Luna-Romero, M., De Ory, S. J., Genebat, M., Pacheco, Y. M., Parras, F. J., et al. (2017). Thymic Function Failure Is Associated With Human Immunodeficiency Virus Disease Progression. Clin Infect Dis 64, 1191-1197.

Ferrando-Martinez, S., Romero-Sanchez, M. C., Solana, R., Delgado, J., de la Rosa, R., Munoz-Fernandez, M. A., Ruiz-Mateos, E. and Leal, M. (2013). Thymic function failure and C-reactive protein levels are independent predictors of all-cause mortality in healthy elderly humans. Age (Dordr) 35, 251-259.

Fink, P. J. (2013). The biology of recent thymic emigrants. Annu Rev Immunol 31, 31-50.

Finkelsztejn, A., Brooks, J. B., Paschoal, F. M., Jr. and Fragoso, Y. D. (2011). What can we really tell women with multiple sclerosis regarding pregnancy? A systematic review and meta-analysis of the literature. BJOG 118, 790-797.

Fletcher, J. M., Lalor, S. J., Sweeney, C. M., Tubridy, N. and Mills, K. H. (2010). T cells in multiple sclerosis and experimental autoimmune encephalomyelitis. Clin Exp Immunol 162, 1-11.

Fontenot, J. D., Gavin, M. A. and Rudensky, A. Y. (2003). Foxp3 programs the development and function of CD4+CD25+ regulatory T cells. Nat Immunol 4, 330-336.

Fox, H. S., Bond, B. L. and Parslow, T. G. (1991). Estrogen regulates the IFN-gamma promoter. J Immunol 146, 4362-4367.

Frisullo, G., Nociti, V., Iorio, R., Patanella, A. K., Marti, A., Caggiula, M., Mirabella, M., Tonali, P. A. and Batocchi, A. P. (2008). IL17 and IFNgamma production by peripheral blood mononuclear cells from clinically isolated syndrome to secondary progressive multiple sclerosis. Cytokine 44, 22-25. 
Galli, E., Hartmann, F. J., Schreiner, B., Ingelfinger, F., Arvaniti, E., Diebold, M., Mrdjen, D., et al. (2019). GM-CSF and CXCR4 define a T helper cell signature in multiple sclerosis. Nat Med 25, 1290-1300.

Garay, L., Gonzalez Deniselle, M. C., Meyer, M., Costa, J. J., Lima, A., Roig, P. and De nicola, A. F. (2009). Protective effects of progesterone administration on axonal pathology in mice with experimental autoimmune encephalomyelitis. Brain Res 1283, 177-185.

Gerli, R., Paganelli, R., Cossarizza, A., Muscat, C., Piccolo, G., Barbieri, D., Mariotti, S., et al. (1999). Long-term immunologic effects of thymectomy in patients with myasthenia gravis. J Allergy Clin Immunol 103, 865-872.

Germain, R. N. (2002). T-cell development and the CD4-CD8 lineage decision. Nat Rev Immunol 2, 309-322.

Gilli, F., Lindberg, R. L., Valentino, P., Marnetto, F., Malucchi, S., Sala, A., Capobianco, M., et al. (2010). Learning from nature: pregnancy changes the expression of inflammation-related genes in patients with multiple sclerosis. PLoS One 5, e8962.

Gilmore, W., Arias, M., Stroud, N., Stek, A., McCarthy, K. A. and Correale, J. (2004). Preliminary studies of cytokine secretion patterns associated with pregnancy in MS patients. J Neurol Sci 224, 69-76.

Goh, K. I., Cusick, M. E., Valle, D., Childs, B., Vidal, M. and Barabasi, A. L. (2007). The human disease network. Proc Natl Acad Sci U S A 104, 8685-8690.

Goverman, J. M. (2011). Immune tolerance in multiple sclerosis. Immunol Rev 241, 228-240.

Granqvist, M., Boremalm, M., Poorghobad, A., Svenningsson, A., Salzer, J., Frisell, T. and Piehl, F. (2018). Comparative Effectiveness of Rituximab and Other Initial Treatment Choices for Multiple Sclerosis. JAMA Neurol 75, 320-327.

Grewal, I. S., Foellmer, H. G., Grewal, K. D., Xu, J., Hardardottir, F., Baron, J. L., Janeway, C. A., Jr. and Flavell, R. A. (1996). Requirement for CD40 ligand in costimulation induction, T cell activation, and experimental allergic encephalomyelitis. Science $273,1864-1867$.

Gudmundsdottir, J., Söderling, J., Berggren, H., Oskarsdottir, S., Neovius, M., Stephansson, O. and Ekwall, O. (2018). Long-term clinical effects of early thymectomy: Associations with autoimmune diseases, cancer, infections, and atopic diseases. J Allergy Clin Immunol 141, 2294-2297 e2298.

Gustafsson, C., Mjösberg, J., Matussek, A., Geffers, R., Matthiesen, L., Berg, G., Sharma, S., Buer, J. and Ernerudh, J. (2008). Gene expression profiling of human decidual macrophages: evidence for immunosuppressive phenotype. PLoS One 3, e2078.

Gustafsson, M., Edström, M., Gawel, D., Nestor, C. E., Wang, H., Zhang, H., Barrenäs, F., et al. (2014). Integrated genomic and prospective clinical studies show the importance of modular pleiotropy for disease susceptibility, diagnosis and treatment. Genome Med 6, 17.

Gustafsson, M., Nestor, C. E., Zhang, H., Barabasi, A. L., Baranzini, S., Brunak, S., Chung, K. F., et al. (2014). Modules, networks and systems medicine for understanding disease and aiding diagnosis. Genome Med 6, 82.

Haas, J., Fritzsching, B., Trubswetter, P., Korporal, M., Milkova, L., Fritz, B., Vobis, D., et al. (2007). Prevalence of newly generated naive regulatory T cells (Treg) is critical for Treg suppressive function and determines Treg dysfunction in multiple sclerosis. J Immunol 179, 1322-1330.

Haas, J., Hug, A., Viehover, A., Fritzsching, B., Falk, C. S., Filser, A., Vetter, T., et al. (2005). Reduced suppressive effect of $C D 4+C D 25$ high regulatory $T$ cells on the $T$ cell immune response against myelin oligodendrocyte glycoprotein in patients with multiple sclerosis. Eur J Immunol 35, 3343-3352.

Haas, J., Korporal, M., Schwarz, A., Balint, B. and Wildemann, B. (2011). The interleukin-7 receptor alpha chain contributes to altered homeostasis of regulatory T cells in multiple sclerosis. Eur J Immunol 41, 845-853. 
Haegert, D. G., Hackenbroch, J. D., Duszczyszyn, D., Fitz-Gerald, L., Zastepa, E., Mason, H., Lapierre, Y., Antel, J. and Bar-Or, A. (2011). Reduced thymic output and peripheral naive CD4 T-cell alterations in primary progressive multiple sclerosis (PPMS). J Neuroimmunol 233, 233-239.

Hartmann, F. J., Khademi, M., Aram, J., Ammann, S., Kockum, I., Constantinescu, C., Gran, B., et al. (2014). Multiple sclerosis-associated IL2RA polymorphism controls GM-CSF production in human TH cells. Nat Commun 5, 5056

Hashash, J. G. and Kane, S. (2015). Pregnancy and Inflammatory Bowel Disease. Gastroenterol Hepatol (N Y) 11, 96-102.

Hauser, S. L., Waubant, E., Arnold, D. L., Vollmer, T., Antel, J., Fox, R. J., Bar-Or, A., et al. (2008). B-cell depletion with rituximab in relapsing-remitting multiple sclerosis. N Engl J Med 358, 676-688.

Havrdova, E., Belova, A., Goloborodko, A., Tisserant, A., Wright, A., Wallstroem, E., Garren, H., Maguire, R. P. and Johns, D. R. (2016). Activity of secukinumab, an anti-IL-17A antibody, on brain lesions in RRMS: results from a randomized, proof-of-concept study. J Neurol 263, 1287-1295.

Hazenberg, M. D., Verschuren, M. C., Hamann, D., Miedema, F. and van Dongen, J. J. (2001). T cell receptor excision circles as markers for recent thymic emigrants: basic aspects, technical approach, and guidelines for interpretation. J Mol Med (Berl) 79, 631-640.

Hedström, A. K., Hillert, J., Olsson, T. and Alfredsson, L. (2013). Smoking and multiple sclerosis susceptibility. Eur J Epidemiol 28, 867-874.

Hedström, A. K., Olsson, T. and Alfredsson, L. (2016). Smoking is a major preventable risk factor for multiple sclerosis. Mult Scler 22, 1021-1026.

Hellberg, S., Eklund, D., Gawel, D. R., Köpsén, M., Zhang, H., Nestor, C. E., Kockum, I., et al. (2016). Dynamic Response Genes in CD4+ T Cells Reveal a Network of Interactive Proteins that Classifies Disease Activity in Multiple Sclerosis. Cell Rep 16, 2928-2939.

Hellings, N., Baree, M., Verhoeven, C., D'Hooghe M, B., Medaer, R., Bernard, C. C., Raus, J. and Stinissen, P. (2001). T-cell reactivity to multiple myelin antigens in multiple sclerosis patients and healthy controls. J Neurosci Res 63, 290-302.

Hellwig, K., Chen, L. H., Stancyzk, F. Z. and Langer-Gould, A. M. (2016). Oral Contraceptives and Multiple Sclerosis/Clinically Isolated Syndrome Susceptibility. PLoS One 11, e0149094.

Hinsinger, G., Galeotti, N., Nabholz, N., Urbach, S., Rigau, V., Demattei, C., Lehmann, S., et al. (2015). Chitinase 3-like proteins as diagnostic and prognostic biomarkers of multiple sclerosis. Mult Scler 21, 1251-1261.

Hohlfeld, R., Dornmair, K., Meinl, E. and Wekerle, H. (2016). The search for the target antigens of multiple sclerosis, part 1: autoreactive CD4+ T lymphocytes as pathogenic effectors and therapeutic targets. Lancet Neurol 15, 198-209.

Holländer, G. A., Krenger, W. and Blazar, B. R. (2010). Emerging strategies to boost thymic function. Curr Opin Pharmacol 10, 443-453.

Hughes, G. C., Clark, E. A. and Wong, A. H. (2013). The intracellular progesterone receptor regulates CD4+ T cells and T cell-dependent antibody responses. J Leukoc Biol 93, 369-375.

Hughes, S. E., Spelman, T., Gray, O. M., Boz, C., Trojano, M., Lugaresi, A., Izquierdo, G., et al. (2014). Predictors and dynamics of postpartum relapses in women with multiple sclerosis. Mult Scler 20, 739-746. 
Håkansson, I., Tisell, A., Cassel, P., Blennow, K., Zetterberg, H., Lundberg, P., Dahle, C., Vrethem, M. and Ernerudh, J. (2017). Neurofilament light chain in cerebrospinal fluid and prediction of disease activity in clinically isolated syndrome and relapsing-remitting multiple sclerosis. Eur J Neurol 24, 703-712.

Håkansson, I., Tisell, A., Cassel, P., Blennow, K., Zetterberg, H., Lundberg, P., Dahle, C., Vrethem, M. and Ernerudh, J. (2018). Neurofilament levels, disease activity and brain volume during follow-up in multiple sclerosis. J Neuroinflammation 15, 209.

Iannello, A., Rolla, S., Maglione, A., Ferrero, G., Bardina, V., Inaudi, I., De Mercanti, S., et al. (2018). Pregnancy Epigenetic Signature in T Helper 17 and T Regulatory Cells in Multiple Sclerosis. Front Immunol 9, 3075.

Ighe, A., Dahlström, O., Skogh, T. and Sjöwall, C. (2015). Application of the 2012 Systemic Lupus International Collaborating Clinics classification criteria to patients in a regional Swedish systemic lupus erythematosus register. Arthritis Res Ther 17, 3.

Innes, A., Cunningham, C., Power, D. A. and Catto, G. R. (1990). The detection of antibodies in pregnancy: a comparison of two assay systems. Am J Reprod Immunol 23, 50-53.

Iorio, R., Frisullo, G., Nociti, V., Patanella, K. A., Bianco, A., Marti, A., Mirabella, M., Tonali, P. A. and Batocchi, A. P. (2009). T-bet, pSTAT1 and pSTAT3 expression in peripheral blood mononuclear cells during pregnancy correlates with post-partum activation of multiple sclerosis. Clin Immunol 131, 70-83.

Itoh, M., Takahashi, T., Sakaguchi, N., Kuniyasu, Y., Shimizu, J., Otsuka, F. and Sakaguchi, S. (1999). Thymus and autoimmunity: production of $C D 25+C D 4+$ naturally anergic and suppressive $T$ cells as a key function of the thymus in maintaining immunologic self-tolerance. J Immunol 162, 5317-5326.

Jangi, S., Gandhi, R., Cox, L. M., Li, N., von Glehn, F., Yan, R., Patel, B., et al. (2016). Alterations of the human gut microbiome in multiple sclerosis. Nat Commun 7, 12015.

Jarde, A., Lutsiv, O., Beyene, J. and McDonald, S. D. (2019). Vaginal progesterone, oral progesterone, 17-OHPC, cerclage, and pessary for preventing preterm birth in at-risk singleton pregnancies: an updated systematic review and network meta-analysis. BJOG 126, 556-567.

Jensen, J., Langkilde, A. R., Fenst, C., Nicolaisen, M. S., Roed, H. G., Christiansen, M. and Sellebjerg, F. (2004). CD4 T cell activation and disease activity at onset of multiple sclerosis. J Neuroimmunol 149, 202-209.

Jones, A. P., Kermode, A. G., Lucas, R. M., Carroll, W. M., Nolan, D. and Hart, P. H. (2017). Circulating immune cells in multiple sclerosis. Clin Exp Immunol 187, 193-203.

Junge, S., Kloeckener-Gruissem, B., Zufferey, R., Keisker, A., Salgo, B., Fauchere, J. C., Scherer, F., et al. (2007). Correlation between recent thymic emigrants and CD31+ (PECAM-1) CD4+ T cells in normal individuals during aging and in lymphopenic children. Eur J Immunol 37, 3270-3280.

Kappos, L., Freedman, M. S., Polman, C. H., Edan, G., Hartung, H. P., Miller, D. H., Montalban, X., et al. (2009). Long-term effect of early treatment with interferon beta-1b after a first clinical event suggestive of multiple sclerosis: 5-year active treatment extension of the phase 3 BENEFIT trial. Lancet Neurol 8, 987-997.

Kaushansky, N., Bakos, E., Becker-Herman, S., Shachar, I. and Ben-Nun, A. (2019). Circulating Picomolar Levels of CCL2 Downregulate Ongoing Chronic Experimental Autoimmune Encephalomyelitis by Induction of Regulatory Mechanisms. J Immunol 203, 1857-1866.

Kay, A. W., Fukuyama, J., Aziz, N., Dekker, C. L., Mackey, S., Swan, G. E., Davis, M. M., Holmes, S. and Blish, C. A. (2014). Enhanced natural killer-cell and T-cell responses to influenza A virus during pregnancy. Proc Natl Acad Sci U S A 111, 14506-14511. 
Kebir, H., Ifergan, I., Alvarez, J. I., Bernard, M., Poirier, J., Arbour, N., Duquette, P. and Prat, A. (2009). Preferential recruitment of interferon-gamma-expressing TH17 cells in multiple sclerosis. Ann Neurol 66, 390402.

Kemppinen, A. K., Kaprio, J., Palotie, A. and Saarela, J. (2011). Systematic review of genome-wide expression studies in multiple sclerosis. BMJ Open 1, e000053.

Kendall, M. D. and Clarke, A. G. (2000). The thymus in the mouse changes its activity during pregnancy: a study of the microenvironment. J Anat 197 Pt 3, 393-411.

Khademi, M., Kockum, I., Andersson, M. L., lacobaeus, E., Brundin, L., Sellebjerg, F., Hillert, J., Piehl, F. and Olsson, T. (2011). Cerebrospinal fluid CXCL13 in multiple sclerosis: a suggestive prognostic marker for the disease course. Mult Scler 17, 335-343.

Khan, D. and Ansar Ahmed, S. (2015). The Immune System Is a Natural Target for Estrogen Action: Opposing Effects of Estrogen in Two Prototypical Autoimmune Diseases. Front Immunol 6, 635.

Khoury, S. J., Guttmann, C. R., Orav, E. J., Kikinis, R., Jolesz, F. A. and Weiner, H. L. (2000). Changes in activated T cells in the blood correlate with disease activity in multiple sclerosis. Arch Neurol 57, 1183-1189.

Kilpatrick, R. D., Rickabaugh, T., Hultin, L. E., Hultin, P., Hausner, M. A., Detels, R., Phair, J. and Jamieson, B. D. (2008). Homeostasis of the naive CD4+ T cell compartment during aging. J Immunol 180, 1499-1507.

Kimmig, S., Przybylski, G. K., Schmidt, C. A., Laurisch, K., Mowes, B., Radbruch, A. and Thiel, A. (2002). Two subsets of naive $T$ helper cells with distinct $T$ cell receptor excision circle content in human adult peripheral blood. J Exp Med 195, 789-794.

Kingwell, E., Marriott, J. J., Jette, N., Pringsheim, T., Makhani, N., Morrow, S. A., Fisk, J. D., et al. (2013). Incidence and prevalence of multiple sclerosis in Europe: a systematic review. BMC Neurol 13, 128.

Kmieciak, M., Gowda, M., Graham, L., Godder, K., Bear, H. D., Marincola, F. M. and Manjili, M. H. (2009). Human T cells express CD25 and Foxp3 upon activation and exhibit effector/memory phenotypes without any regulatory/suppressor function. J Transl Med 7, 89.

Kobelt, G., Thompson, A., Berg, J., Gannedahl, M., Eriksson, J., Group, M. S. and European Multiple Sclerosis, P. (2017). New insights into the burden and costs of multiple sclerosis in Europe. Mult Scler 23, 1123-1136.

Koetz, K., Bryl, E., Spickschen, K., O'Fallon, W. M., Goronzy, J. J. and Weyand, C. M. (2000). T cell homeostasis in patients with rheumatoid arthritis. Proc Natl Acad Sci U S A 97, 9203-9208.

Koopman, L. A., Kopcow, H. D., Rybalov, B., Boyson, J. E., Orange, J. S., Schatz, F., Masch, R., et al. (2003). Human decidual natural killer cells are a unique NK cell subset with immunomodulatory potential. J Exp Med 198, 1201-1212.

Kourtis, A. P., Read, J. S. and Jamieson, D. J. (2014). Pregnancy and infection. N Engl J Med 371, 1077.

Kraus, T. A., Engel, S. M., Sperling, R. S., Kellerman, L., Lo, Y., Wallenstein, S., Escribese, M. M., et al. (2012). Characterizing the pregnancy immune phenotype: results of the viral immunity and pregnancy (VIP) study. J Clin Immunol 32, 300-311.

Kroner, A., Mehling, M., Hemmer, B., Rieckmann, P., Toyka, K. V., Maurer, M. and Wiendl, H. (2005). A PD-1 polymorphism is associated with disease progression in multiple sclerosis. Ann Neurol 58, 50-57.

Ku, C. W., Allen, J. C., Jr., Lek, S. M., Chia, M. L., Tan, N. S. and Tan, T. C. (2018). Serum progesterone distribution in normal pregnancies compared to pregnancies complicated by threatened miscarriage from 5 to 13 weeks gestation: a prospective cohort study. BMC Pregnancy Childbirth 18, 360. 
Kurtzke, J. F. (1983). Rating neurologic impairment in multiple sclerosis: an expanded disability status scale (EDSS). Neurology 33, 1444-1452.

Kwon, M. J., Shin, H. Y., Cui, Y., Kim, H., Thi, A. H., Choi, J. Y., Kim, E. Y., Hwang, D. H. and Kim, B. G. (2015). CCL2 Mediates Neuron-Macrophage Interactions to Drive Proregenerative Macrophage Activation Following Preconditioning Injury. J Neurosci 35, 15934-15947.

Laan, M., Haljasorg, U., Kisand, K., Salumets, A. and Peterson, P. (2016). Pregnancy-induced thymic involution is associated with suppression of chemokines essential for T-lymphoid progenitor homing. Eur J Immunol 46, 2008-2017.

Lassmann, H., Bruck, W. and Lucchinetti, C. (2001). Heterogeneity of multiple sclerosis pathogenesis: implications for diagnosis and therapy. Trends Mol Med 7, 115-121.

Lavon, I., Heli, C., Brill, L., Charbit, H. and Vaknin-Dembinsky, A. (2019). Blood Levels of Co-inhibitory-Receptors: A Biomarker of Disease Prognosis in Multiple Sclerosis. Front Immunol 10, 835.

Lee, J. H., Lydon, J. P. and Kim, C. H. (2012). Progesterone suppresses the mTOR pathway and promotes generation of induced regulatory T cells with increased stability. Eur J Immunol 42, 2683-2696.

Lee, J. H., Ulrich, B., Cho, J., Park, J. and Kim, C. H. (2011). Progesterone promotes differentiation of human cord blood fetal T cells into T regulatory cells but suppresses their differentiation into Th17 cells. J Immunol 187, 1778-1787.

Lidström, C., Matthiesen, L., Berg, G., Sharma, S., Ernerudh, J. and Ekerfelt, C. (2003). Cytokine secretion patterns of NK cells and macrophages in early human pregnancy decidua and blood: implications for suppressor macrophages in decidua. Am J Reprod Immunol 50, 444-452.

Lindsey, J. W., Agarwal, S. K. and Tan, F. K. (2011). Gene expression changes in multiple sclerosis relapse suggest activation of T and non-T cells. Mol Med 17, 95-102.

Lissauer, D., Eldershaw, S. A., Inman, C. F., Coomarasamy, A., Moss, P. A. and Kilby, M. D. (2015). Progesterone promotes maternal-fetal tolerance by reducing human maternal T-cell polyfunctionality and inducing a specific cytokine profile. Eur J Immunol 45, 2858-2872.

Liu, W., Putnam, A. L., Xu-Yu, Z., Szot, G. L., Lee, M. R., Zhu, S., Gottlieb, P. A., et al. (2006). CD127 expression inversely correlates with FoxP3 and suppressive function of human CD4+ T reg cells. J Exp Med 203, 1701-1711.

Lock, C., Hermans, G., Pedotti, R., Brendolan, A., Schadt, E., Garren, H., Langer-Gould, A., et al. (2002). Genemicroarray analysis of multiple sclerosis lesions yields new targets validated in autoimmune encephalomyelitis. Nat Med 8, 500-508.

Lopez, C., Comabella, M., Tintore, M., Sastre-Garriga, J. and Montalban, X. (2006). Variations in chemokine receptor and cytokine expression during pregnancy in multiple sclerosis patients. Mult Scler 12, 421-427.

Lovett-Racke, A. E., Trotter, J. L., Lauber, J., Perrin, P. J., June, C. H. and Racke, M. K. (1998). Decreased dependence of myelin basic protein-reactive T cells on CD28-mediated costimulation in multiple sclerosis patients. A marker of activated/memory T cells. J Clin Invest 101, 725-730.

Lucchinetti, C., Bruck, W., Parisi, J., Scheithauer, B., Rodriguez, M. and Lassmann, H. (2000). Heterogeneity of multiple sclerosis lesions: implications for the pathogenesis of demyelination. Ann Neurol 47, 707-717.

Lutterotti, A., Yousef, S., Sputtek, A., Sturner, K. H., Stellmann, J. P., Breiden, P., Reinhardt, S., et al. (2013). Antigen-specific tolerance by autologous myelin peptide-coupled cells: a phase 1 trial in multiple sclerosis. Sci Transl Med 5, 188ra175. 
Lycke, J. and Zetterberg, H. (2017). The role of blood and CSF biomarkers in the evaluation of new treatments against multiple sclerosis. Expert Rev Clin Immunol 13, 1143-1153.

Lynch, H. E., Goldberg, G. L., Chidgey, A., Van den Brink, M. R., Boyd, R. and Sempowski, G. D. (2009). Thymic involution and immune reconstitution. Trends Immunol 30, 366-373.

Lynch, S. V. and Pedersen, O. (2016). The Human Intestinal Microbiome in Health and Disease. N Engl J Med 375, 2369-2379.

Mahad, D., Callahan, M. K., Williams, K. A., Ubogu, E. E., Kivisakk, P., Tucky, B., Kidd, G., et al. (2006). Modulating CCR2 and CCL2 at the blood-brain barrier: relevance for multiple sclerosis pathogenesis. Brain 129, 212-223.

Mahad, D. J., Howell, S. J. and Woodroofe, M. N. (2002). Expression of chemokines in the CSF and correlation with clinical disease activity in patients with multiple sclerosis. J Neurol Neurosurg Psychiatry 72, 498-502.

Majumdar, S. and Nandi, D. (2018). Thymic Atrophy: Experimental Studies and Therapeutic Interventions. Scand J Immunol 87, 4-14.

Makrygiannakis, D., Hermansson, M., Ulfgren, A. K., Nicholas, A. P., Zendman, A. J., Eklund, A., Grunewald, J., et al. (2008). Smoking increases peptidylarginine deiminase 2 enzyme expression in human lungs and increases citrullination in BAL cells. Ann Rheum Dis 67, 1488-1492.

Mallone, R., Mannering, S. I., Brooks-Worrell, B. M., Durinovic-Bello, I., Cilio, C. M., Wong, F. S., Schloot, N. C. and T-Cell Workshop Committee, I. O. D. S. (2011). Isolation and preservation of peripheral blood mononuclear cells for analysis of islet antigen-reactive T cell responses: position statement of the T-Cell Workshop Committee of the Immunology of Diabetes Society. Clin Exp Immunol 163, 33-49.

Marioni, J. C., Mason, C. E., Mane, S. M., Stephens, M. and Gilad, Y. (2008). RNA-seq: an assessment of technical reproducibility and comparison with gene expression arrays. Genome Res 18, 1509-1517.

McDonald, W. I., Compston, A., Edan, G., Goodkin, D., Hartung, H. P., Lublin, F. D., McFarland, H. F., et al. (2001). Recommended diagnostic criteria for multiple sclerosis: guidelines from the International Panel on the diagnosis of multiple sclerosis. Ann Neurol 50, 121-127.

Medawar, P. B. (1953). Some immunological and endocrinological problems raised by the evolution of viviparity in vertebrates. Symp Soc Exp Biol 44, 320-338.

Mellergård, J., Edström, M., Jenmalm, M. C., Dahle, C., Vrethem, M. and Ernerudh, J. (2013). Increased B cell and cytotoxic NK cell proportions and increased T cell responsiveness in blood of natalizumab-treated multiple sclerosis patients. PLoS One 8, e81685.

Mellergård, J., Edström, M., Vrethem, M., Ernerudh, J. and Dahle, C. (2010). Natalizumab treatment in multiple sclerosis: marked decline of chemokines and cytokines in cerebrospinal fluid. Mult Scler 16, 208-217.

Menche, J., Sharma, A., Kitsak, M., Ghiassian, S. D., Vidal, M., Loscalzo, J. and Barabasi, A. L. (2015). Disease networks. Uncovering disease-disease relationships through the incomplete interactome. Science 347, 1257601.

Michel, L., Touil, H., Pikor, N. B., Gommerman, J. L., Prat, A. and Bar-Or, A. (2015). B Cells in the Multiple Sclerosis Central Nervous System: Trafficking and Contribution to CNS-Compartmentalized Inflammation. Front Immunol 6, 636.

Mikol, D. D., Barkhof, F., Chang, P., Coyle, P. K., Jeffery, D. R., Schwid, S. R., Stubinski, B., Uitdehaag, B. and group, R. s. (2008). Comparison of subcutaneous interferon beta-1a with glatiramer acetate in patients with relapsing multiple sclerosis (the REbif vs Glatiramer Acetate in Relapsing MS Disease [REGARD] study): a multicentre, randomised, parallel, open-label trial. Lancet Neurol 7, 903-914. 
Miller, D. H. and Leary, S. M. (2007). Primary-progressive multiple sclerosis. Lancet Neurol 6, 903-912.

Miyara, M., Yoshioka, Y., Kitoh, A., Shima, T., Wing, K., Niwa, A., Parizot, C., et al. (2009). Functional delineation and differentiation dynamics of human CD4+ T cells expressing the FoxP3 transcription factor. Immunity 30 , 899-911.

Miyaura, H. and Iwata, M. (2002). Direct and indirect inhibition of Th1 development by progesterone and glucocorticoids. J Immunol 168, 1087-1094.

Mjösberg, J., Berg, G., Jenmalm, M. C. and Ernerudh, J. (2010). FOXP3+ regulatory T cells and T helper 1, T helper 2, and Thelper 17 cells in human early pregnancy decidua. Biol Reprod 82, 698-705.

Mjösberg, J., Svensson, J., Johansson, E., Hellström, L., Casas, R., Jenmalm, M. C., Boij, R., et al. (2009). Systemic reduction of functionally suppressive CD4dimCD25highFoxp3+ Tregs in human second trimester pregnancy is induced by progesterone and 17beta-estradiol. J Immunol 183, 759-769.

Mohammad, I., Starskaia, I., Nagy, T., Guo, J., Yatkin, E., Vaananen, K., Watford, W. T. and Chen, Z. (2018). Estrogen receptor alpha contributes to $T$ cell-mediated autoimmune inflammation by promoting $T$ cell activation and proliferation. Sci Signal 11.

Molyneux, P. D., Filippi, M., Barkhof, F., Gasperini, C., Yousry, T. A., Truyen, L., Lai, H. M., et al. (1998). Correlations between monthly enhanced MRI lesion rate and changes in T2 lesion volume in multiple sclerosis. Ann Neurol 43, 332-339.

Montalban, X., Hauser, S. L., Kappos, L., Arnold, D. L., Bar-Or, A., Comi, G., de Seze, J., et al. (2017). Ocrelizumab versus Placebo in Primary Progressive Multiple Sclerosis. N Engl J Med 376, 209-220.

Mor, G., Aldo, P. and Alvero, A. B. (2017). The unique immunological and microbial aspects of pregnancy. Nat Rev Immunol 17, 469-482.

Mor, G. and Cardenas, I. (2010). The immune system in pregnancy: a unique complexity. Am J Reprod Immunol $63,425-433$.

Moreira, M. A., Souza, A. L., Lana-Peixoto, M. A., Teixeira, M. M. and Teixeira, A. L. (2006). Chemokines in the cerebrospinal fluid of patients with active and stable relapsing-remitting multiple sclerosis. Braz J Med Biol Res 39, 441-445.

Moutsianas, L., Jostins, L., Beecham, A. H., Dilthey, A. T., Xifara, D. K., Ban, M., Shah, T. S., et al. (2015). Class II HLA interactions modulate genetic risk for multiple sclerosis. Nat Genet 47, 1107-1113.

MSIF (2013). Atlas of MS 2013: Mapping Multiple Sclerosis Around the World. London: Multiple Sclerosis International Federation (MSIF).

Nakashima, A., Ito, M., Yoneda, S., Shiozaki, A., Hidaka, T. and Saito, S. (2010). Circulating and decidual Th17 cell levels in healthy pregnancy. Am J Reprod Immunol 63, 104-109.

Nakayama, T., Hirahara, K., Onodera, A., Endo, Y., Hosokawa, H., Shinoda, K., Tumes, D. J. and Okamoto, Y. (2017). Th2 Cells in Health and Disease. Annu Rev Immunol 35, 53-84.

Ndiaye, K., Poole, D. H., Walusimbi, S., Cannon, M. J., Toyokawa, K., Maalouf, S. W., Dong, J., Thomas, P. and Pate, J. L. (2012). Progesterone effects on lymphocytes may be mediated by membrane progesterone receptors. J Reprod Immunol 95, 15-26.

Nobile, M., Correa, R., Borghans, J. A., D'Agostino, C., Schneider, P., De Boer, R. J., Pantaleo, G. and Swiss, H. I. V. C. S. (2004). De novo T-cell generation in patients at different ages and stages of HIV-1 disease. Blood 104, 470-477. 
Norman, J. E., Marlow, N., Messow, C. M., Shennan, A., Bennett, P. R., Thornton, S., Robson, S. C., et al. (2016). Vaginal progesterone prophylaxis for preterm birth (the OPPTIMUM study): a multicentre, randomised, doubleblind trial. Lancet 387, 2106-2116.

O'Connor, P., Filippi, M., Arnason, B., Comi, G., Cook, S., Goodin, D., Hartung, H. P., et al. (2009). 250 microg or 500 microg interferon beta-1b versus $20 \mathrm{mg}$ glatiramer acetate in relapsing-remitting multiple sclerosis: a prospective, randomised, multicentre study. Lancet Neurol 8, 889-897.

O'Gorman, C., Lin, R., Stankovich, J. and Broadley, S. A. (2013). Modelling genetic susceptibility to multiple sclerosis with family data. Neuroepidemiology 40, 1-12.

O'Leary, P., Boyne, P., Flett, P., Beilby, J. and James, I. (1991). Longitudinal assessment of changes in reproductive hormones during normal pregnancy. Clin Chem 37, 667-672.

Odoardi, F., Sie, C., Streyl, K., Ulaganathan, V. K., Schlager, C., Lodygin, D., Heckelsmiller, K., et al. (2012). T cells become licensed in the lung to enter the central nervous system. Nature 488, 675-679.

Okabe, H., Makino, S., Kato, K., Matsuoka, K., Seki, H. and Takeda, S. (2014). The effect of progesterone on genes involved in preterm labor. J Reprod Immunol 104-105, 80-91.

Oliveira-dos-Santos, A. J., Ho, A., Tada, Y., Lafaille, J. J., Tonegawa, S., Mak, T. W. and Penninger, J. M. (1999). CD28 costimulation is crucial for the development of spontaneous autoimmune encephalomyelitis. J Immunol $162,4490-4495$.

Olsson, T., Barcellos, L. F. and Alfredsson, L. (2017). Interactions between genetic, lifestyle and environmental risk factors for multiple sclerosis. Nat Rev Neurol 13, 25-36.

Panitch, H. S., Hirsch, R. L., Haley, A. S. and Johnson, K. P. (1987). Exacerbations of multiple sclerosis in patients treated with gamma interferon. Lancet 1, 893-895.

Park, M. J., Kim, Y. A., Lee, S. S., Kim, B. C., Kim, M. K. and Cho, K. H. (2004). Appearance of systemic lupus erythematosus in patients with myasthenia gravis following thymectomy: two case reports. J Korean Med Sci 19, 134-136.

Patas, K., Engler, J. B., Friese, M. A. and Gold, S. M. (2013). Pregnancy and multiple sclerosis: feto-maternal immune cross talk and its implications for disease activity. J Reprod Immunol 97, 140-146.

Patsopoulos, N. A., Bayer Pharma, M. S. G. W. G., Steering Committees of Studies Evaluating, I.-b., a, C. C. R. A., Consortium, A. N., GeneMsa, International Multiple Sclerosis Genetics, C., et al. (2011). Genome-wide metaanalysis identifies novel multiple sclerosis susceptibility loci. Ann Neurol 70, 897-912.

Patsopoulos, N. A., International Multiple Sclerosis Genetics Consortium (2017). The Multiple Sclerosis Genomic Map: Role of peripheral immune cells and resident microglia in disease susceptibility. BioRxiv, 143933.

Perrin, P. J., June, C. H., Maldonado, J. H., Ratts, R. B. and Racke, M. K. (1999). Blockade of CD28 during in vitro activation of encephalitogenic T cells or after disease onset ameliorates experimental autoimmune encephalomyelitis. J Immunol 163, 1704-1710.

Pertea, M., Pertea, G. M., Antonescu, C. M., Chang, T. C., Mendell, J. T. and Salzberg, S. L. (2015). StringTie enables improved reconstruction of a transcriptome from RNA-seq reads. Nat Biotechnol 33, 290-295.

Petri, M., Howard, D. and Repke, J. (1991). Frequency of lupus flare in pregnancy. The Hopkins Lupus Pregnancy Center experience. Arthritis Rheum 34, 1538-1545.

Piccinni, M. P., Giudizi, M. G., Biagiotti, R., Beloni, L., Giannarini, L., Sampognaro, S., Parronchi, P., et al. (1995). Progesterone favors the development of human $\mathrm{T}$ helper cells producing Th2-type cytokines and promotes both IL-4 production and membrane CD30 expression in established Th1 cell clones. J Immunol 155, 128-133. 
Piccinni, M. P., Lombardelli, L., Logiodice, F., Kullolli, O., Parronchi, P. and Romagnani, S. (2016). How pregnancy can affect autoimmune diseases progression? Clin Mol Allergy 14, 11.

Planas, R., Santos, R., Tomas-Ojer, P., Cruciani, C., Lutterotti, A., Faigle, W., Schaeren-Wiemers, N., et al. (2018). GDP-I-fucose synthase is a CD4(+) T cell-specific autoantigen in DRB3*02:02 patients with multiple sclerosis. Sci Transl Med 10.

Polese, B., Gridelet, V., Araklioti, E., Martens, H., Perrier d'Hauterive, S. and Geenen, V. (2014). The Endocrine Milieu and CD4 T-Lymphocyte Polarization during Pregnancy. Front Endocrinol (Lausanne) 5, 106.

Polman, C. H., O'Connor, P. W., Havrdova, E., Hutchinson, M., Kappos, L., Miller, D. H., Phillips, J. T., et al. (2006). A randomized, placebo-controlled trial of natalizumab for relapsing multiple sclerosis. N Engl J Med 354, 899-910.

Polman, C. H., Reingold, S. C., Banwell, B., Clanet, M., Cohen, J. A., Filippi, M., Fujihara, K., et al. (2011). Diagnostic criteria for multiple sclerosis: 2010 revisions to the McDonald criteria. Ann Neurol 69, 292-302.

Ponsonby, A. L., Lucas, R. M., van der Mei, I. A., Dear, K., Valery, P. C., Pender, M. P., Taylor, B. V., et al. (2012). Offspring number, pregnancy, and risk of a first clinical demyelinating event: The AusImmune Study. Neurology $78,867-874$.

Power, D. A., Catto, G. R., Mason, R. J., MacLeod, A. M., Stewart, G. M., Stewart, K. N. and Shewan, W. G. (1983). The fetus as an allograft: evidence for protective antibodies to HLA-linked paternal antigens. Lancet 2, 701-704.

Priyanka, H. P., Krishnan, H. C., Singh, R. V., Hima, L. and Thyagarajan, S. (2013). Estrogen modulates in vitro T cell responses in a concentration- and receptor-dependent manner: effects on intracellular molecular targets and antioxidant enzymes. Mol Immunol 56, 328-339.

Probstel, A. K. and Baranzini, S. E. (2018). The Role of the Gut Microbiome in Multiple Sclerosis Risk and Progression: Towards Characterization of the "MS Microbiome". Neurotherapeutics 15, 126-134.

Quinn, E. M., Coleman, C., Molloy, B., Dominguez Castro, P., Cormican, P., Trimble, V., Mahmud, N. and McManus, R. (2015). Transcriptome Analysis of CD4+ T Cells in Coeliac Disease Reveals Imprint of BACH2 and IFNgamma Regulation. PLoS One 10, e0140049.

Raghupathy, R. (1997). Th1-type immunity is incompatible with successful pregnancy. Immunol Today 18, 478482.

Raphael, I., Webb, J., Stuve, O., Haskins, W. and Forsthuber, T. (2015). Body fluid biomarkers in multiple sclerosis: how far we have come and how they could affect the clinic now and in the future. Expert Rev Clin Immunol 11, 69-91.

Ratzer, R., Sondergaard, H. B., Christensen, J. R., Bornsen, L., Borup, R., Sorensen, P. S. and Sellebjerg, F. (2013). Gene expression analysis of relapsing-remitting, primary progressive and secondary progressive multiple sclerosis. Mult Scler 19, 1841-1848.

Ravkov, E., Slev, P. and Heikal, N. (2017). Thymic output: Assessment of CD4+ recent thymic emigrants and TCell receptor excision circles in infants. Cytometry B Clin Cytom 92, 249-257.

Raychaudhuri, S. P., Navare, T., Gross, J. and Raychaudhuri, S. K. (2003). Clinical course of psoriasis during pregnancy. Int J Dermatol 42, 518-520.

Riedhammer, C. and Weissert, R. (2015). Antigen Presentation, Autoantigens, and Immune Regulation in Multiple Sclerosis and Other Autoimmune Diseases. Front Immunol 6, 322. 
Rodriguez, M. (2009). Have we finally identified an autoimmune demyelinating disease? Ann Neurol 66, 572573.

Rotstein, D. and Montalban, X. (2019). Reaching an evidence-based prognosis for personalized treatment of multiple sclerosis. Nat Rev Neurol 15, 287-300.

Rotstein, D. L., Healy, B. C., Malik, M. T., Chitnis, T. and Weiner, H. L. (2015). Evaluation of no evidence of disease activity in a 7-year longitudinal multiple sclerosis cohort. JAMA Neurol 72, 152-158.

Roxburgh, R. H., Seaman, S. R., Masterman, T., Hensiek, A. E., Sawcer, S. J., Vukusic, S., Achiti, I., et al. (2005). Multiple Sclerosis Severity Score: using disability and disease duration to rate disease severity. Neurology 64, 1144-1151.

Runmarker, B. and Andersen, O. (1995). Pregnancy is associated with a lower risk of onset and a better prognosis in multiple sclerosis. Brain 118, 253-261.

Sacks, G., Sargent, I. and Redman, C. (1999). An innate view of human pregnancy. Immunol Today 20, 114-118.

Sacks, G. P., Studena, K., Sargent, K. and Redman, C. W. (1998). Normal pregnancy and preeclampsia both produce inflammatory changes in peripheral blood leukocytes akin to those of sepsis. Am J Obstet Gynecol 179, 80-86.

Saez-Torres, I., Brieva, L., Espejo, C., Barrau, M. A., Montalban, X. and Martinez-Caceres, E. M. (2002). Specific proliferation towards myelin antigens in patients with multiple sclerosis during a relapse. Autoimmunity $35,45-$ 50.

Sairafi, D., Mattsson, J., Uhlin, M. and Uzunel, M. (2012). Thymic function after allogeneic stem cell transplantation is dependent on graft source and predictive of long term survival. Clin Immunol 142, 343-350.

Saito, S., Nakashima, A., Shima, T. and Ito, M. (2010). Th1/Th2/Th17 and regulatory T-cell paradigm in pregnancy. Am J Reprod Immunol 63, 601-610.

Sakaguchi, S., Sakaguchi, N., Asano, M., Itoh, M. and Toda, M. (1995). Immunologic self-tolerance maintained by activated T cells expressing IL-2 receptor alpha-chains (CD25). Breakdown of a single mechanism of selftolerance causes various autoimmune diseases. J Immunol 155, 1151-1164.

Salama, A. D., Chitnis, T., Imitola, J., Ansari, M. J., Akiba, H., Tushima, F., Azuma, M., et al. (2003). Critical role of the programmed death-1 (PD-1) pathway in regulation of experimental autoimmune encephalomyelitis. J Exp Med 198, 71-78.

Sallusto, F., Lanzavecchia, A. and Mackay, C. R. (1998). Chemokines and chemokine receptors in T-cell priming and Th1/Th2-mediated responses. Immunol Today 19, 568-574.

Santner-Nanan, B., Peek, M. J., Khanam, R., Richarts, L., Zhu, E., Fazekas de St Groth, B. and Nanan, R. (2009). Systemic increase in the ratio between Foxp3+ and IL-17-producing CD4+ T cells in healthy pregnancy but not in preeclampsia. J Immunol 183, 7023-7030.

Saraste, M., Vaisanen, S., Alanen, A., Airas, L., Finnish Multiple, S. and Pregnancy Study, G. (2007). Clinical and immunologic evaluation of women with multiple sclerosis during and after pregnancy. Gend Med 4, 45-55.

Satoh, J., Nakanishi, M., Koike, F., Onoue, H., Aranami, T., Yamamoto, T., Kawai, M., et al. (2006). T cell gene expression profiling identifies distinct subgroups of Japanese multiple sclerosis patients. J Neuroimmunol 174, 108-118.

Sawcer, S., Hellenthal, G., Pirinen, M., Spencer, C. C., Patsopoulos, N. A., Moutsianas, L., Dilthey, A., et al. (2011). Genetic risk and a primary role for cell-mediated immune mechanisms in multiple sclerosis. Nature 476 , 214-219. 
Scholz, C., Patton, K. T., Anderson, D. E., Freeman, G. J. and Hafler, D. A. (1998). Expansion of autoreactive T cells in multiple sclerosis is independent of exogenous B7 costimulation. J Immunol 160, 1532-1538.

Schumacher, A., Costa, S. D. and Zenclussen, A. C. (2014). Endocrine factors modulating immune responses in pregnancy. Front Immunol 5, 196.

Schumacher, G. A., Beebe, G., Kibler, R. F., Kurland, L. T., Kurtzke, J. F., McDowell, F., Nagler, B., et al. (1965). Problems of Experimental Trials of Therapy in Multiple Sclerosis: Report by the Panel on the Evaluation of Experimental Trials of Therapy in Multiple Sclerosis. Ann N Y Acad Sci 122, 552-568.

Sellebjerg, F., Royen, L., Soelberg Sorensen, P., Oturai, A. B. and Jensen, P. E. H. (2018). Prognostic value of cerebrospinal fluid neurofilament light chain and chitinase-3-like-1 in newly diagnosed patients with multiple sclerosis. Mult Scler, 1352458518794308.

Setiadi, A. F., Abbas, A. R., Jeet, S., Wong, K., Bischof, A., Peng, I., Lee, J., et al. (2019). IL-17A is associated with the breakdown of the blood-brain barrier in relapsing-remitting multiple sclerosis. J Neuroimmunol 332, 147154 .

Shah, N. M., Herasimtschuk, A. A., Boasso, A., Benlahrech, A., Fuchs, D., Imami, N. and Johnson, M. R. (2017). Changes in T Cell and Dendritic Cell Phenotype from Mid to Late Pregnancy Are Indicative of a Shift from Immune Tolerance to Immune Activation. Front Immunol 8, 1138.

Sharpe, A. H. and Freeman, G. J. (2002). The B7-CD28 superfamily. Nat Rev Immunol 2, 116-126.

Simms, P. E. and Ellis, T. M. (1996). Utility of flow cytometric detection of CD69 expression as a rapid method for determining poly- and oligoclonal lymphocyte activation. Clin Diagn Lab Immunol 3, 301-304.

Singh, S. P., Zhang, H. H., Foley, J. F., Hedrick, M. N. and Farber, J. M. (2008). Human T cells that are able to produce IL-17 express the chemokine receptor CCR6. J Immunol 180, 214-221.

Sjögren, M. and Lycke, J. (2007). Graviditet och MS kräver initierad rådgivning och anpassad terapi. Läkartidningen 104, 2500-2505.

Soares, A., Govender, L., Hughes, J., Mavakla, W., de Kock, M., Barnard, C., Pienaar, B., et al. (2010). Novel application of Ki67 to quantify antigen-specific in vitro lymphoproliferation. J Immunol Methods 362, 43-50.

Soldin, O. P., Guo, T., Weiderpass, E., Tractenberg, R. E., Hilakivi-Clarke, L. and Soldin, S. J. (2005). Steroid hormone levels in pregnancy and 1 year postpartum using isotope dilution tandem mass spectrometry. Fertil Steril 84, 701-710.

Sorensen, T. L., Tani, M., Jensen, J., Pierce, V., Lucchinetti, C., Folcik, V. A., Qin, S., et al. (1999). Expression of specific chemokines and chemokine receptors in the central nervous system of multiple sclerosis patients. J Clin Invest $103,807-815$.

Spadaro, M., Martire, S., Marozio, L., Mastromauro, D., Montanari, E., Perga, S., Montarolo, F., et al. (2019). Immunomodulatory Effect of Pregnancy on Leukocyte Populations in Patients With Multiple Sclerosis: A Comparison of Peripheral Blood and Decidual Placental Tissue. Frontiers in Immunology 10, 1935.

Spelman, T., Frisell, T., Piehl, F. and Hillert, J. (2018). Comparative effectiveness of rituximab relative to IFNbeta or glatiramer acetate in relapsing-remitting MS from the Swedish MS registry. Mult Scler 24, 1087-1095.

Steinborn, A., Rebmann, V., Scharf, A., Sohn, C. and Grosse-Wilde, H. (2003). Soluble HLA-DR levels in the maternal circulation of normal and pathologic pregnancy. Am J Obstet Gynecol 188, 473-479.

Stenager, E., Stenager, E. N. and Jensen, K. (1994). Effect of pregnancy on the prognosis for multiple sclerosis. A 5-year follow up investigation. Acta Neurol Scand 90, 305-308. 
Stites, D. P., Bugbee, S. and Siiteri, P. K. (1983). Differential actions of progesterone and cortisol on lymphocyte and monocyte interaction during lymphocyte activation--relevance to immunosuppression in pregnancy. J Reprod Immunol 5, 215-228.

Stites, D. P. and Siiteri, P. K. (1983). Steroids as immunosuppressants in pregnancy. Immunol Rev 75, 117-138.

Straub, R. H. (2007). The complex role of estrogens in inflammation. Endocr Rev 28, 521-574.

Stys, P. K., Zamponi, G. W., van Minnen, J. and Geurts, J. J. (2012). Will the real multiple sclerosis please stand up? Nat Rev Neurosci 13, 507-514.

Swami, S., Tong, I., Bilodeau, C. C. and Bourjeily, G. (2012). Thymic involution in pregnancy: a universal finding? Obstet Med 5, 130-132.

Svenningsson, A. (2016). Metodbok MS: MS-specifik behandling. Svenska MS-sällskapet.

Svensson-Arvelund, J., Ernerudh, J., Buse, E., Cline, J. M., Haeger, J. D., Dixon, D., Markert, U. R., et al. (2014). The placenta in toxicology. Part II: Systemic and local immune adaptations in pregnancy. Toxicol Pathol 42, 327338.

Svensson, J., Jenmalm, M. C., Matussek, A., Geffers, R., Berg, G. and Ernerudh, J. (2011). Macrophages at the fetal-maternal interface express markers of alternative activation and are induced by M-CSF and IL-10. J Immunol 187, 3671-3682.

Svärd, A., Skogh, T., Alfredsson, L., llar, A., Klareskog, L., Bengtsson, C. and Kastbom, A. (2015). Associations with smoking and shared epitope differ between IgA- and IgG-class antibodies to cyclic citrullinated peptides in early rheumatoid arthritis. Arthritis Rheumatol 67, 2032-2037.

Szekeres-Bartho, J., Hadnagy, J. and Pacsa, A. S. (1985). The suppressive effect of progesterone on lymphocyte cytotoxicity: unique progesterone sensitivity of pregnancy lymphocytes. J Reprod Immunol 7, 121-128.

Takahama, Y. (2006). Journey through the thymus: stromal guides for T-cell development and selection. Nat Rev Immunol 6, 127-135.

Tan, H., Yi, L., Rote, N. S., Hurd, W. W. and Mesiano, S. (2012). Progesterone receptor-A and -B have opposite effects on proinflammatory gene expression in human myometrial cells: implications for progesterone actions in human pregnancy and parturition. J Clin Endocrinol Metab 97, E719-730.

Tengvall, K., Huang, J., Hellström, C., Kammer, P., Biström, M., Ayoglu, B., Lima Bomfim, I., et al. (2019). Molecular mimicry between Anoctamin 2 and Epstein-Barr virus nuclear antigen 1 associates with multiple sclerosis risk. Proc Natl Acad Sci U S A.

Thompson, A. J., Banwell, B. L., Barkhof, F., Carroll, W. M., Coetzee, T., Comi, G., Correale, J., et al. (2018). Diagnosis of multiple sclerosis: 2017 revisions of the McDonald criteria. Lancet Neurol 17, 162-173.

Thompson, D. S., Nelson, L. M., Burns, A., Burks, J. S. and Franklin, G. M. (1986). The effects of pregnancy in multiple sclerosis: a retrospective study. Neurology 36, 1097-1099.

Tibbetts, T. A., DeMayo, F., Rich, S., Conneely, O. M. and O'Malley, B. W. (1999). Progesterone receptors in the thymus are required for thymic involution during pregnancy and for normal fertility. Proc Natl Acad Sci U S A 96, 12021-12026.

Tilburgs, T., Roelen, D. L., van der Mast, B. J., de Groot-Swings, G. M., Kleijburg, C., Scherjon, S. A. and Claas, F. $H$. (2008). Evidence for a selective migration of fetus-specific CD4+CD25bright regulatory T cells from the peripheral blood to the decidua in human pregnancy. J Immunol 180, 5737-5745. 
Tilburgs, T., Roelen, D. L., van der Mast, B. J., van Schip, J. J., Kleijburg, C., de Groot-Swings, G. M., Kanhai, H. H., Claas, F. H. and Scherjon, S. A. (2006). Differential distribution of CD4(+)CD25(bright) and CD8(+)CD28(-) T-cells in decidua and maternal blood during human pregnancy. Placenta 27 Suppl A, S47-53.

Tintore, M., Vidal-Jordana, A. and Sastre-Garriga, J. (2019). Treatment of multiple sclerosis - success from bench to bedside. Nat Rev Neurol 15, 53-58.

Toldi, G., Molvarec, A., Stenczer, B., Muller, V., Eszes, N., Bohacs, A., Bikov, A., et al. (2011). Peripheral $\mathrm{T}(\mathrm{h}) 1 / \mathrm{T}(\mathrm{h}) 2 / \mathrm{T}(\mathrm{h}) 17 /$ regulatory $\mathrm{T}$-cell balance in asthmatic pregnancy. Int Immunol 23, 669-677.

Trundley, A. and Moffett, A. (2004). Human uterine leukocytes and pregnancy. Tissue Antigens 63, 1-12.

Tzartos, J. S., Friese, M. A., Craner, M. J., Palace, J., Newcombe, J., Esiri, M. M. and Fugger, L. (2008). Interleukin-17 production in central nervous system-infiltrating T cells and glial cells is associated with active disease in multiple sclerosis. Am J Pathol 172, 146-155.

University of California San Francisco M. S. Epic Team, Cree, B. A., Gourraud, P. A., Oksenberg, J. R., Bevan, C., Crabtree-Hartman, E., Gelfand, J. M., et al. (2016). Long-term evolution of multiple sclerosis disability in the treatment era. Ann Neurol 80, 499-510.

Wagner, M. I., Jost, M., Spratte, J., Schaier, M., Mahnke, K., Meuer, S., Zeier, M. and Steinborn, A. (2016). Differentiation of ICOS+ and ICOS- recent thymic emigrant regulatory T cells (RTE T regs) during normal pregnancy, pre-eclampsia and HELLP syndrome. Clin Exp Immunol 183, 129-142.

Wagner, M. I., Mai, C., Schmitt, E., Mahnke, K., Meuer, S., Eckstein, V., Ho, A. D., et al. (2015). The role of recent thymic emigrant-regulatory T-cell (RTE-Treg) differentiation during pregnancy. Immunol Cell Biol 93, 858-867.

Walker, S. E. (2011). Estrogen and autoimmune disease. Clin Rev Allergy Immunol 40, 60-65.

van Munster, C. E. and Uitdehaag, B. M. (2017). Outcome Measures in Clinical Trials for Multiple Sclerosis. CNS Drugs 31, 217-236.

Wang, J., Ioan-Facsinay, A., van der Voort, E. I., Huizinga, T. W. and Toes, R. E. (2007). Transient expression of FOXP3 in human activated nonregulatory CD4+ T cells. Eur J Immunol 37, 129-138.

Wang, Z., Gerstein, M. and Snyder, M. (2009). RNA-Seq: a revolutionary tool for transcriptomics. Nat Rev Genet 10, 57-63.

Vassiliadou, N. and Bulmer, J. N. (1996). Quantitative analysis of T lymphocyte subsets in pregnant and nonpregnant human endometrium. Biol Reprod 55, 1017-1022.

Waubant, E., Lucas, R., Mowry, E., Graves, J., Olsson, T., Alfredsson, L. and Langer-Gould, A. (2019). Environmental and genetic risk factors for MS: an integrated review. Ann Clin Transl Neurol.

Wegmann, T. G., Lin, H., Guilbert, L. and Mosmann, T. R. (1993). Bidirectional cytokine interactions in the maternal-fetal relationship: is successful pregnancy a TH2 phenomenon? Immunol Today 14, 353-356.

Weinshenker, B. G., Hader, W., Carriere, W., Baskerville, J. and Ebers, G. C. (1989). The influence of pregnancy on disability from multiple sclerosis: a population-based study in Middlesex County, Ontario. Neurology 39, 1438-1440.

Wells, A. D., Gudmundsdottir, H. and Turka, L. A. (1997). Following the fate of individual T cells throughout activation and clonal expansion. Signals from T cell receptor and CD28 differentially regulate the induction and duration of a proliferative response. J Clin Invest 100, 3173-3183.

Venken, K., Hellings, N., Liblau, R. and Stinissen, P. (2010). Disturbed regulatory T cell homeostasis in multiple sclerosis. Trends Mol Med 16, 58-68. 
Venken, K., Hellings, N., Thewissen, M., Somers, V., Hensen, K., Rummens, J. L., Medaer, R., Hupperts, R. and Stinissen, P. (2008). Compromised CD4+ CD25(high) regulatory T-cell function in patients with relapsingremitting multiple sclerosis is correlated with a reduced frequency of FOXP3-positive cells and reduced FOXP3 expression at the single-cell level. Immunology $123,79-89$.

Verschuren, M. C., Wolvers-Tettero, I. L., Breit, T. M., Noordzij, J., van Wering, E. R. and van Dongen, J. J. (1997). Preferential rearrangements of the T cell receptor-delta-deleting elements in human T cells. J Immunol 158, 1208-1216.

Viglietta, V., Baecher-Allan, C., Weiner, H. L. and Hafler, D. A. (2004). Loss of functional suppression by CD4+CD25+ regulatory T cells in patients with multiple sclerosis. J Exp Med 199, 971-979.

Vogt, M. H., Lopatinskaya, L., Smits, M., Polman, C. H. and Nagelkerken, L. (2003). Elevated osteopontin levels in active relapsing-remitting multiple sclerosis. Ann Neurol 53, 819-822.

Workman, C. J., Szymczak-Workman, A. L., Collison, L. W., Pillai, M. R. and Vignali, D. A. (2009). The development and function of regulatory T cells. Cell Mol Life Sci 66, 2603-2622.

Vukusic, S., El-Etr, M., Ionescu, I., Cotton, F., Merle, H., Cornu, C., Frangoulis, B., et al. (2012). The POPARTMUS French-Italian multicentric trial of Post Partum Progestin and Estriol in Multiple Sclerosis: final results. 45-45. Multiple Sclerosis.

Xu, Y., He, H., Li, C., Shi, Y., Wang, Q., Li, W. and Song, W. (2011). Immunosuppressive effect of progesterone on dendritic cells in mice. J Reprod Immunol 91, 17-23.

Yamane, H. and Paul, W. E. (2013). Early signaling events that underlie fate decisions of naive CD4(+) T cells toward distinct T-helper cell subsets. Immunol Rev 252, 12-23.

Yates, M. A., Li, Y., Chlebeck, P., Proctor, T., Vandenbark, A. A. and Offner, H. (2010). Progesterone treatment reduces disease severity and increases IL-10 in experimental autoimmune encephalomyelitis. J Neuroimmunol 220, 136-139.

Zapata, L. B., Oduyebo, T., Whiteman, M. K., Houtchens, M. K., Marchbanks, P. A. and Curtis, K. M. (2016). Contraceptive use among women with multiple sclerosis: a systematic review. Contraception 94, 612-620.

Zhao, S., Fung-Leung, W. P., Bittner, A., Ngo, K. and Liu, X. (2014). Comparison of RNA-Seq and microarray in transcriptome profiling of activated T cells. PLoS One 9, e78644.

Zhu, J. (2018). T Helper Cell Differentiation, Heterogeneity, and Plasticity. Cold Spring Harb Perspect Biol 10.

Zoller, A. L., Schnell, F. J. and Kersh, G. J. (2007). Murine pregnancy leads to reduced proliferation of maternal thymocytes and decreased thymic emigration. Immunology 121, 207-215.

Zubizarreta, I., Florez-Grau, G., Vila, G., Cabezon, R., Espana, C., Andorra, M., Saiz, A., et al. (2019). Immune tolerance in multiple sclerosis and neuromyelitis optica with peptide-loaded tolerogenic dendritic cells in a phase $1 b$ trial. Proc Natl Acad Sci U S A 116, 8463-8470.

Zuluaga, M. I., Otero-Romero, S., Rovira, A., Perez-Hoyos, S., Arrambide, G., Negrotto, L., Galan, I., et al. (2019). Menarche, pregnancies, and breastfeeding do not modify long-term prognosis in multiple sclerosis. Neurology 92, e1507-e1516. 


\section{Papers}

The papers associated with this thesis have been removed for copyright reasons. For more details about these see:

http://urn.kb.se/resolve?urn=urn:nbn:se:liu:diva-161091 


\section{FACULTY OF MEDICINE AND HEALTH SCIENCES}

Linköping University Medical Dissertation No. 1705, 2019

Department of Clinical and Experimental Medicine

Linköping University

SE-581 83 Linköping, Sweden

\section{www.liu.se}

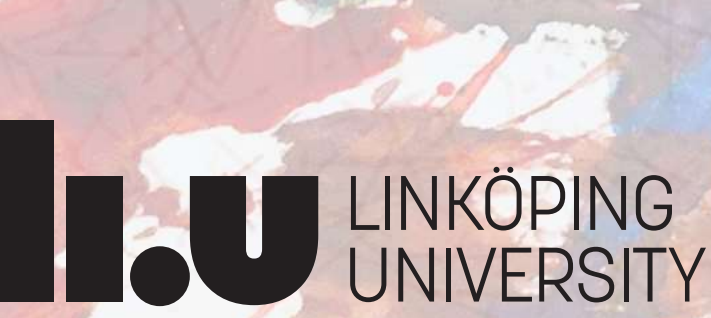

